UCRL-ID-119685

\title{
Process Modeling of Hydrothermal Treatment of Municipal Solid Waste to form High Solids Slurries in a Pilot Scale System
}

C.B. Thorsness

February 16, 1995

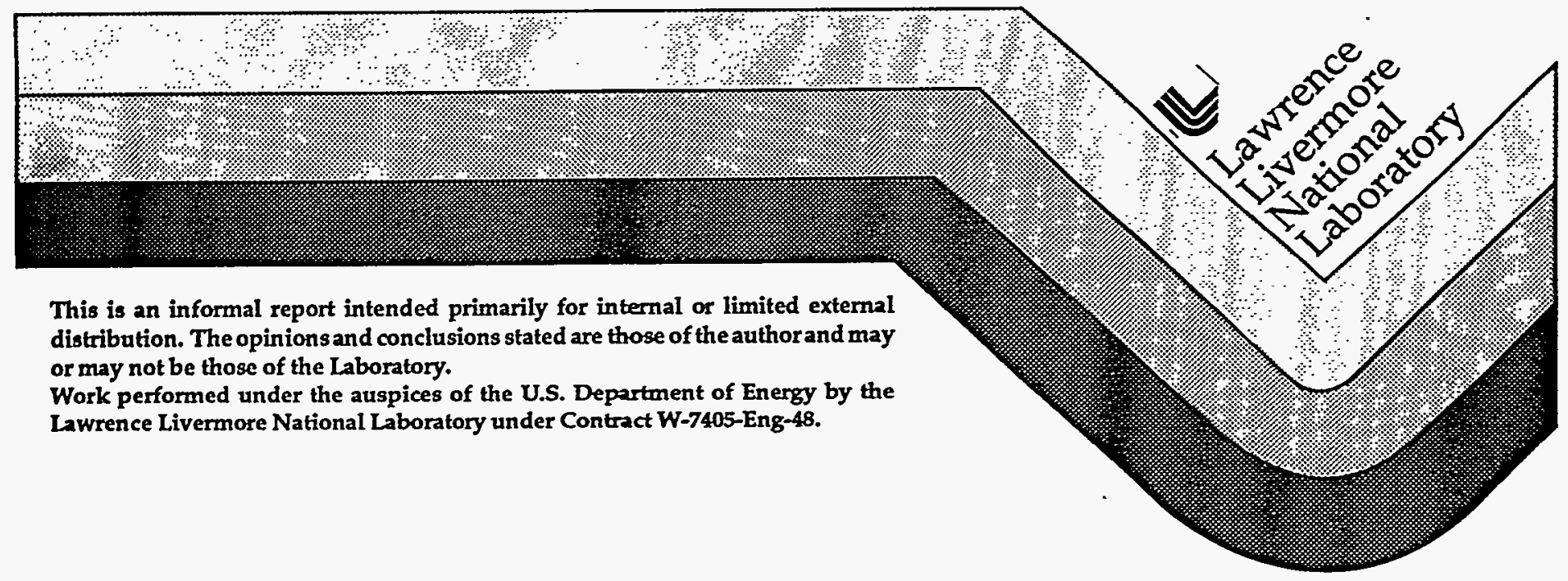

DISTRIBUTION OF THIS DOCUMENT IS UNLIMITED
DG 


\section{DISCLAIMER}

This document was prepared as an account of work sponsored by an agency of the United States Government. Neither the United States Covernment nor the University of California nor any of their employees, makes any warranty, express or implied, or assumes any legal liability or responsibility for the accuracy, completeness, or usefulness of any information, apparatus, product, or process disclosed, or represents that its use would not infringe privately onmed rights. Reference herein to any specific commercial product, process, or service by trade name, trademark, manufacturer, or otherwise, does not necessarily constitute or imply its endorsement, recommendation, or favoring by the United States Government or the University of California. The views and opinions of authors expressed herein do not necessarily state or reflect those of the United States Government or the University of California, and shall not be used for advertising or product endorsement purposes.

This report has been reproduced

directly from the best available copy.

Available to DOE and DOE contractors from the Office of Scientific and Technical Information P.O. Box 62, Oak Ridge, TN 37831

Prices available from (615) 576-8401, FTS 626-8401

Available to the public from the National Technical Information Service

U.S. Department of Commerce 5285 Port Royal Rd., Springfield, VA 22161 


\section{DISCLAIMER}

Portions of this document may be illegible in electronic image products. Images are produced from the best available original document. 


\title{
PROCESS MODELING OF HYDROTHERMAL \\ TREATMENT OF MUNICIPAL SOLID WASTE TO \\ FORM HIGH SOLIDS SLURRIES IN A \\ PILOT SCALE SYSTEM
}

\author{
C. B. Thorsness \\ Lawrence Livermore National Laboratory \\ P.O. Box 808, L-365 \\ Livermore, CA. 94550
}




\section{TABLE OF CONTENTS}

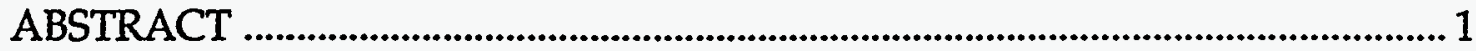

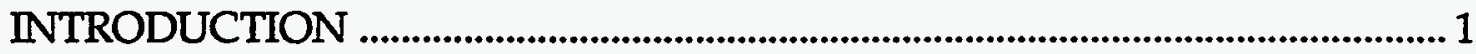

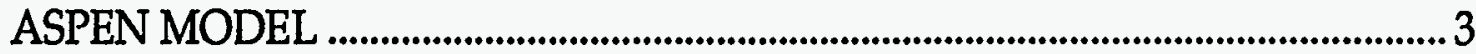

TRANSIENT MODEL EQUATIONS …............................................................ 5

Vessel 1 Mass Balance Equations .................................................................. 6

Vessel 2 Mass Balance Equations ............................................................... 8

Energy Balance Equations.................................................................................. 9

Valve Opening Algorithm ................................................................................ 11

SOLUTION OF TRANSIENT MODEL EQUATIONS .............................................. 12

TRANSIENT MODEL COMPUTED RESULTS ................................................. 12

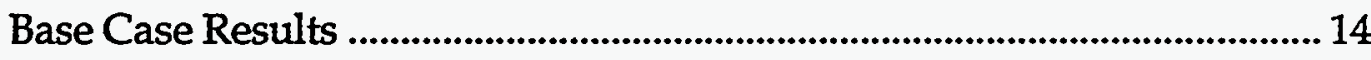

Steam Injection Rate....................................................................................... 22

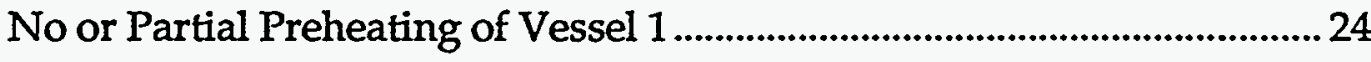

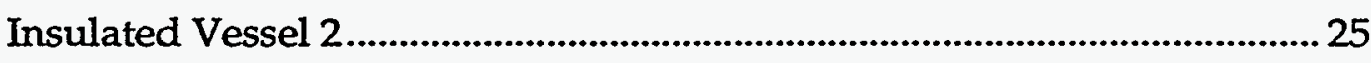

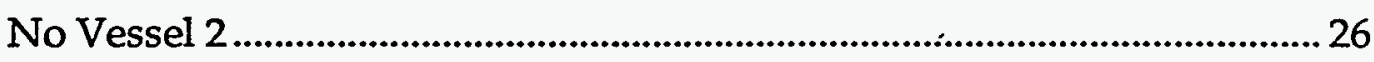

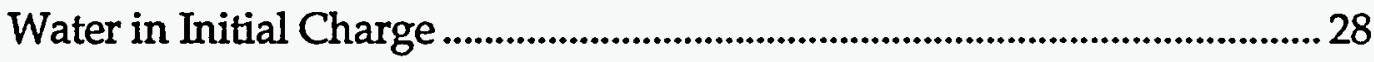

Reduced Gas Make ................................................................................................ 31

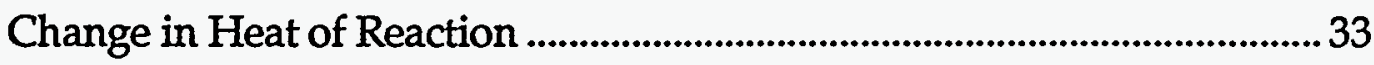

Newspaper Charge ........................................................................................ 35

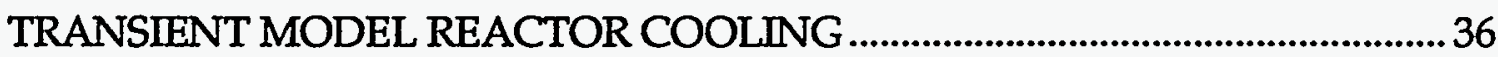

TRANSIENT MODEL - EXTENDED COOLING …............................................38

TRANSIENT MODEL - PREFERRED OPERATING STRATEGY ......................... 44

The First Experiment ........................................................................................ 49

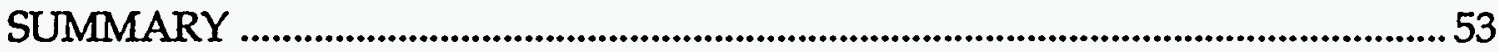

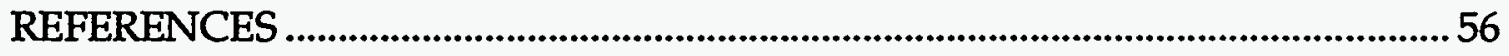

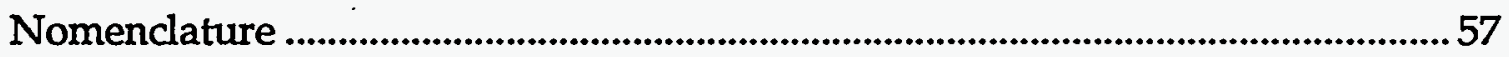

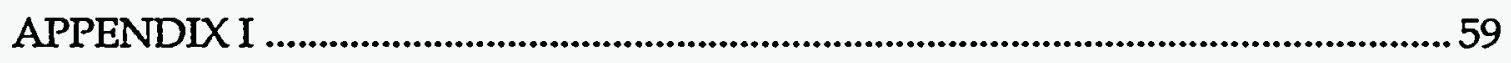

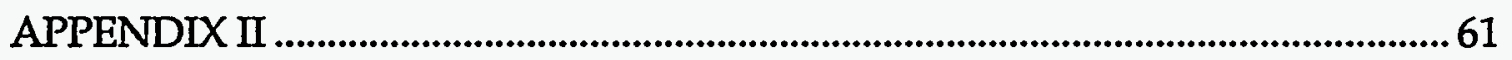

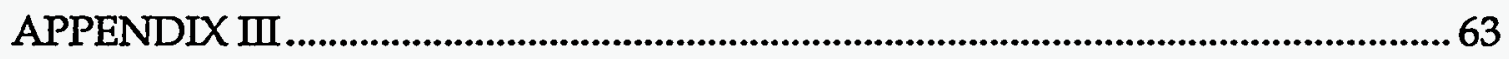

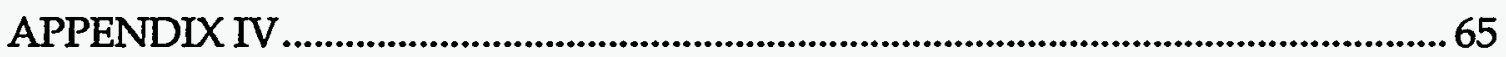




\section{ABSTRACT}

Two models are developed for characterizing the hydrothermal decomposition of municipal solid waste (MSW) in a pilot scale facility. The process modeled involves the use of high pressure steam to directly heat surrogate MSW, newspaper, to temperatures and pressures where decomposition reactions breakdown the organic matter to form a coal like solid having properties which make it suitable as a feedstock for a commercial gasifier. One model uses the ASPEN steady-state simulator. This model is only capable of computing a limited number of process variables. To more adequately deal with the transient behavior of the inherently batch process a second transient model is formulated. The model allows important process temperatures, pressures, gas flows and compositions to be calculated as a function of time. The model has been used to scope possible operating scenarios for proposed pilot scale experiments and these results are presented. Based on computed results a recommendation is made that the first pilot experiment use a dampened feed material containing a water-to-dry newspaper ratio of 0.5 to 1 . The transient model predicts that this will result in a slurry product in the reactor vessel after cooldown containing $57 \mathrm{wt} . \%$ water.

\section{INTRODUCTION}

It has been suggested that Municipal Solid Waste (MSW) could be used as an alternative feedstock to coal in a commercial slurry fed gasifier ${ }^{1}$. The proposed commercial gasification scheme uses a liquid feed system to introduce feedstock into a pressurized gasifier. Consequently, any feedstock must be pumpable, and at the same time contain enough fuel value to allow suitably efficient operation of the unit. For slurries made of biomass derived materials, which MSW is for the most part, the fuel value of a pumpable slurry is low. This is primarily due to the cellular structure of the solid material which leads to the sequestering of water and as a result this water does not contribute to the fluidity of the slurry. For example, paper pulp slurries are pumpable up to a solids loading of no more than $10 \%$. Therefore, to make a slurry feed with solids content on the order of $50 \%$ or more, required by the gasifier, something must be done to break down the physical cell structure of the MSW. In addition, biomass has relatively a lower energy value than coal because of its high oxygen content. So it is also beneficial to remove oxygen from the solid to boost its energy value per unit weight.

One means of accomplishing the required transformation of the raw MSW into a slurry suitable for gasification is to treat it hydrothermally. This involves heating the raw slurry to temperatures of $250-350^{\circ} \mathrm{C}$ at pressures sufficient to maintain the water phase. At these temperatures the organic matter in biomass begins to breakdown in a process very much paralleling the formation of coal in natural 
settings. The cell structure is destroyed and the oxygen content is reduced by the evolution of carbon dioxide and water. One option for heating MSW to the required temperature is to use high pressure steam.

As a first step in looking at a steam heat option for preparing a suitable slurry from MSW some pilot scale experiments using shredded newspaper as a surrogate for MSW are planned. The planned pilot facility is shown schematically in Fig 1 . The processing would be accomplished in a batch mode. First the newspaper would be loaded into the reactor vessel. The vessel would then be sealed and steam introduced into the reactor. As the temperature increases the pressure in the system would increase. At some point the upper pressure limit for the system would be reached. At this point the steam injection would be reduced and gas and steam would begin to exit through the back pressure control valve. After a suitable reaction time, steam injection would be terminated and the system pressure would be relieved by gradual opening of the pressure control valve. During the reaction and blowdown phase, water vapor would be produced from the system and pass through a downstream condenser. After the pressure letdown some water would also remain in the reactor and the dropout vessels. The drop out vessel is linked to the reactor vessel by a $5 \mathrm{~cm}$ line. Scrubber and charcoal filter units in the downstream line insure that the noncondensable gas, primarily carbon dioxide, is suitable for discharge to the atmosphere.

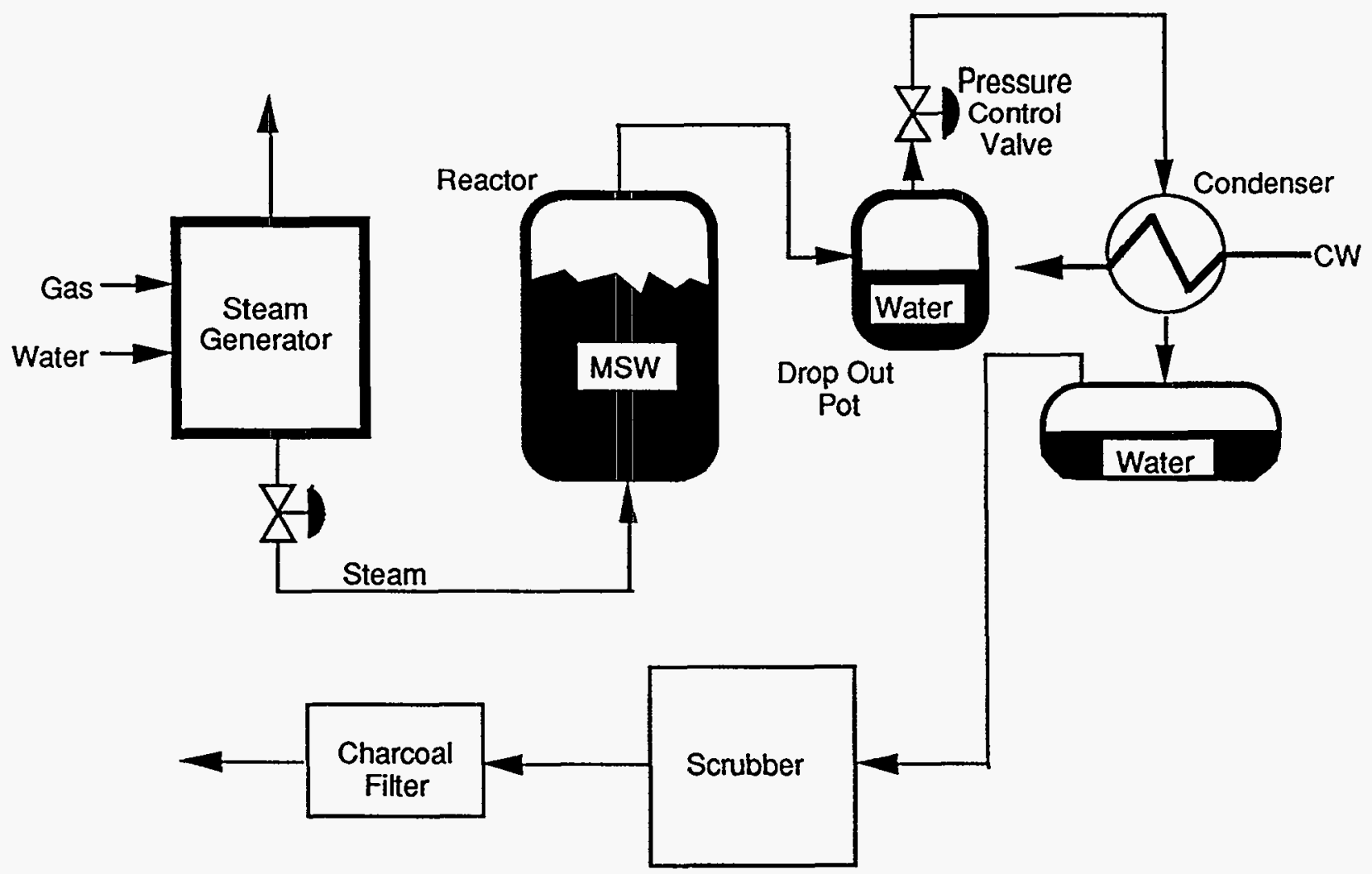

Figure 1. Schematic of pilot process. 
In order to adequately plan future pilot runs it is useful to do some preliminary modeling of the system to help elucidate the influence of operating parameters on operational performance, particularly with respect to the quantities of steam required and the final amounts of water present in the system. Two modeling approaches have been used. In the first, a simple model of the system was put together using the ASPEN process simulator. The ASPEN process simulator is a general purpose chemical process simulator aimed primarily at modeling of continuous systems. However, certain aspects of batch operations can be computed with this type of model. In order to look at more details of the proposed operation a second, transient model, was constructed which explicitly follows important aspects of the time history of the operations.

In the following, typical results obtained from the ASPEN simulation are presented. This is followed by a detailed description of the equations used to construct the transient model. Finally, results computed using the transient model in a variety of operating scenarios are presented.

\section{ASPEN MODEL}

The ASPEN model of the process considers the operation of the reactor and the condenser systems. The simulation assumes complete reaction of the newspaper feed according to the overall reaction (from reference 1) stoichiometry given in Tables 1 and 2. As described in the reference the heat of reaction is estimated to be $0.27 \mathrm{~kJ} / \mathrm{kg}$.

Table 1. Composition of newspaper and newspaper solid decomposition product on an ash-free basis.

\begin{tabular}{|ccc|}
\hline & Wt. $\%$ & Atom/C \\
\cline { 2 - 3 } Newspaper & & \\
C & 49.9 & 1 \\
H & 6.2 & 1.49 \\
O & 43.69 & 0.66 \\
N & 0.05 & 0.0009 \\
S & 0.16 & 0.0012 \\
Solid Product & & \\
C & 65.4 & 1 \\
H & 5.5 & 1 \\
O & 28.8 & 0.33 \\
N & 0.07 & 0.0009 \\
S & 0.22 & 0.0013 \\
\hline
\end{tabular}


Table 2. Assumed decomposition stoichiometry on a per kilogram of ash-free newspaper basis.

\begin{tabular}{|ccc|}
\hline Solid Product & Wt. & Moles \\
\cline { 2 - 3 } Carbon dioxide & 0.72 & \\
Carbon monoxide & 0.0028 & 2.05 \\
Hydrogen & 0.00036 & 0.10 \\
Methane & 0.0037 & 0.23 \\
Water & 0.19 & 10.5 \\
\hline
\end{tabular}

Computed results for the ASPEN simulation are given in Fig. 2. The model actually allows some influence of the reactor wall heating/cooling to be incorporated into the simulation. For the case shown however, it is assumed that the newspaper effectively insulates the contents of the reactor from the walls during the blowdown phase and that the reactor walls are preheated to the reaction temperature prior to introduction of the steam. The results show flow rates based on a characteristic time of 60 minutes. If approximate rates are needed for particular aspects of the process a ratio can be used. For instance, if it is assumed that the reactor will be depressurized over the course of two hours at a constant flow rate then that flow would be $60 / 120 *(1.95+0.13)=1.0 \mathrm{~mol} / \mathrm{s}$. The cooling water flow rate is estimated from computed cooling rate, $93 \mathrm{~kW}$, and a $20 \mathrm{C}$ temperature rise of the cooling water.

This simulation of the batch process with a continuous model gives useful estimates of total amounts of materials. However, it is difficult to use such a model to explore the details of the operation of the unit. For instance, the actual process will involve initial steam injection at a fairly high rate, followed by smaller rates after the reaction pressure has been reached. This continuous model can not be used to explore the influence of these rates on the heating and pressurization of the system. Also, questions about the timing of the release of the noncondensable gases and their influence on system pressure can not be readily addressed. Consequently, a transient process model was developed to explore the time evolution of the process and is described in the following sections. 


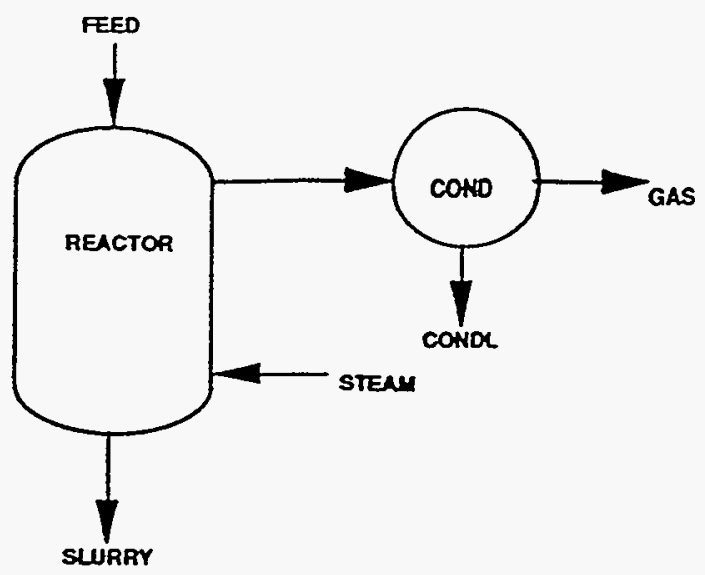

\begin{tabular}{|lcccccc|}
\hline & FEED & STEAM & REACTOR & SLURRY & CONDL & GAS \\
\cline { 2 - 7 } Total Flow Rate (kg/s) & 0.0525 & 0.043 & 0.074 & 0.056 & 0.035 & 0.0047 \\
Total (kg) & 189 & 155 & 266 & 202 & 126 & 17 \\
Temperature (C) & 25 & 280 & 270 & 100 & 40 & 40 \\
Pressure (MPa) & 6.3 & 6.3 & 6.3 & 0.1 & 0.1 & 0.1 \\
Water (wt. \%) & 0 & & $48 \%$ & $32 \%$ & & \\
Conventional & & & & & & \\
Flow Rate (kg/s) & & 0.043 & 0.0356 & 0.0176 & 0.035 & 0.0047 \\
Flow Rate (mol/s) & 2.4 & 1.98 & 0.98 & 1.95 & 0.13 \\
Total Flow (kg) & & 154.8 & 128 & 63 & 126 & 17 \\
H2O (mol \%) & & 100 & 99.98 & 100 & 99.96 & 7.5 \\
CO2 (mol \%) & & 0 & 0.02 & 0 & 0.04 & 73.9 \\
CO (mol \%) & & 0 & 0 & 0 & 0 & 3.7 \\
H2 (mol \%) & & 0 & 0 & 0 & 0 & 6.5 \\
CH4 (mol \%) & 0 & 0 & 0 & 0 & 8.4 \\
Nonconventional & & & & & & \\
Flow Rate (kg/s) & 0.0525 & & 0.0382 & 0.0382 & & \\
Total (kg) & 189 & & 138 & 138 & & \\
Ash (wt \%) & 1.5 & & 2.1 & 2.1 & & \\
Newspaper (wt \%) & 98.5 & & 0 & 0 & & \\
Solid Product (wt \%) & 0 & & 97.9 & 97.9 & & \\
Time Scale (min.) & 60.0 & & & & & \\
Cooling (kW) & 93 & & & & & \\
Cooling Water Flow (gpm) & 18 & & & & & \\
\hline
\end{tabular}

Figure 2. Results from the ASPEN simulation, all rates are computed assuming a 60 minute characteristic time.

\section{TRANSIENT MODEL EOUATIONS}

The transient model was formulated to allow estimates of the time history of the reactor and dropout vessels and their contents to be made. The system modeled is shown schematically in Fig. 3. It consists of the two vessels connected together . Gas can exit out of Vessel 2 depending on the position of the control valve. Steam is introduced into the main reactor, Vessel 1 . Heat can flow to/from the vessel walls and the environment or the vessel contents. An initial charge of newspaper 
is assumed to be present in the main reactor Vessel 1. Air is assumed to initially fill the void space in each vessel.

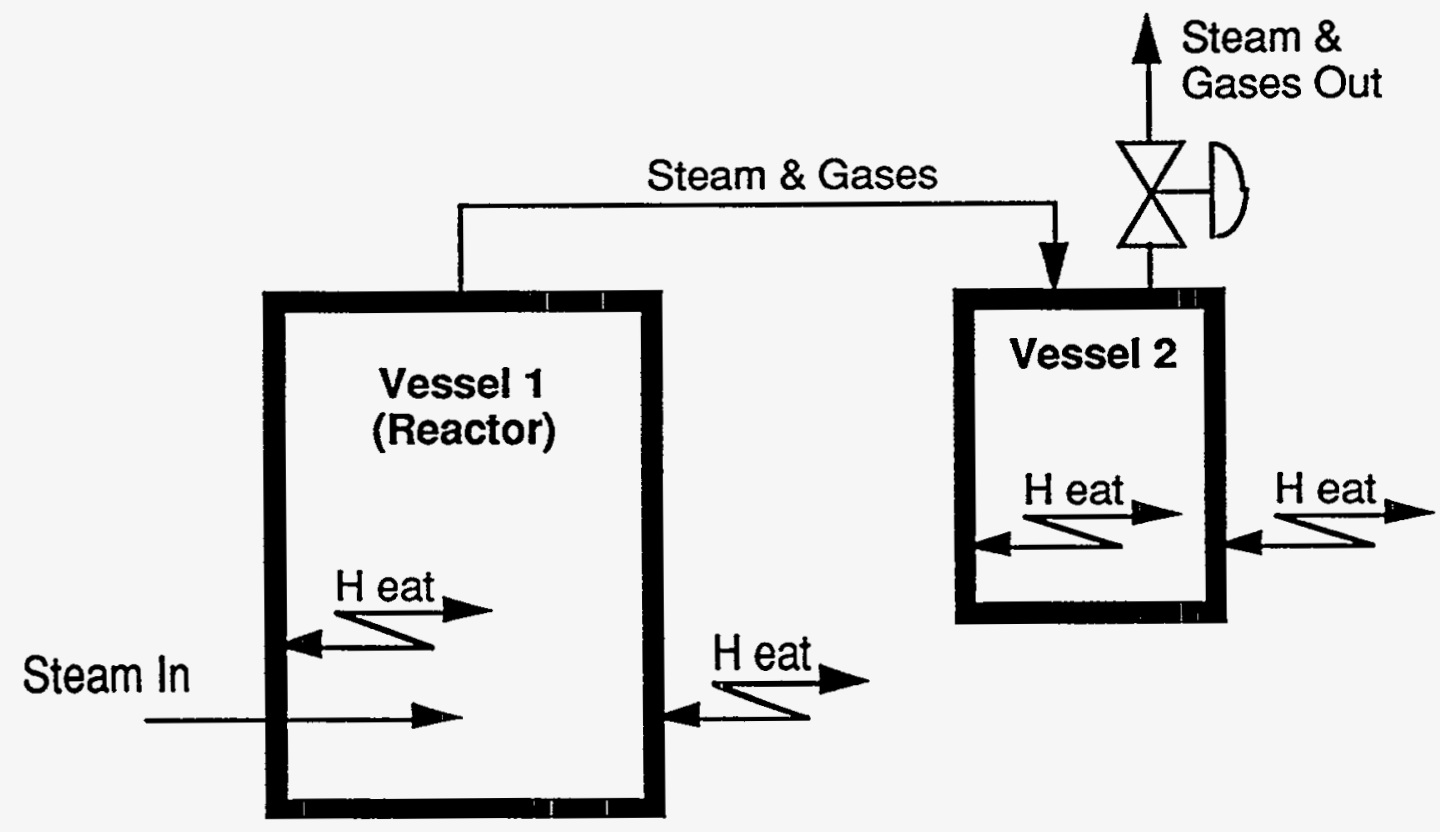

Figure 3. Schematic of the two vessel system used in formulating the transient model.

Material and energy balances are written for the two vessels and energy balances for the vessel walls. It is assumed that the newspaper present in Vessel 1 undergoes a first order reaction to produce solid product, noncondensable gases and water. Three gas phase species, one liquid are two solid species are assumed present in the system. The gases are assumed to consist of air, noncondensable gas products from the decomposition and water vapor or steam. The only liquid species considered is water and the solids are newspaper and the solid product of the hydrothermal decomposition reaction. An overall decomposition reaction,

$$
\text { Newspaper } \rightarrow \alpha_{S}(\text { Solid Product })+\alpha_{W}(\text { Water })+\alpha_{G} \text { (Noncondensable Gas) }
$$

is assumed, where $\alpha$ 's are the stoichiometric coefficients for the assumed overall reaction. The solid product coefficient is assumed to be expressed on a weight per weight of newspaper basis while the water and gas coefficients are assumed to be expressed on a mole per weight of newspaper basis.

\section{Vessel 1 Mass Balance Equations}

Six differential material balances are written for Vessel 1, one each for the following materials: newspaper, solid product, noncondensable product gas, 
steam, water, and total gas. The solid phase species, newspaper and solid product material, are created or destroyed by the hydrothermal reaction leading to the two simple balances

$$
\begin{aligned}
& \frac{d N}{d t}=-r_{N}, \\
& \frac{d S}{d t}=\alpha_{s} r_{N} .
\end{aligned}
$$

Here $t$ is time, $N$ is the mass of newspaper, $S$ is the mass of solid product, and $r_{N}$ is the hydrothermal reaction rate. The reaction rate is assumed to be first order and given by the simple Arrhenius' form

$$
r_{N}=A e^{\frac{-T_{a}}{T}} N
$$

where $A$ is the pre-exponential factor, $T_{a}$ the activation temperature and $T_{1}$ the temperature of Vessel 1.

In dealing with the water and steam mass balances the change in phase is not treated explicitly as an equilibrium process, but rather as a rate process. This allows the formulation of the defining balance equations to be posed as a differential equations and not a mixed differential/algebraic system which can be more difficult to solve. By formulating the rate process of steam/water interchange appropriately, a system can be arrived at which retains the equilibrium character of the steam and the water. The water balance in Vessel 1 using a rate based condensation/evaporation expression is,

$$
\begin{aligned}
& \frac{d W_{1}}{d t}=\alpha_{w} k N+r_{w_{1}}, \\
& r_{w_{1}}=\beta\left(P_{w_{1}}-P\left\langle T_{1}\right\rangle\right),
\end{aligned}
$$

where $W_{1}$ is the mass of water in Vessel 1 expressed in moles, $r_{w 1}$ is the rate of steam condensation (negative rates are water evaporation), $\beta$ is a transport constant for condensation/evaporation, $P_{\mathrm{w}_{1}}$ is the partial pressure of steam in Vessel 1 and $\mathscr{P}\left\langle T_{1}\right\rangle$ is the vapor pressure of water evaluated at the temperature of Vessel 1 (see Appendix I for correlation used). $\beta$ is set large enough to simulate near equilibrium conditions (i.e. $P_{W_{1}}=\mathcal{P}\left\langle T_{1}\right\rangle$ ) consistent with stability of the solution scheme. It is assumed that Raoult's law holds and the ideal gas law is valid. 
The final three mass balances for Vessel 1 are for two of the three gas components and the overall amount of gas. The component balances are written in terms of their mole fractions. The third gas mole fraction is obtained by difference. The overall gas balance in Vessel 1 is

$$
\frac{d g_{1}}{d t}=f_{s}+\alpha_{G} r_{N}-f-r_{w_{1}}
$$

where $g_{1}$ is the moles of gas in Vessel $1, f_{s}$ is the flow rate of steam into the vessel, and $f$ is the flow of gas from Vessel 1 to Vessel 2 (positive direction from 1 to 2). The vessels are connect by a fairly large diameter pipe $(5 \mathrm{~cm})$ and to a very good approximation the pressures in each vessel should be equal. However, it is most convenient to use the fact that the flow between vessels is pressure driven. A relation for the flow, $f$ is written as

$$
f=\Omega\left(P_{1}-P_{2}\right),
$$

where $\Omega$ is a constant. It is chosen large enough to maintain the pressures in each vessel nearly equal, but not so large as to cause undue computational difficulties. The vessel pressures are obtained from the computed moles of gas, the ideal gas law and the void volume. The void volume in Vessel 1 is computed simply by

$$
V_{1}=V_{0_{1}}-\frac{W_{1}}{\rho_{W}}-\frac{N}{\rho_{N}}-\frac{S}{\rho_{S}},
$$

where $V_{o_{1}}$ is the vessel volume and the $\rho$ 's are densities. The species balances for noncondensable product gas and steam are

$$
\begin{aligned}
& \frac{d y_{G_{1}}}{d t}=\frac{1}{g_{1}}\left[-y_{G_{1}} \frac{d g_{1}}{d t}+\alpha_{G} r_{N}-b_{G}\right], \text { and } \\
& \frac{d y_{w_{1}}}{d t}=\frac{1}{g_{1}}\left[-y_{w_{1}} \frac{d g_{1}}{d t}+f_{s}-b_{w}-r_{w_{1}}\right],
\end{aligned}
$$

where $y_{w_{1}}$ is the mole fraction of steam in Vessel $1, y_{G_{1}}$ is the mole fraction of non-condensable product gas, $b_{G}$ is the molar flow of noncondensable product gas between vessels, and $b_{w}$ is the molar flow of steam between vessels. The positive direction for the flow between vessels is taken as out of Vessel 1 into Vessel 2. The flow terms, $b_{G}$ and $b_{w}$, are obtained from the total flow, $f$, and the gas mole fraction in the vessel from which the flow is exiting. Since the flow is nearly always from Vessel 1 to Vessel 2, these are nearly always the Vessel 1 mole fractions.

\section{Vessel 2 Mass Balance Equations}

In Vessel 2 only water and gas species are assumed to be present. The differential mass balances used are 


$$
\begin{aligned}
& \frac{d W_{2}}{d t}=r_{w_{2}}=\beta\left(P_{\mathrm{w}_{2}}-P\left(T_{2}\right)\right), \\
& \frac{d g_{2}}{d t}=f-f_{c}-r_{w_{2}}, \\
& \frac{d y_{G_{2}}}{d t}=\frac{1}{g_{2}}\left[-y_{G_{2}} \frac{d g_{2}}{d t}+b_{G}-y_{G_{2}} f_{e}\right], \text { and } \\
& \frac{d y_{w_{2}}}{d t}=\frac{1}{g_{2}}\left[-y_{w_{2}} \frac{d g_{2}}{d t}+b_{w}-y_{w_{2}} f_{e}-r_{w_{2}}\right],
\end{aligned}
$$

where $f_{e}$ is the molar flow rate of gas exiting Vessel 2 through the pressure control valve. The rate of which gas exits Vessel $2, f_{e}$ is determined in one of two ways depending on the phase of the experiment. During the heatup and reaction phase it is assumed that the flow from Vessel 2 is controlled by a pressure controller set to maintain a desired maximum vessel pressure. The relations during these periods are given by

$$
\begin{gathered}
f_{e}=\sigma\left(P_{2}-P_{r}\right) \text { for } P_{2} \geq P_{r} \text { and } \\
f_{e}=0 \text { for } P_{2}<P_{r},
\end{gathered}
$$

where $P_{r}$ is the maximum desired reactor pressure and $\sigma$ is a constant picked large enough to maintain $P_{2}$ reasonably close to $P_{r}$ without causing computational difficulties. During the pressure blowdown phase of the experiment the flow is assumed to be controlled by the $C_{v}$ of the valve using the relations from Walas ${ }^{2}$

$$
\begin{gathered}
f_{e}=4.9 \times 10^{-5} C_{v} \sqrt{\frac{\left(P_{2}-P_{\infty}\right) P_{2}}{\gamma T_{2}}} \text { for } \frac{P_{\infty}}{P_{2}} \geq 0.5 \text { and } \\
f_{e}=\frac{2.44 \times 10^{-5} C_{v} P_{2}}{\sqrt{\gamma T_{2}}} \text { for } \frac{P_{\infty}}{P_{2}}<0.5,
\end{gathered}
$$

where $P_{\infty}$ is the downstream pressure, and $\gamma$ is the specific gravity of the exiting gas relative to air at the same conditions. The flow is in $\mathrm{mol} / \mathrm{s}$, pressure in pascals and temperature in Kelvins. During the blowdown phase the value of $C_{v}$ is assumed to be a function of time.

\section{Energy Balance Equations}

In writing energy balances for the system it is assumed that in each vessel the gas, solid and liquid phases have the same temperature and a single temperature characterizes the wall.

Energy balances for the two vessel walls are simply given by the equation 


$$
\frac{d T_{w_{i}}}{d t}=\frac{1}{m_{i} c_{m}}\left(Q_{i}-q_{i}\right),
$$

where $T_{w_{i}}$ is the wall temperature of vessel $i, m_{i}$ is the mass of the wall of vessel $i$, $c_{m}$ is the heat capacity of the metal wall, $Q_{i}$ is the heat transfer rate from the wall of vessel $i$ to its interior and $q_{i}$ is the heat transfer rate from vessel $i$ to the surroundings. This formulation assumes that the metal wall heat capacity is constant. The heat transfer rates are given by simple overall heat transfer coefficients and an appropriate area

$$
\begin{aligned}
Q_{i} & =H_{i} A_{i}\left(T_{i}-T_{w_{i}}\right) \text { and } \\
q_{i} & =h_{i} A_{i}\left(T_{w_{i}}-T_{\infty}\right),
\end{aligned}
$$

where $H_{i}$ and $h_{i}$ are heat transfer coefficients for vessel $i, A_{i}$ is the wall area of vessel $i$, and $T_{\infty}$ is the ambient air temperature.

The energy balance for Vessel 1, assuming constant heat capacities, is given by

$$
\frac{d T_{1}}{d t}=\frac{-Q_{1}-r_{w_{1}} \Delta H_{w}\left\langle T_{1}\right\rangle-r_{N} \Delta H_{N}\left\langle T_{1}\right\rangle+f_{s} c_{p_{w}}\left(T_{s}-T_{1}\right)+B_{1}}{\left[N c_{N}+S c_{s}+W_{1} c_{W}+g_{1}\left(y_{w_{1}} c_{p_{w}}+y_{G_{1}} c_{P G}+y_{a_{1}} c_{p_{a}}\right)\right]},
$$

where $\Delta H_{w}\left\langle T_{1}\right\rangle$ is the heat of steam condensation at temperature $T_{1}, \Delta H_{N}\left\langle T_{1}\right\rangle$ is the heat of reaction of newspaper decomposition at temperature $T_{1}, B_{1}$ is an inflow correction term defined below, $c_{N}$ is the heat capacity of newspaper, $c_{s}$ is the heat capacity of solid product, $c_{w}$ is the heat capacity of water, $c_{p_{w}}$ is the heat capacity of steam, $c_{p G}$ is the heat capacity of noncondensable product gas, and $c_{p_{a}}$ is the heat capacity of air. This formulation assumes constant heat capacities. The inflow correction term, $B_{1}$ is defined to be

$$
\begin{gathered}
B_{1}=f\left(y_{w_{1}} c_{p_{w}}+y_{G_{1}} c_{p_{G}}+y_{a_{1}} c_{p_{a}}\right) \text { for } f>0, \text { and } \\
B_{1}=0 \text { for } f \leq 0 .
\end{gathered}
$$

The negative signs on the reaction terms are required because of the convention used in defining the heats of reaction, endothermic reactions having a negative heat of reaction. The heat of reaction is given in terms of the heats of formation and heat capacities of involved species by

$$
\begin{aligned}
\Delta H_{N}\left\langle T_{1}\right\rangle= & \alpha_{s} H_{f s}+\alpha_{W} H_{f_{W}}+\alpha_{G} H_{f_{G}}-H_{f_{N}}+ \\
& \left(\alpha_{s} c_{s}+\alpha_{\mathrm{w}} c_{\mathrm{w}}+\alpha_{G} c_{P G}-\alpha_{N} c_{N}\right)\left(T_{1}-298\right),
\end{aligned}
$$




$$
\Delta H_{W}\left\langle T_{1}\right\rangle=H_{f_{W}}-H_{f_{w}}+\left(c_{W}-c_{p_{w}}\right)\left(T_{1}-298\right),
$$

where the $H_{f}$ 's are heats of formation at $25 \mathrm{C}$.

The energy balance for Vessel 2 is

$$
\begin{gathered}
\frac{d T_{2}}{d t}=\frac{-Q_{2}-r_{w_{2}} \Delta H_{w}\left\langle T_{2}\right\rangle+B_{2}}{\left[W_{2} c_{W}+g_{2}\left(y_{w_{2}} c_{p_{w}}+y_{G_{2}} c_{p_{G}}+y_{a_{2}} c_{p_{a}}\right)\right]}, \\
B_{2}=f\left(y_{w_{2}} c_{p_{w}}+y_{G_{2}} c_{p_{G}}+y_{a_{2}} c_{p_{a}}\right) \text { for } f \geq 0, \\
B_{2}=0 \text { for } f<0 .
\end{gathered}
$$

\section{Valve Opening Algorithm}

During the pressure blowdown phase the steam production rate needs to be controlled. In practice, this could easily be accomplished with a valve controller tied to a flow meter. The experimental setup does not include this capability so the valve opening will be hand controlled. To approximate the desired constant flow rate a simple algorithm based on the exponential nature of the temperature water vapor pressure curve has been incorporated into the model. The algorithm is

$$
\begin{gathered}
C_{v}=C_{v_{0}} \exp \left[-4666\left(\frac{1}{T_{r}-k t}-\frac{1}{T_{r}}\right)\right] \text { for } C_{v}<C_{v_{\max }}, \\
C_{v}=C_{v_{\max }} \text { otherwise, }
\end{gathered}
$$

where $C_{v_{0}}$ is the initial $C_{v}$ of the valve, $C_{v_{\max }}$ is the maximum $C_{v}$ of the valve, $T_{r}$ is the final reaction temperature and $k$ is the desired rate of temperature decrease. To a first approximation a constant rate of temperature decrease corresponds to a constant flow of steam out of the vessel. $C_{v_{0}}$ can be estimated using Eqn 18 and some reasonable values for $T_{r}$ and $\gamma$,

$$
C_{v_{0}}=\frac{f_{e}}{1.42 \times 10^{-6} P_{r}} .
$$

where $f_{c}$ is the desired exit flow rate. 


\section{SOLUTION OF TRANSIENT MODEL EQUATIONS}

Equations. 1, 2, 4, 5, 6, 9-14, 19, 22 and 27 represent 14 nonlinear first order ordinary differential equations describing the system to be modeled. This system is solved as an initial value problem through the use of a FORTRAN computer program which uses the ODE solver LSODE ${ }^{3}$. The solution of a typical problem representing 3-48 hours of experiment takes less than a minute on an HP$9000 / 730$ workstation.

The solution of the ODE's with time are influenced not only by the initial conditions of the specific problem but also by the way inputs and outputs to the vessels change with time. The two of the most important of these are the steam injection rate and the gas production rate.

The steam flow rate is allowed to vary with time. In the current model version changes in the steam flow rate are made stepwise. The stepwise changes were chosen because this is the natural way flow rates would be controlled in practice and this mode, based on some initial testing, resulted in more robust and rapid solutions. The detail of the method of implementing the flow changes has some small effect on the solutions and consequently are outlined here. The LSODE software allows solutions to equations to be integrated forward a selected amount of time, which is designated here as the adjustment time interval. In the model the adjustment time interval is a parameter, generally set at five minutes. After each adjustment time interval the model checks the solution and determines if the maximum pressure has been reached. If it has the injected flow rate is changed according to a schedule in which time is measured relative to the time at which the maximum pressure was reached. A flow reduction which is associated with reaching the system pressure will occur no later then one adjustment time interval after reaching the maximum pressure.

In a similar manner the beginning of the blowdown period will occur within one adjustment time interval and changes to the outlet control valve are only made once every adjustment time interval.

The program has been written to include a variety of options in terms of initial conditions and type of wall heat transfer. In the next section a variety of computed results are described and model options are discussed.

\section{TRANSIENT MODEL COMPUTED RESULTS}

The transient model equations have been solved for a variety of possible experimental conditions. The computed results have all used the set of model parameters listed in Table 3, except where noted. The flow adjustment time interval for the base case is five minutes. 
Table 3. Base case model parameters

\begin{tabular}{|c|c|c|}
\hline Parameter & Value & Units \\
\hline$\beta$ & 1000 & $\mathrm{~mol} / \mathrm{s}-\mathrm{Pa}$ \\
\hline$\sigma$ & $1.0 \times 10^{-4}$ & $\mathrm{~mol} / \mathrm{s}-\mathrm{Pa}$ \\
\hline $\boldsymbol{\Omega}$ & $1.0 \times 10^{-2}$ & $\mathrm{~mol} / \mathrm{s}-\mathrm{Pa}$ \\
\hline$P_{\infty}$ & 0.1 & $\mathrm{MPa}$ \\
\hline$f_{s}$ during heatup & 2 & $\mathrm{~mol} / \mathrm{s}$ \\
\hline$f_{s}$ during relief & 0.4 & $\mathrm{~mol} / \mathrm{s}$ \\
\hline$T_{S}$ & 275 & C \\
\hline$P_{r}$ & 6.3 & $\mathrm{MPa}$ \\
\hline$C_{v_{\max }}$ & 11 & $\mathrm{~mol} \mathrm{~K} 0.5 / \mathrm{Pa}-\mathrm{s}$ \\
\hline$C_{v}$ & 0.33 & $\mathrm{~mol} \mathrm{~K} \mathrm{~K}^{0.5} / \mathrm{Pa}-\mathrm{s}$ \\
\hline$T_{\infty}$ & 25 & C \\
\hline$A$ & $6.3 \times 10^{4}$ & $1 / \mathrm{s}$ \\
\hline$T_{a}$ & 10000 & $\mathbf{K}$ \\
\hline$\alpha_{S}$ & 0.72 & $\mathrm{~kg} / \mathrm{kg}$-newspaper \\
\hline$\alpha_{W}$ & 10.56 & mol/kg-newspaper \\
\hline$\alpha_{G}$ & 2.38 & mol/kg-newspaper \\
\hline$H_{f_{N}}$ & 0.725 & $\mathrm{MJ} / \mathrm{kg}$ \\
\hline$H_{f_{S}}$ & 0 & $\mathrm{~J} / \mathrm{kg}$ \\
\hline$H_{f_{W}}$ & -44 & $\mathrm{~kJ} / \mathrm{mol}$ \\
\hline$H_{f_{G}}, H_{f_{w}}$ & 0 & $\mathrm{~J} / \mathrm{mol}$ \\
\hline
\end{tabular}

\begin{tabular}{|c|c|c|}
\hline Parameter & Value & Units \\
\hline$c_{N}$ & 1000 & $\mathrm{~J} / \mathrm{kg}-\mathrm{K}$ \\
\hline$c_{s}$ & 1000 & $\mathrm{~J} / \mathrm{kg}-\mathrm{K}$ \\
\hline$c_{W}$ & 75.24 & $\mathrm{~J} / \mathrm{mol}-\mathrm{K}$ \\
\hline$c_{m}$ & 420 & $\mathrm{~J} / \mathrm{kg}-\mathrm{K}$ \\
\hline$c_{p_{a}}$ & 30 & $\mathrm{~J} / \mathrm{mol}-\mathrm{K}$ \\
\hline$c_{P G}$ & 40 & J/mol-K \\
\hline$c_{p_{w}}$ & 34 & $\mathrm{~J} / \mathrm{mol}-\mathrm{K}$ \\
\hline$\rho_{N}$ & 1000 & $\mathrm{~kg} / \mathrm{m}^{3}$ \\
\hline$\rho_{S}$ & 1000 & $\mathrm{~kg} / \mathrm{m}^{3}$ \\
\hline$\rho_{\mathrm{W}}$ & 4444 & $\mathrm{~mol} / \mathrm{m}^{3}$ \\
\hline$V_{0_{1}}$ & 1.42 & $\mathrm{~m}^{3}$ \\
\hline $\mathrm{V}_{\mathrm{O}_{2}}$ & 0.13 & $\mathrm{~m}^{3}$ \\
\hline$m_{1}$ & 3553 & $\mathrm{~kg}$ \\
\hline$m_{2}$ & 1033 & $\mathrm{~kg}$ \\
\hline$A_{1}$ & 1.17 & $\mathrm{~m}^{2}$ \\
\hline$A_{2}$ & 0.13 & $\mathrm{~m}^{2}$ \\
\hline$h_{1}$ & 0 & $\mathrm{~W} / \mathrm{m}^{2}-\mathrm{K}$ \\
\hline$h_{2}$ & 10 & $\mathrm{~W} / \mathrm{m}^{2}-\mathrm{K}$ \\
\hline$T_{\infty}$ & 25 & C \\
\hline$H_{1}$ & 0 & $\mathrm{~W} / \mathrm{m}^{2}-\mathrm{K}$ \\
\hline $\mathrm{H}_{2}$ & 1000 & $\mathrm{~W} / \mathrm{m}^{2}-\mathrm{K}$ \\
\hline
\end{tabular}

This base set of parameters assumes that Vessel 1 is insulated, and effectively has a zero heat transfer coefficient to the surroundings. It also assumes that the walls of Vessel 1 will be preheated and thus no steam condensation will be necessary to heat them. The coupling of the wall to its contents during the pressure relief phase is assumed to be poor. The reasoning is that as water turns to steam the material near the wall will dry out and effectively insulate the bulk of the material in Vessel 1 from its walls, consequently the internal heat transfer coefficient has been taken as zero.

Vessel 2, on the other hand, is assumed to be uninsulated and a heat transfer coefficient typical of natural convection cooling has been used. (Estimates over a range of temperatures for natural convection cooling of this vessel are given in Appendix II.) Because this vessel contains only water and gases it is assumed that 
the heat transfer between its walls and contents is very good. This would be especially true during the heatup phase when the primary heat transfer mechanism would be steam condensation at the walls. During the blowdown phase the coupling of walls and interior would be poorer but for simplicity one large heat transfer coefficient value is assumed for both phases.

The relief pressure was chosen because of limitations of available reactor vessels. The value of $6.3 \mathrm{MPa}$ will allow maximum temperature of about $275 \mathrm{C}$ to be reached.

The reaction rate parameters were chosen to yield a time constant of 10 minutes for the newspaper decomposition at $300 \mathrm{C}$ and have a relatively low activation temperature. This means for an isothermal case about 50 minutes would be required to react $90 \%$ of the newspaper at $275 \mathrm{C}$. These reaction parameters are educated guesses at this point based on limited experimental work. In reality, the decomposition reactions are much more complicated than the simple reaction modeled here. If it is necessary to model the reaction more completely the current model framework can easily be modified.

The base set of initial conditions assumes that Vessel 1 has an initial charge of $189 \mathrm{~kg}$ of newspaper at a temperature of $30 \mathrm{C}$. Vessel 2 is assumed to be empty. The wall temperature of Vessel 1 is assumed to be $275 \mathrm{C}$, although for the base set there is no coupling to the process so its value is not relevant. Vessel 2's wall temperature is assumed to be $25 \mathrm{C}$. All the void space in both vessels is assumed to be initially filled with air at $0.1 \mathrm{MPa}$ and $30 \mathrm{C}$. The pressure blowdown phase is assumed to continue until the internal pressure reaches $0.1 \mathrm{MPa}$.

\section{Base Case Results}

Computed results for the case using the base case parameters indicate that the reactor vessel will reach the maximum pressure of $6.3 \mathrm{MPa}$ in 53 minutes. After holding at this pressure for 60 minutes the blowdown phase takes about 90 minutes, for a total time of 210 minutes. The computed conversion of newspaper is $95.8 \%$ and the maximum temperature reached is $272.3 \mathrm{C}$. If the system instantaneously reached $272.3 \mathrm{C}$ the $95.8 \%$ conversion would occur in 77.3 minutes based on the assumed kinetics.

The compute pressure of the system as a function of time is shown in Fig 4. The steam injection begins at time zero and continues at $2 \mathrm{~mol} / \mathrm{s}$ until the maximum reactor pressure of $6.3 \mathrm{MPa}$ is reached. Soon after reaching the maximum pressure the steam flow is reduced to $0.5 \mathrm{~mol} / \mathrm{s}$. The slight sag in pressure soon after reaching the maximum pressure is caused by a slight cooling of the reactor as a result of the small endotherm assumed for the decomposition reaction $(0.27$ $\mathrm{MJ} / \mathrm{kg}$ ) and the reduction steam injection rate which occurs soon after reaching 
the maximum pressure. As time goes on the accumulation of gases compensates for the temperature sag and pressure returns to a point where gas begins venting again.

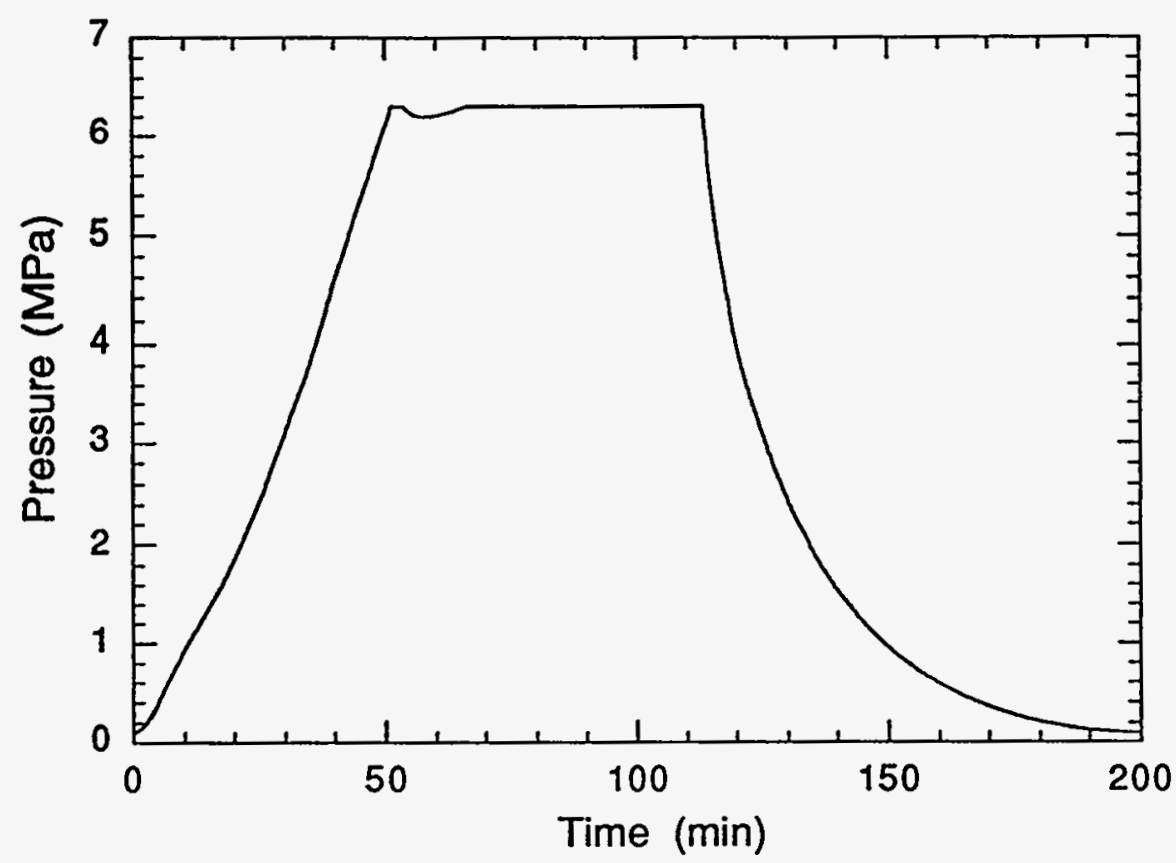

Figure 4. Reactor pressure for base case

In Fig. 5 computed temperatures for the base case are shown. The wall temperature of Vessel 1 is omitted because the nature of the base case assumptions result in no change to this temperature. The highest temperature in Vessel 1, 272.3 C, is reached just after the maximum pressure is reached. The slight reduction, as mentioned above is a result of the slight endotherm of the reaction and the reduction in steam injection rate.

The temperature of the contents of Vessel 2 and its wall are essentially the same. The actual difference in these two temperatures is a result of the size of the heat transfer coefficient used. A value of $1000 \mathrm{~W} / \mathrm{K}-\mathrm{m}^{2}$ has been used. This number was chosen to represent close coupling but not so close that undue computational difficulty would occur. The value of $1000 \mathrm{~W} / \mathrm{K}-\mathrm{m}^{2}$ appears to couple the two temperatures adequately. Unlike the Vessel 1 temperature, the Vessel 2 temperatures continue to rise during the reaction period. This temperature is largely dictated by the relative amount of noncondensable gas in Vessel 2 which tends to decline as venting from the vessel continues. The temperature of Vessel 2 remains less than Vessel 1 during the heatup and reaction phases because of the assumed close coupling of content and walls in Vessel 2 and the assumption that Vessel 2 is uninsulated and loses heat to the environment. 


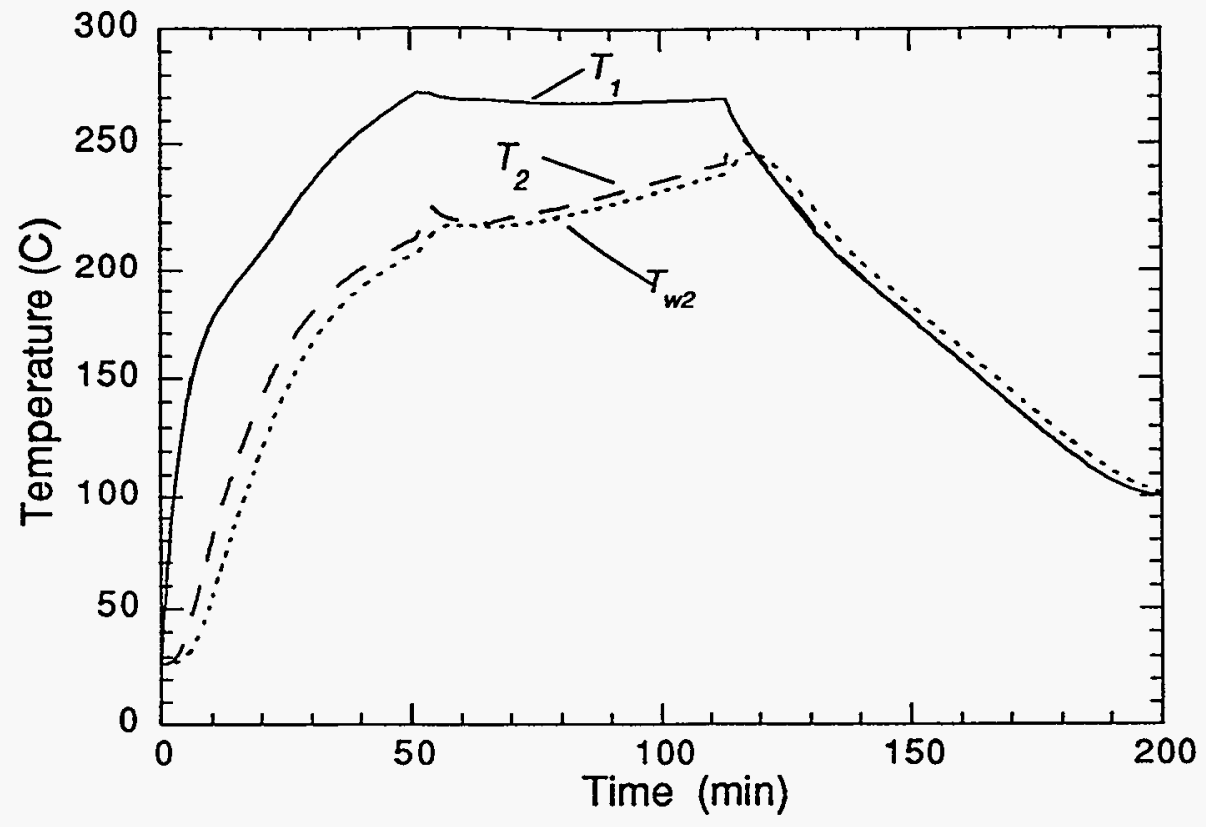

Figure 5. Vessel 1 and 2 internal temperatures and Vessel 2 wall temperature for base case.

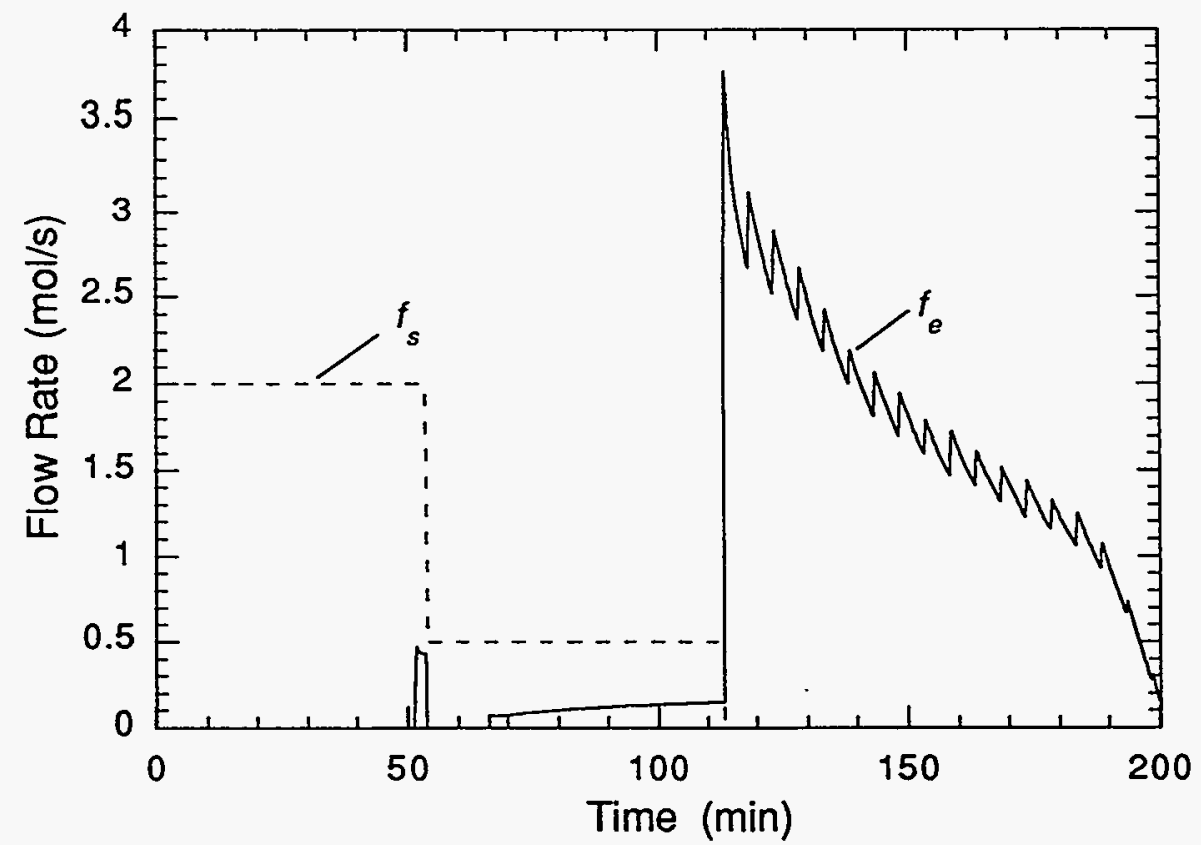

Figure 6. Injected steam and produced gas flow rates for base case A simple steam injection scheme is used, see Fig. 6 , in the base case. The flow rate is constant flow at $2 \mathrm{~mol} / \mathrm{s}$ until the reactor reaches the maximum working pressure and then it is reduced to $0.5 \mathrm{~mol} / \mathrm{s}$. Higher steam flows after the start of venting would result in a slight increase in the system temperature but most of the steam would simply be vented from the system. Some flow, however, is needed during this period to help sweep out the produced noncondensable gases 
so that partial pressure of steam remains fairly high and condensation can effectively maintain the desired reactor temperature.

Also shown in Fig. 6 is the exit gas flow rate. The first blip of gas exiting the reactor occurs at the time the vent pressure is reached. This initial flow of gas exiting the system is a pulse rather than a gradual increase from zero because of the exact timing of the arrival of the system at the maximum operating, or gas relief pressure, and the reduction of the steam flow rate. In this case the heatup steam flow persists for several minutes after the vent pressure is reached. Shortly after this initial gas pulse the gas buildup in system does result in a smooth increase of exit gas flow at a relatively low flow rate. At the end of the reaction period the steam flow is turned off and the outlet control valve is opened in accordance with the simple valve opening algorithm described above. As mentioned previously, the outlet control valve is opened in steps, in this case once every five minutes, see Fig. 7, causing the spiky nature of the outlet gas flow rate. The valve opening algorithm was chosen to maintain the outlet gas flow rate within reasonable limits. In this case less than $4 \mathrm{~mol} / \mathrm{s}$. It takes about 90 minutes for the venting to sufficiently cool the vessel contents to drop the pressure to one atmosphere.

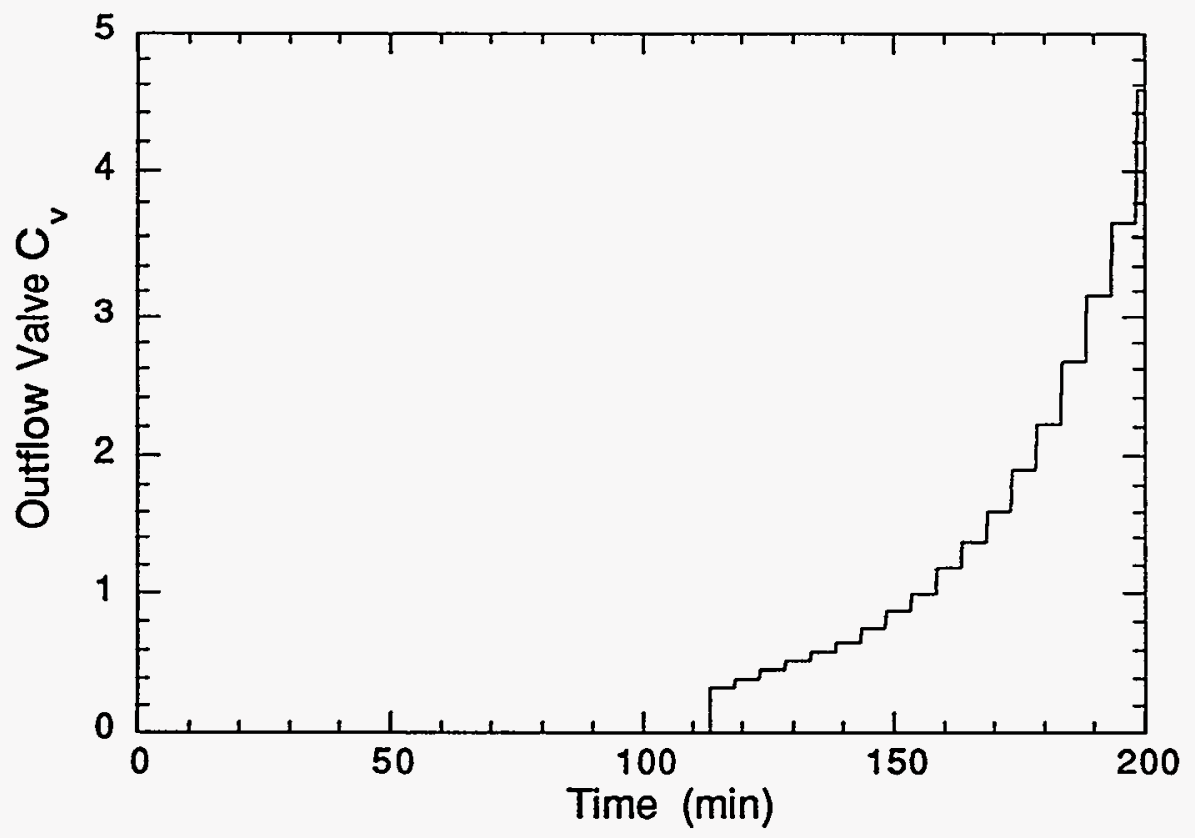

Figure 7. Programmed increase in outlet control valve $C_{v}$ for base case.

During the venting operation the superficial gas velocities within the reactor should be relatively small. Estimates based on results from the model indicate that the highest velocities will be present during the blowdown phase and that the superficial velocities in Vessel 2 will be ten times higher than those in Vessel 1. The superficial velocities were estimated from the vessel cross sectional areas the flow rate out of each vessel and the conditions within each vessel. The computed 
velocities during the blowdown phase in Vessel 2 are shown in Fig. 8. The maximum computed superficial velocity in Vessel 1 was computed to be $0.002 \mathrm{~m} / \mathrm{s}$ and in Vessel $2,0.055 \mathrm{~m} / \mathrm{s}$. These velocities are quite small and should lead to little entrainment of solid or liquid.

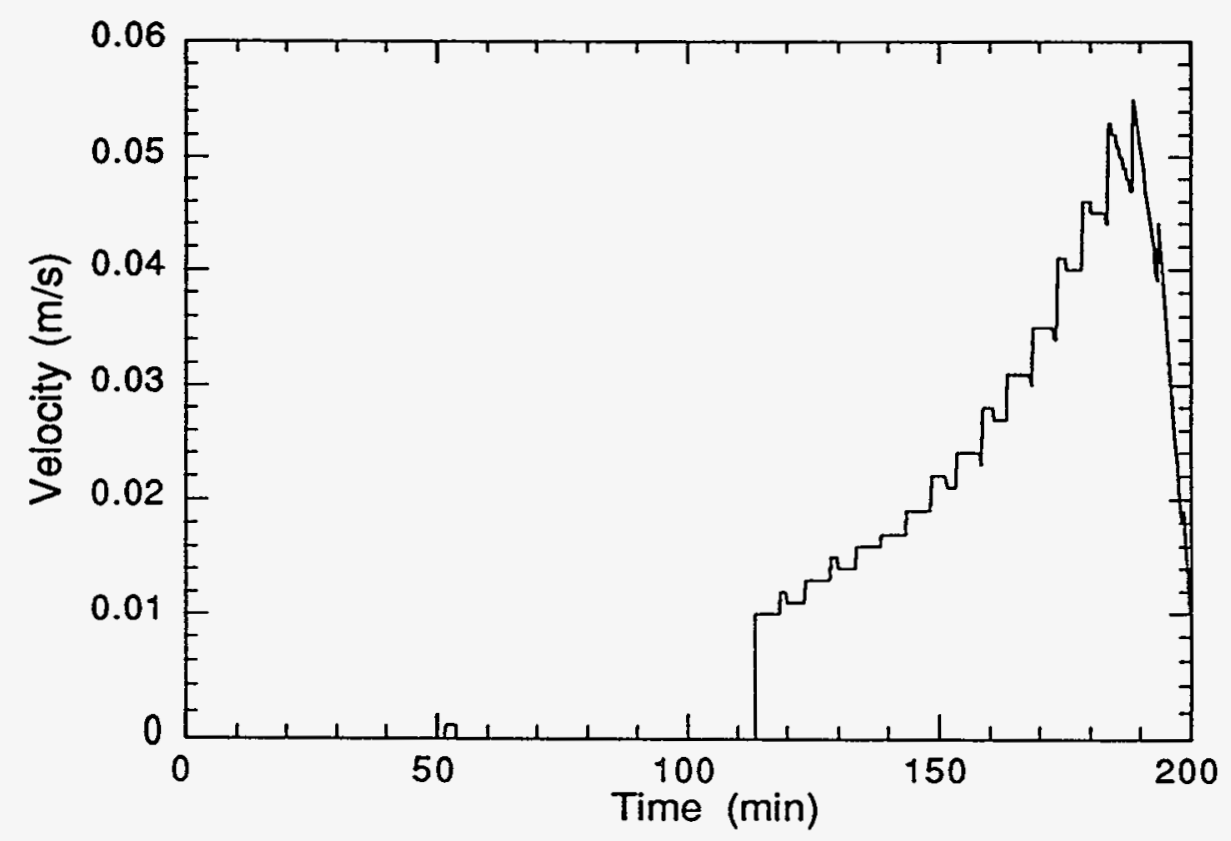

Figure 8. Average superficial gas velocity inside of Vessel 1 for base case.

Flow rates between Vessel 1 and Vessel 2 are computed to be modest over the entire course of the operation, see Fig. 9. The maximum computed flow is 4.3 occurring at the start of the blowdown phase.

The vessels are assumed to initially contain air at one atmosphere. As the system is pressurized and heated the air is compressed and its mole fraction rapidly declines, see Fig. 10. As the contents of Vessel 1 heat sufficiently to begin the decomposition reactions production of noncondensable product gases begins and their mole fraction climbs. The increase in mole fraction of product gases is reduced by the presence of the continued steam feed. As the blowdown begins all gases except steam are rapidly swept from the system. Just prior to the blowdown phase over half of the 431 moles of product gas computed to be produced from the newspaper decomposition remain in the vessels, 210 moles in Vessel 1 and 53 moles in Vessel 2. 


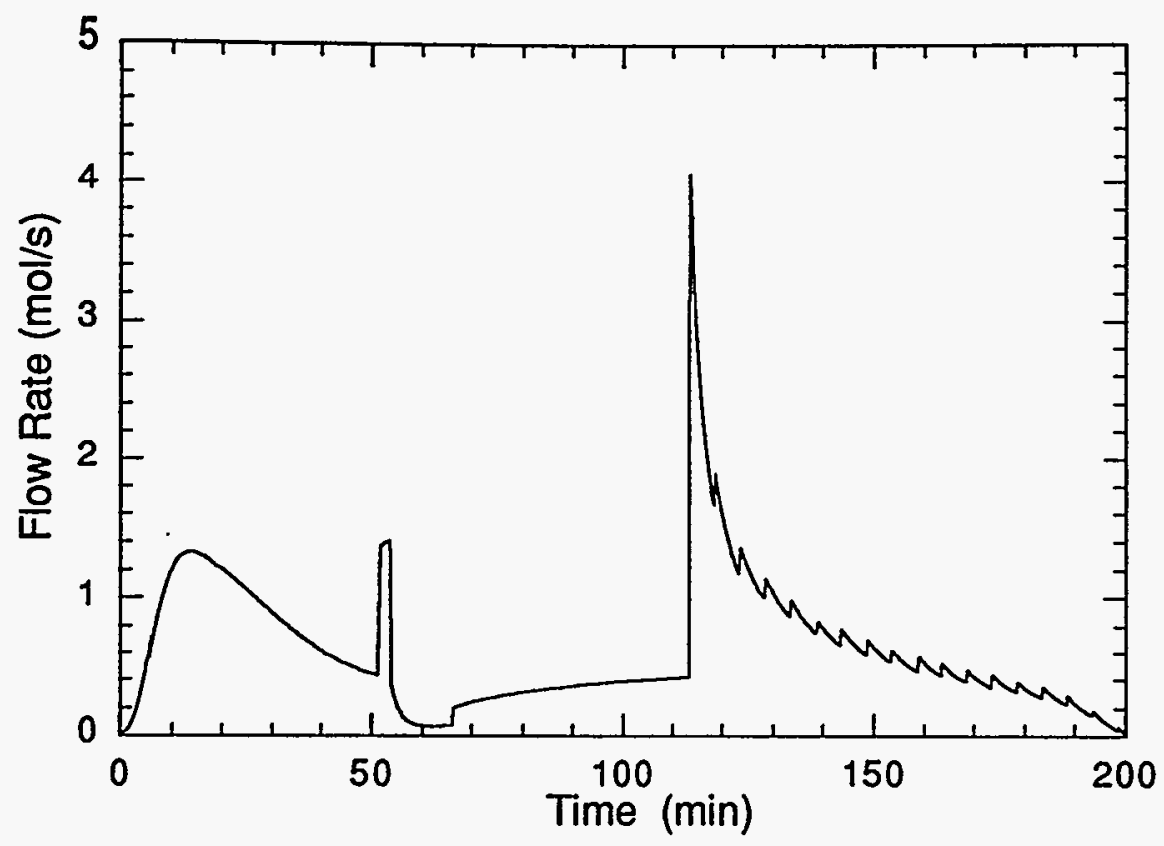

Figure 9. The flow between vessels for base case

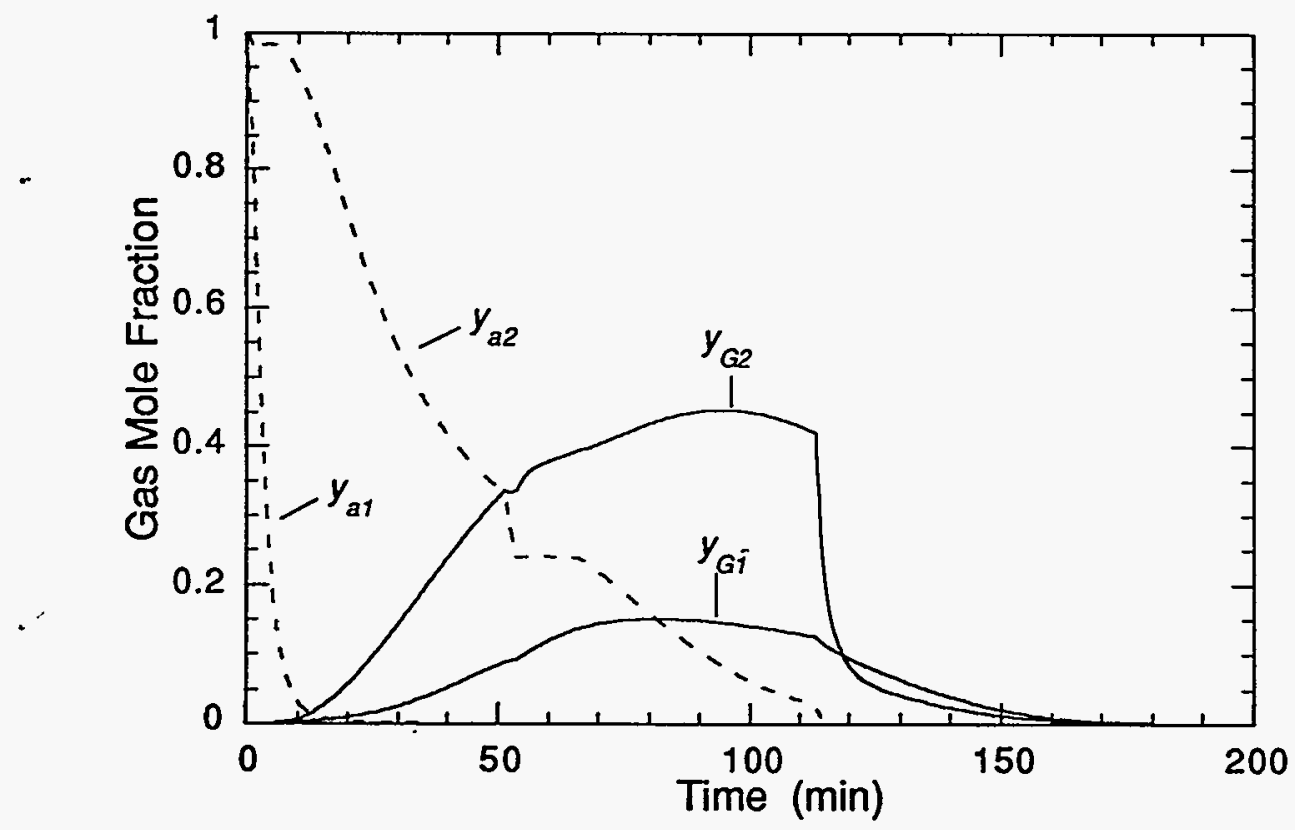

Figure 10. The mole fraction of noncondensable gases (air and product gases) for base case.

The computed amount of water in each vessel increases with time, Fig. 11, up to the point at which the blowdown phase begins. After the blowdown the final water in Vessel 1 is about 60\% of its maximum amount and in Vessel 2 about $40 \%$ of its maximum. As a result of water accumulation, each vessel is at its minimum void volume just prior to the blowdown. In Vessel 1 the void volume is estimated 
to be about $1.2 \mathrm{~m}^{3}$ and in Vessel $2,0.08 \mathrm{~m}^{3}$. The void volume is computed assuming a density of $1000 \mathrm{~kg} / \mathrm{m}^{3}$ for the solids remaining in Vessel 1.

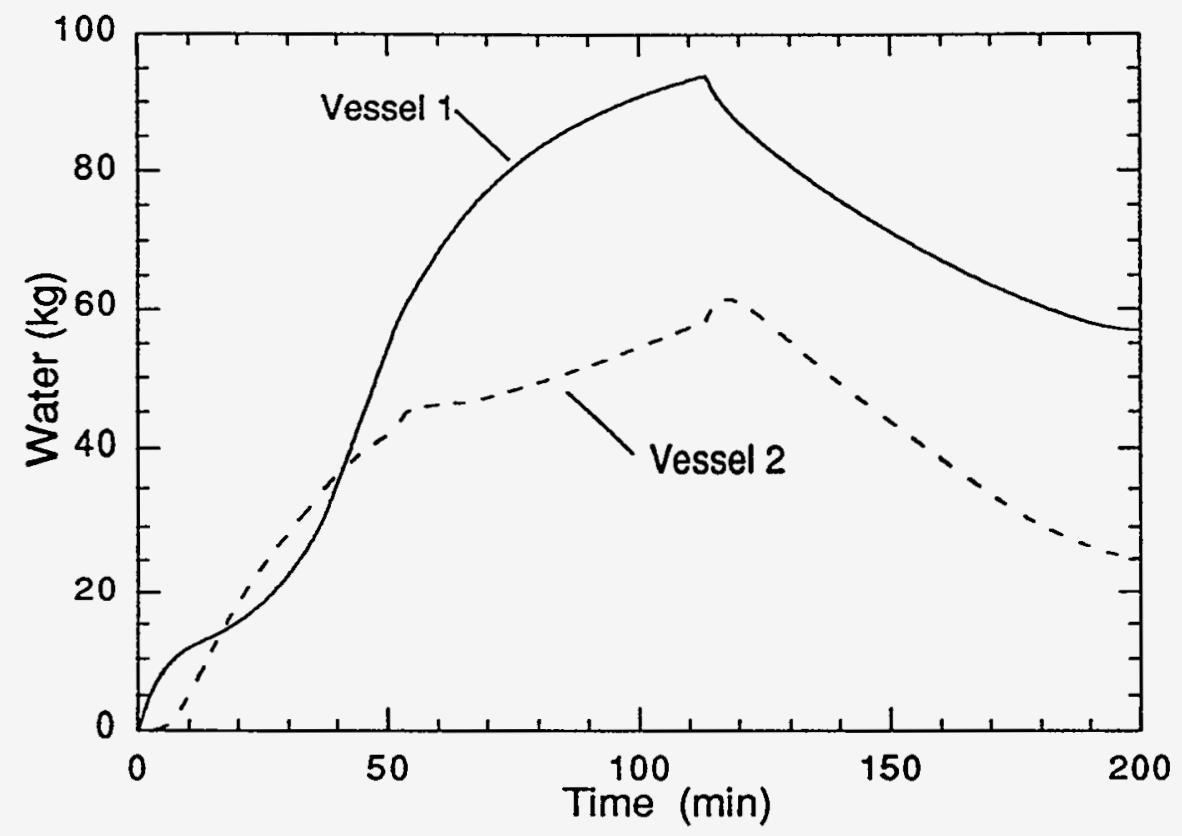

Figure 11. The amount of water in Vessels 1 and 2 for base case.

Figs. $12 \& 13$ show the computed change in newspaper, solid product, water and percent water in Vessel 1. The water content of the solid/liquid slurry in Vessel 1 is about $45 \mathrm{wt}$. \% during most of the reaction phase. After the blowdown phase the final water content in the mixture is only $29 \mathrm{wt}$. \%.

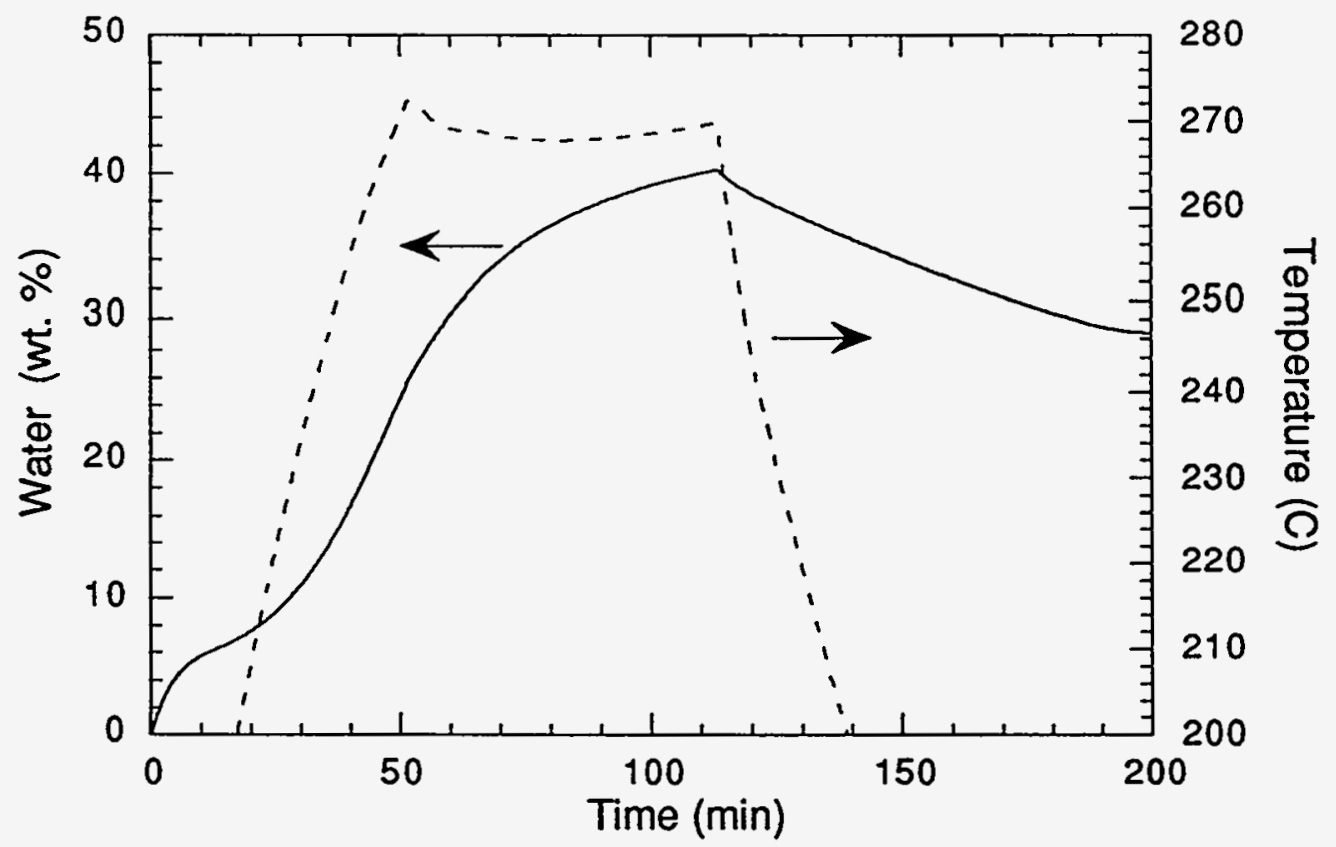

Figure 12. The percent water in Vessel 1 and Vessel 1 internal temperature for base case. 


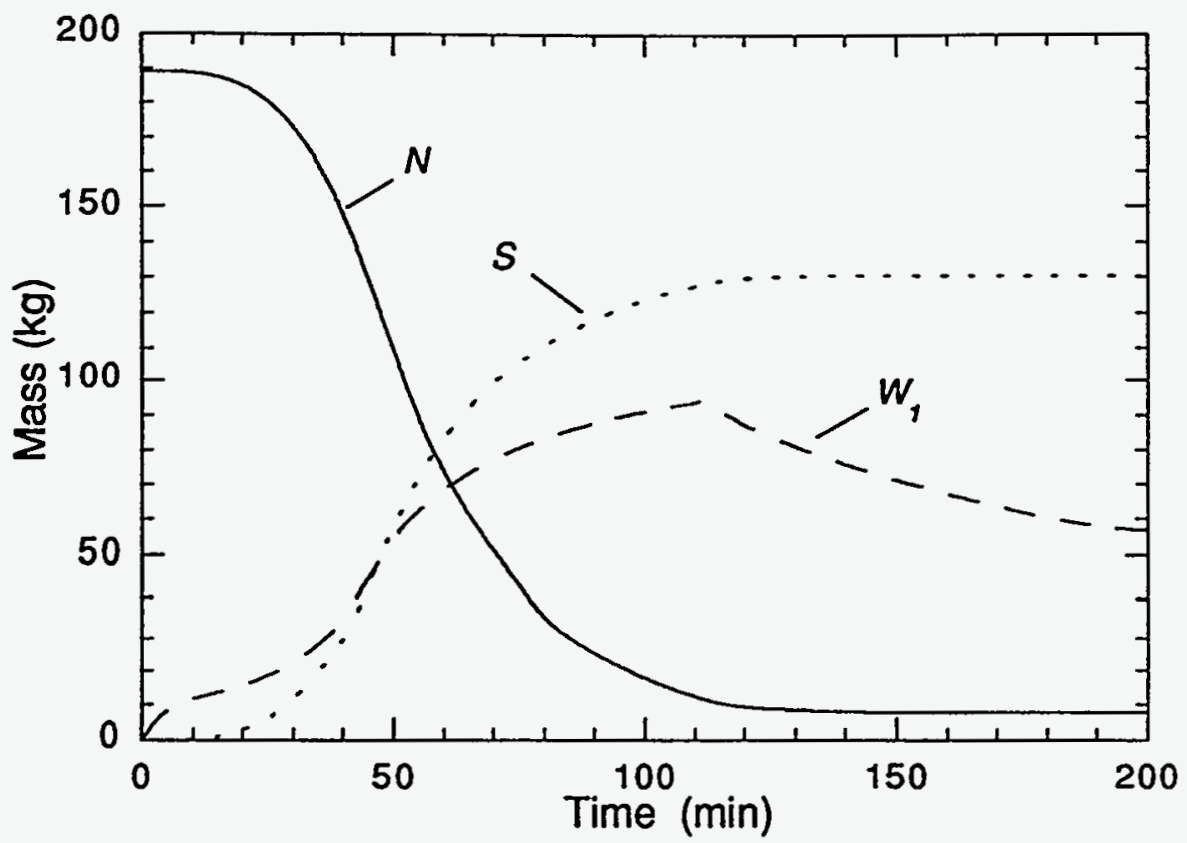

Figure 13. The amount of newspaper, solid product and water in Vessel 1 for base case.

Most of the important results for the base calculations are summarized in Table 4. The "Steam out" entry refers to the amount of water vapor exiting the vessels and presumably captured in the condenser system. This represents nearly $75 \%$ of the injected steam. These overall results agree quite well with those obtained from the ASPEN model. The total steam required is $154 \mathrm{~kg}$ from the ASPEN results compared to $148 \mathrm{~kg}$ in the transient model. The produced steam is computed to be $100 \mathrm{~kg}$ in both results. The maximum temperature of $272 \mathrm{C}$ is very close to the $270 \mathrm{C}$ computed in the ASPEN results. The water content in the hot reacted contents of the Vessel 1 is computed to be $45 \mathrm{wt} . \%$ by the transient model and 48 wt.\% by the ASPEN model. The final water content of product computed by the transient model is $29 \mathrm{wt} . \%$ and $32 \mathrm{wt} . \%$ for the ASPEN model. 
Table 4. Selected results for base case.

\begin{tabular}{|ccc|}
\hline & Value & Units \\
\cline { 2 - 3 } Initial $N$ & 189 & $\mathrm{~kg}$ \\
Final $N$ & 7.9 & $\mathrm{~kg}$ \\
Final $S$ & 130.4 & $\mathrm{~kg}$ \\
Maximum $W_{1}$ & 93.9 & $\mathrm{~kg}$ \\
Final $W_{1}$ & 56.8 & $\mathrm{~kg}$ \\
Maximum $W_{2}$ & 61.4 & $\mathrm{~kg}$ \\
Final $W_{2}$ & 25.1 & $\mathrm{~kg}$ \\
Steam in & 148.3 & $\mathrm{~kg}$ \\
Steam out & 100.0 & $\mathrm{~kg}$ \\
Maximum $T_{1}$ & 272.3 & $\mathrm{C}$ \\
Time to $P_{r}$ & 53 & $\mathrm{~min}$ \\
Time at $P_{r}$ & 60 & $\mathrm{~min}$ \\
Total Time & 206.7 & $\mathrm{~min}$ \\
Maximum $f$ & 4.1 & $\mathrm{~mol} / \mathrm{s}$ \\
Maximum $f_{e}$ & 3.8 & $\mathrm{~mol} / \mathrm{s}$ \\
\hline
\end{tabular}

In the remainder of the report selected results are presented for model calculations in which various process parameters are varied from their base case values. Additional model features are also described. Among the parameters and conditions varied are: steam injection rate, degree of preheating of Vessel 1, insulation of Vessel 2, presence of Vessel 2, amount of water in initial feed, amount of produced noncondensable gas, magnitude of the heat of reaction of the newspaper decomposition, and the size of the initial newspaper charge. In subsequent sections the model equations are extended to deal with the possible development of a dried layer near the Vessel 1 wall. Also, the consequence of extending the operations beyond the point at which the internal reactor pressure reached one atmosphere are explored. In a final section, the base case assumptions are modified, based on the results of the parametric calculations, to reflect the most likely operating scenario for initial pilot experiments.

\section{Steam Injection Rate}

The rate of steam injection during the reaction phase has an influence on the temperature of the contents of Vessel 1 and thus on the computed extent of decomposition of newspaper. Calculations have been done for various flow rates during the reaction period, expressed as a percent of the heatup steam rate. All other parameters are those of the base case. Results of these calculations are shown in Table 5 and in Fig. 14. 
Table 5. Computed maximum temperature and extent of newspaper decomposition for different steam flow rates during the reaction phase, the initial steam injection is $2 \mathrm{~mol} / \mathrm{s}$ in all cases.

\begin{tabular}{|cccc|}
\hline $\begin{array}{c}\text { Steam Flow During } \\
\begin{array}{c}\text { Reaction Phase } \\
\text { (\% of Initial) }\end{array}\end{array}$ & $\begin{array}{c}\text { Maximum } \mathrm{T}_{1} \\
(\mathrm{C})\end{array}$ & $\begin{array}{c}\text { Final } N \\
(\mathrm{~kg})\end{array}$ & $\begin{array}{c}\text { Final } N \\
\text { (\% Original) }\end{array}$ \\
\hline 100 & 277.5 & 4.0 & 2.1 \\
75 & 276.6 & 4.3 & 2.3 \\
50 & 274.5 & 5.4 & 2.9 \\
35 & 272.3 & 6.5 & 3.4 \\
25 & 272.3 & 7.9 & 4.2 \\
12.5 & 272.3 & 11.0 & 5.8 \\
5 & 272.3 & 16.4 & 8.7 \\
0 & 272.3 & 20.7 & 11.0 \\
\hline
\end{tabular}

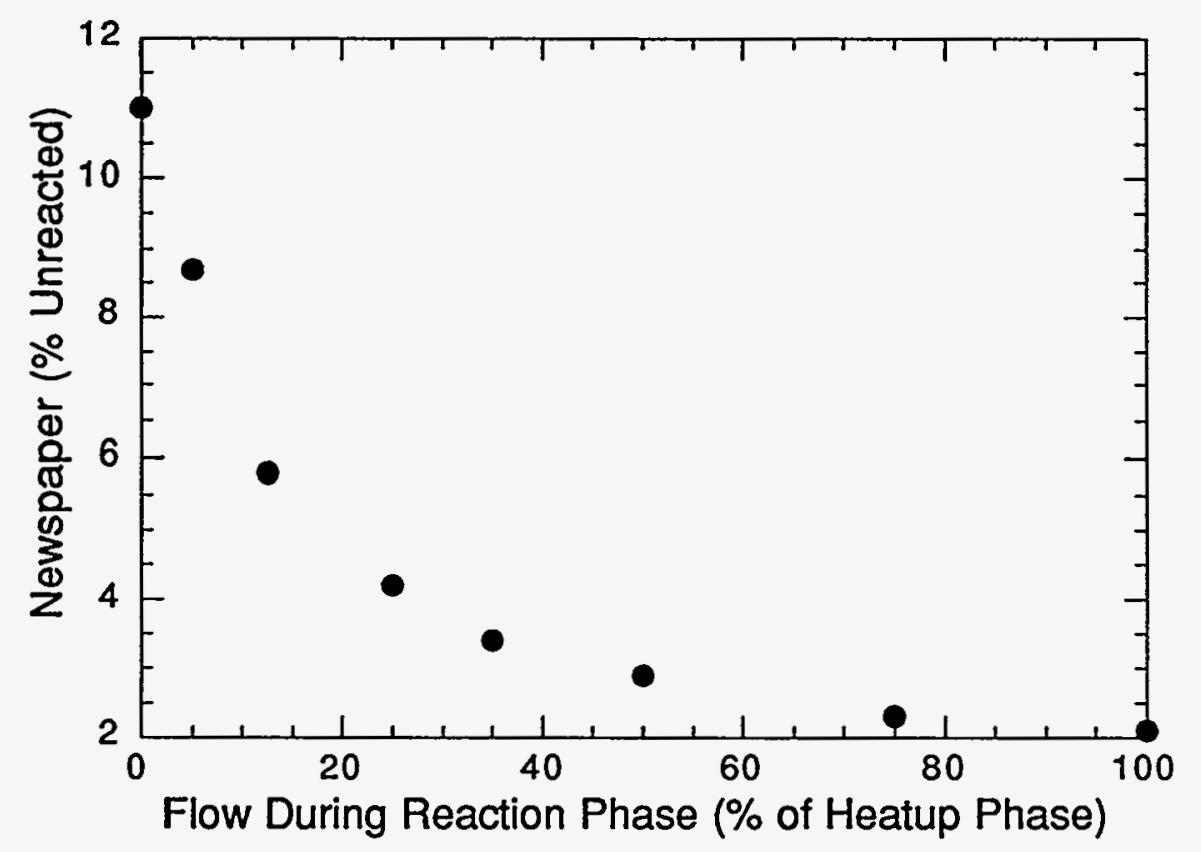

Figure 14. The computed fraction of unreacted newspaper decreases with increasing flow rate of steam during reaction phase.

The maximum computed temperature is highest for the highest reaction phase steam rate. This temperature decreases as the steam flow is increased until the flow drops to $35 \%$ of the heatup phase flow. At this point the maximum computed temperature plateaus at $272 \mathrm{C}$. At this point, which corresponds to a flow of $0.7 \mathrm{~mol} / \mathrm{s}$ of steam, the temperature is a maximum just after the reaction pressure is reached. For the higher flows the maximum temperature is reached at the end of the reaction phase just prior to the blowdown phase.

Based on these results a flow rate of $25 \%$ of the initial steam rate, or $0.5 \mathrm{~mol} / \mathrm{s}$, appears to be a reasonable compromise between steam use and extent of reaction. The choice of the this flow does not appear critical. Even if the steam is turned off 
during the reaction phase nearly $90 \%$ of the newspaper is computed to decompose. Also, the ultimate extent of reaction can be influenced by the length of the reaction phase.

The maximum delivery rate of the steam generator available for use in the pilot operation is $4.9 \mathrm{~mol} / \mathrm{s}$. The base case used an assumed initial steam rate of 2 $\mathrm{mol} / \mathrm{s}$. Selected results for computations using other steam rates are given in Table 6. If higher rates are used the total time of the processing can be reduced, but more total steam is needed. The maximum temperature goes up slightly at the higher rates, primarily because the steam rate during the reaction phase was set to $25 \%$ of that used in the initial phase and thus at the higher flows more inert gas is swept from the reactor during the reaction phase. The computations indicate the amount of water in Vessel 1 is essentially constant at the end of the process over the range of flow rates given in Table 6.

Table 6. Selected model results for heatup phase steam flow rates achievable with the available steam generator.

\begin{tabular}{|ccccc|}
\hline $\begin{array}{c}\text { Steam Rate } \\
(\mathrm{mol} / \mathrm{s})\end{array}$ & $\begin{array}{c}\text { Time to } P_{\mathrm{r}} \\
(\mathrm{min})\end{array}$ & $\begin{array}{c}\text { Total Time } \\
(\mathrm{min})\end{array}$ & $\begin{array}{c}\text { Maximum } T_{1} \\
(\mathrm{C})\end{array}$ & $\begin{array}{c}\text { Steam In } \\
(\mathrm{kg})\end{array}$ \\
\hline 1 & 107 & 257 & 269.2 & 131.7 \\
2 & 53 & 207 & 272.3 & 148.3 \\
3 & 37 & 190 & 274.0 & 169.8 \\
4 & 27 & 180 & 275.0 & 181.6 \\
\hline
\end{tabular}

\section{No or Partial Preheating of Vessel 1}

In the pilot reactor the vessel walls, Vessel 1 , can be heated electrically. In the base case it was assumed that the process would be run with the Vessel 1 walls preheated to $275 \mathrm{C}$. Computations were done to explore the consequence of heating the vessel walls less, or not at all. At the same time the influence of the assumed heat transfer coupling between the vessel walls and interior were explored. The assumed coupling between walls and interior is important because of the large mass of the vessel walls.

Selected results of the computations are given in Table 7. Results are given for two extremes in heat transfer between the walls and the interior. In the "Total Coupling" results it is assumed that heat transfer between walls and interior is very good during both the heatup phase and the blowdown phase. Since the walls would be heated by steam condensation during the heatup the assumption of good heat transfer is probably not unreasonable. However, during the blowdown phase when the walls are hotter than the interior the coupling is more in doubt. As the blowdown starts the walls would transfer their heat to wet 
material and cause steam formation. In this early phase the effective heat transfer would be good. However, later as the material near the wall begins to dry the transport rate could decrease substantially. In a later section an approximate model for the way in which the coupling may change with time is proposed, but in this section the limit of a zero heat transfer coefficient is used. This is labeled "No Coupling During Blowdown" in the table and is the same heat transfer assumption made in the base case.

Table 7. Selected model results for cases in which heat transfer coupling of Vessel 1 interior to it walls is high and for cases when coupling is only good during the heatup phase.

\begin{tabular}{|ccc|cc|cc|}
\hline & & & \multicolumn{2}{|c|}{ Total Coupling } & \multicolumn{2}{c|}{$\begin{array}{c}\text { Noupling During } \\
\text { Blowdown }\end{array}$} \\
\cline { 4 - 7 } Initial $T_{\mathrm{w}_{1}}$ & Time to $P_{\mathrm{r}}$ & Steam In & Total Time & Final $W_{1}$ & Total Time & Final $W_{1}$ \\
$(\mathrm{C})$ & $(\mathrm{min})$ & $(\mathrm{kg})$ & $(\mathrm{min})$ & $(\mathrm{kg})$ & $(\mathrm{min})$ & $(\mathrm{kg})$ \\
\hline 27 & 137 & 329 & 323 & 90.3 & 300 & 193.7 \\
100 & 113 & 278 & 300 & 49.4 & 273 & 153.3 \\
150 & 93 & 235 & 277 & 21.1 & 253 & 124.5 \\
200 & 77 & 199 & 250 & 0.0 & 233 & 96.7 \\
275 & 50 & 142 & 203 & 0 & 200 & 56.2 \\
\hline
\end{tabular}

Since both cases assume good heat transfer during the heatup phase the computed operation of the process during this phase is identical for a given wall temperature. The amount of total steam injected and the time to reach the maximum pressure are therefore the same for both cases.

For colder walls the time to heat the interior, and thus reach the maximum pressure, goes up as the initial wall temperature goes down. Similarly the amount of total steam increases. Nearly twice as much steam is required for the $100 \mathrm{C}$ wall case as is needed for the $275 \mathrm{C}$ wall case.

\section{Insulated Vessel 2}

The current pilot system has no insulation on the Vessel 2. In the initial design of the pilot Vessel 2 was not intimately connected to the main reaction vessel. However, in the current proposed operations it is connected to the main vessel with an open $5 \mathrm{~cm}$ line. A model run was performed to determine whether insulating Vessel 2 would lead to some improved performance of the system.

Computed results for insulated and uninsulated operations are given in Table 8. Interestingly, very few of the important results change from uninsulated to insulated operation. The largest difference, as expected, is in the amount final 
water in Vessel 2, which increase from 54.8 to $61.4 \mathrm{~kg}$. Even with this increased water Vessel 2 is still over half empty at the end of the operation.

Based on these computed results there appears to be no incentive to insulate Vessel 2. However, if it is advantageous to insulate it for other reasons it appears that this would have little impact on process operation.

Table 8. Selected computed results for operations with and without insulation on Vessel 2.

\begin{tabular}{|ccc|}
\hline & Insulated & Uninsulated \\
\cline { 2 - 3 } Initial $N(\mathrm{~kg})$ & 189 & 189 \\
Final $N(\mathrm{~kg})$ & 7.0 & 7.9 \\
Final $S(\mathrm{~kg})$ & 131.0 & 130.4 \\
Maximum $W_{1}(\mathrm{~kg})$ & 94.2 & 93.9 \\
Final $W_{1}(\mathrm{~kg})$ & 57.1 & 56.8 \\
Maximum $W_{2}(\mathrm{~kg})$ & 54.8 & 61.4 \\
Final $W_{2}(\mathrm{~kg})$ & 11.0 & 25.1 \\
Steam in $(\mathrm{kg})$ & 148.8 & 148.3 \\
Steam out $(\mathrm{kg})$ & 114.5 & 100.0 \\
Maximum $T_{1}(\mathrm{C})$ & 272.3 & 272.3 \\
Time to $P_{\mathrm{r}}(\mathrm{min})$ & 53 & 53 \\
Time at $P_{\mathrm{r}}(\mathrm{min})$ & 60 & 60 \\
Total Time $(\mathrm{min})$ & 223.3 & 206.7 \\
Maximum $f(\mathrm{~mol} / \mathrm{s})$ & 2.9 & 4.1 \\
Maximum $f_{\mathrm{e}}(\mathrm{mol} / \mathrm{s})$ & 3.8 & 3.8 \\
\hline
\end{tabular}

\section{No Vessel 2}

The base calculations include Vessel 2, which functions as a dropout vessel to protect downstream equipment from entrained liquid and solids. It is not clear whether this vessel is actually needed, although current experimental plans call for it to be in place. The need for it can not really be directly addressed by the models since they involve complicated issues of droplet formation, coalescence and entrainment. However, the model can be used to indicate how the basic operating parameters would change if the vessel was removed.

Without Vessel 2 the maximum pressure is reached more quickly; 30 minutes rather than 53. However, the average temperature during the reaction phase is slightly cooler, about 4 degrees. These changes cause the computed decomposition of newspaper to be slightly less without Vessel 2. This is easily compensated for by increasing the reaction phase time, see Fig. 9. 
For a 90 minute reaction time the total time is still less than the base case, because of the reduced heatup and blowdown times, yet the steam consumption is essentially the same as the base case. The final water content of the reactor is computed to be $33 \%$ compared to $29 \%$ for the base case.

Table 9. Selected results for cases in which no Vessel 2 is present.

\begin{tabular}{|cccccc|}
\hline $\begin{array}{c}\text { Reaction Time } \\
(\min )\end{array}$ & $\begin{array}{c}\text { Total Time } \\
(\mathrm{min})\end{array}$ & $\begin{array}{c}\text { Newspaper } \\
(\mathrm{kg})\end{array}$ & $\begin{array}{c}\text { Final } W_{1} \\
(\mathrm{~kg})\end{array}$ & $\begin{array}{c}\text { Steam In } \\
(\mathrm{kg})\end{array}$ & $\begin{array}{c}\text { Steam Out } \\
(\mathrm{kg})\end{array}$ \\
\hline 60 & 160 & 13.7 & 56.8 & 98.4 & 74.2 \\
90 & 190 & 4.6 & 59.6 & 114.5 & 89.2 \\
120 & 220 & 1.4 & 60.6 & 130.4 & 104.7 \\
\hline
\end{tabular}

As the reaction time is increased, the computed undercomposed newspaper amount decreases, primarily because of the increased time at temperature, however, the longer reaction times also lead to higher average temperatures, see Fig. 15. The recovery of the temperature with time show in Fig. 15 is a result of the continued steam feed compensating for the reaction endotherm and reducing the amount of noncondensable gases. For the 120 minute reaction time the steam mole fraction climbs to 0.92 before pressure reduction begins. This leads to a peak final temperature of $277 \mathrm{C}$.

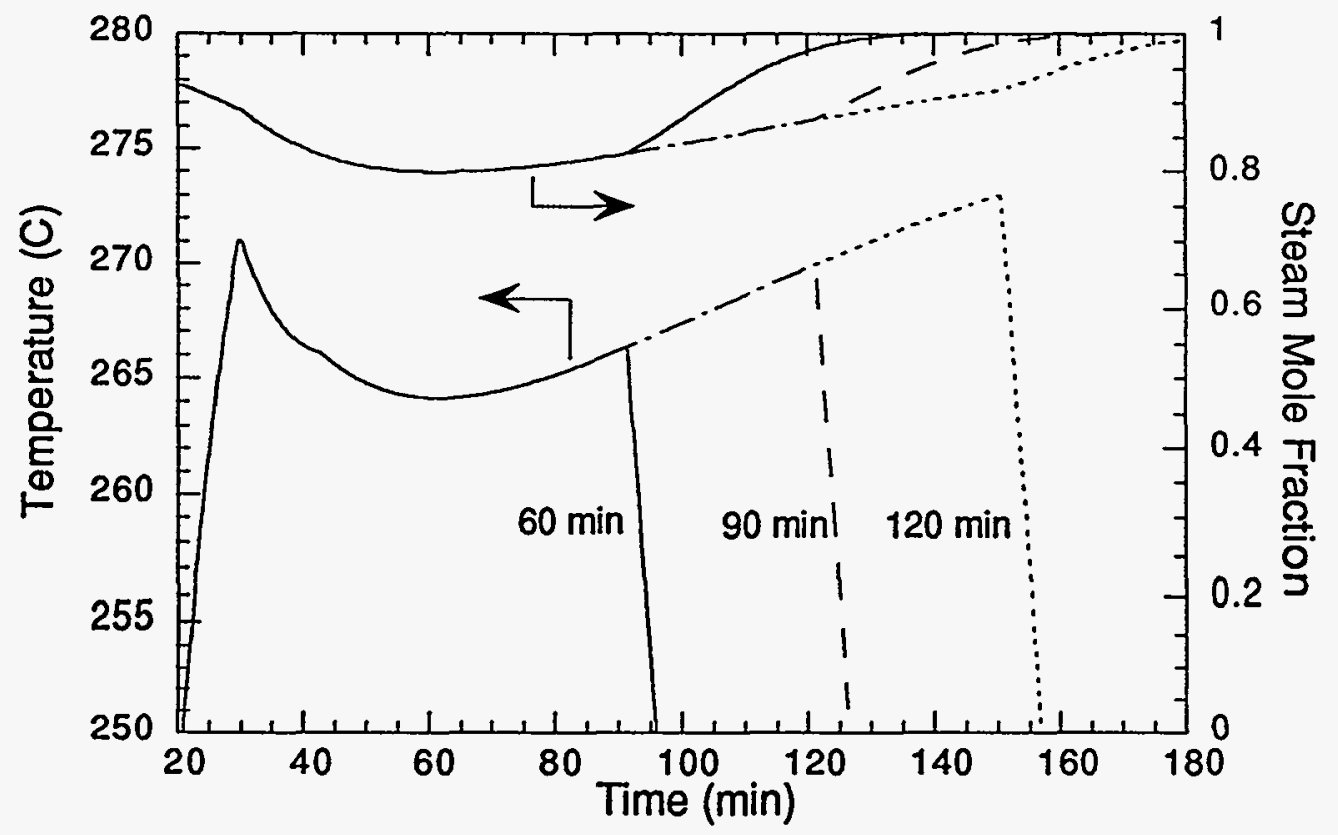

Figure 15. Computed temperatures and steam mole fractions in Vessel 1 when no Vessel 2 is present. Results are presented for three different reaction phase hold times. 
Fig 16 shows base case Vessel 1 temperature and steam mole fraction compared to results computed for the case in which Vessel 2 is absent and the reaction time has been extended to 90 minutes to compensate for slightly reduced newspaper decomposition. Notice that the no Vessel 2 case always has a lower steam mole fraction since Vessel 2 is not present to act as a reservoir for noncondensable gases. This reduced steam mole fraction keeps the temperature slightly depressed for the no Vessel 2 case compared to the base case.

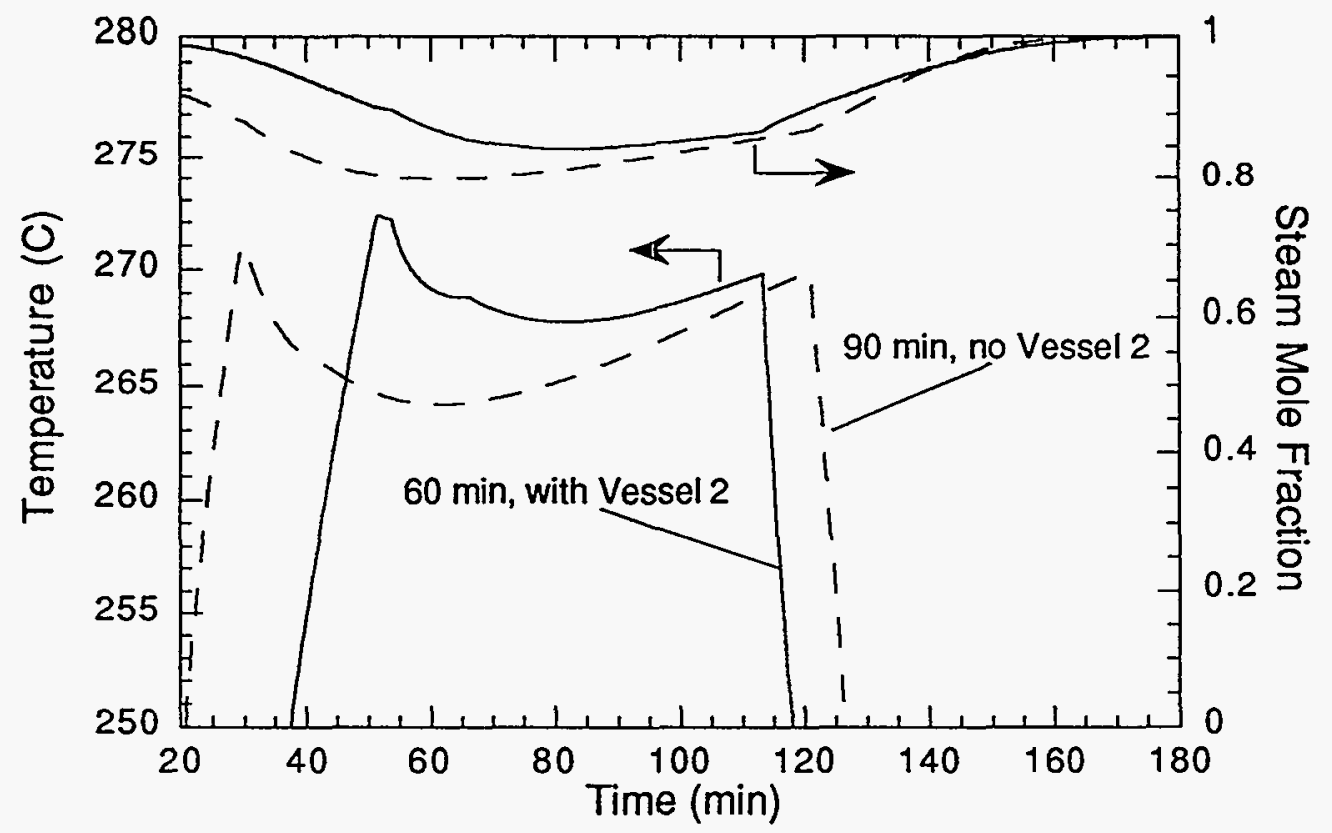

Figure 16. Computed temperatures and steam mole fractions in Vessel 1 when no Vessel 2 is present compared to base case results with Vessel 2. The reaction time in the no Vessel 2 has been extended to 90 minutes to return newspaper decomposition levels to those of the base case.

\section{Water in Initial Charge}

The base case computations assume that the feed newspaper is dry. In some cases the newspaper may be wetted to control water content in Vessel 1 during the reaction phase, to change the final product mix or to simulate wet MSW. Consequently, calculations have been done to investigate the influence of initial water content on important process variables. Results for initial water to dry newspaper mass ratios from zero, the base case, to slightly more than one-to-one are listed in Table 10. 
Table 10. Selected results for varying amounts of water present in the initial charge to Vessel 1

\begin{tabular}{|cccccc|}
\hline Initial $W_{1}(\mathrm{~kg})$ & 0 & 50 & 100 & 150 & 200 \\
\hline Initial $N(\mathrm{~kg})$ & 189 & 189 & 189 & 189 & 189 \\
Final $N(\mathrm{~kg})$ & 7.9 & 7.9 & 6.6 & 6.9 & 7.0 \\
Final $S(\mathrm{~kg})$ & 130.4 & 130.4 & 131.3 & 131.1 & 131.1 \\
Maximum $W_{1}(\mathrm{~kg})$ & 93.9 & 170.2 & 247.7 & 323.8 & 399.9 \\
Final $W_{1}(\mathrm{~kg})$ & 56.8 & 111.4 & 166.4 & 221.0 & 275.5 \\
Maximum $W_{2}(\mathrm{~kg})$ & 61.4 & 61.1 & 63.3 & 62.9 & 62.9 \\
Final $W_{2}(\mathrm{~kg})$ & 25.1 & 25.6 & 26.6 & 27.0 & 27.4 \\
Steam in $(\mathrm{kg})$ & 148.3 & 170.1 & 198.7 & 220.3 & 242.3 \\
Steam out $(\mathrm{kg})$ & 100.0 & 116.8 & 139.7 & 156.3 & 173.4 \\
Maximum $T_{1}(\mathrm{C})$ & 272.3 & 271.6 & 270.9 & 270.1 & 269.0 \\
Time to $P_{\mathrm{r}}(\mathrm{min})$ & 53 & 63 & 77 & 87 & 97 \\
Time at $P_{\mathrm{r}}(\mathrm{min})$ & 60 & 60 & 60 & 60 & 60 \\
Total Time $(\mathrm{min})$ & 206.7 & 220.0 & 240.0 & 253.3 & 266.7 \\
Maximum $f_{(\mathrm{mol} / \mathrm{s})}$ & 4.1 & 4.6 & 4.4 & 4.7 & 4.7 \\
Maximum $f_{\mathrm{t}}(\mathrm{mol} / \mathrm{s}$ & 3.8 & 3.9 & 3.8 & 3.9 & 4.0 \\
\hline
\end{tabular}

Since water initially in Vessel 1 represents an additional heat load to the system, the amount of steam and the time required to heat the Vessel 1 contents increases steadily as the initial water load increases. This increases the water content of Vessel 1 during the reaction period and after cooldown. Over the range looked at the increase in water in the vessel, see Fig 17, is linear. Little change in the water in Vessel 2 is found over the entire range and the computed newspaper decomposition remains essentially constant.

The amount of water present in the system is important for several reasons. First the amount of water present in Vessel 1 during the high temperature phase of the process must be sufficient to allow good interaction between the water and the newspaper. Secondly, the desired final product of the process is a slurry containing the maximum fuel value. Obviously, one important factor which dictates the fuel value of the final product is the amount of water present. Finally, from an operations standpoint it is important to minimize the amount of waste water generated. 


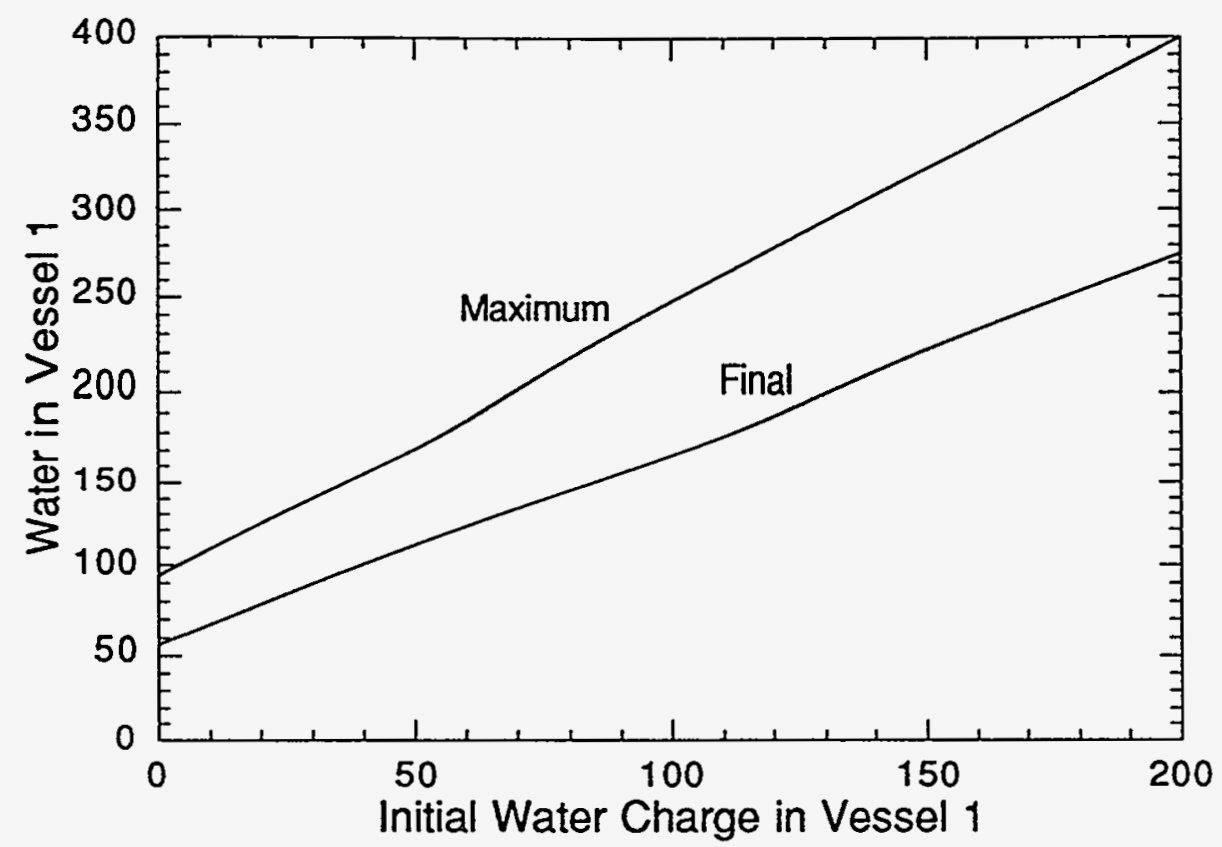

Figure 17. The computed amount of water in Vessel 1 as a function of the amount of water in the initial charge. The amount of newspaper is held constant at $189 \mathrm{~kg}$.

In the absence of any filtering or post process drying the minimum water content achievable from a run will be simply that of the final contents of Vessel 1. Also of interest from a waste minimization standpoint would be the water levels which would result by recombining condensate with the final content of Vessel 1. Two sources of condensate are present in the process. One is the water which collects in Vessel 2 and the other is the water from operation of the downstream condenser. From a waste standpoint the water in Vessel 2 is more likely to contain undesirable contaminants than the condenser water.

Table 11 and Fig. 18 have been constructed to allow the various possible product slurry water contents from runs using different initial charges water to be compared. Also included, as a measure of the water content of Vessel 1 during the time the newspaper is decomposing, is the weight percent water in Vessel 1 at the end of the reaction period. From the table, it can be seen that the computed minimum possible final water content of a product slurry is $29 \%$ when dry newspaper is used, and for this same case, which is the base case, the water content of the slurry in which all water produced during the operation was added back to the final product slurry would be $57 \mathrm{wt} . \%$. In this same case the maximum water content in Vessel 1 during the reaction phase is only $40 \%$. This amount of water may be too little to insure that all the newspaper remains adequately wetted during the high temperature phase of the process. 
Consequently, it may be necessary to add some water to the initial charge to insure a slightly higher water content during the reaction phase.

Table 11. Computed water content of Vessel 1 and product slurries as a function of the initial water charge for different assumptions about addition of condensate to the final product. In each case the initial newspaper charge is constant at $189 \mathrm{~kg}$.

\begin{tabular}{|cccccc|}
\hline Initial $W_{1}(\mathrm{~kg})$ & 0 & 50 & 100 & 150 & 200 \\
\hline With Maximum Vessel 1 Water & $40 \%$ & $55 \%$ & $64 \%$ & $70 \%$ & $74 \%$ \\
With Final Vessel 1 Water & $29 \%$ & $45 \%$ & $55 \%$ & $62 \%$ & $67 \%$ \\
With Final Vessel 1 \& 2 Water & $37 \%$ & $50 \%$ & $58 \%$ & $64 \%$ & $69 \%$ \\
With Final Vessel 1, 2 \& Condensate Water & $57 \%$ & $63 \%$ & $69 \%$ & $74 \%$ & $77 \%$ \\
\hline
\end{tabular}

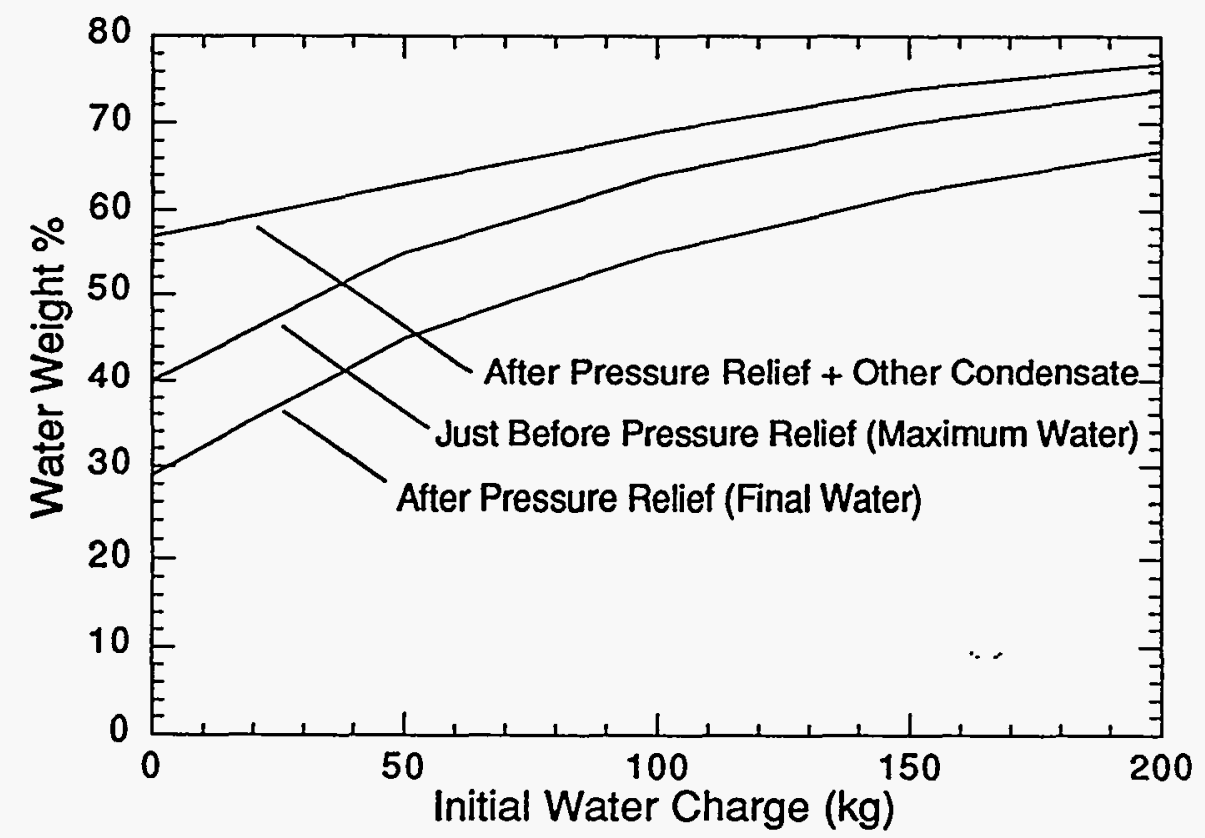

Figure 18. The computed percentage of water in the final slurry with/without adding condensate, and the water content of Vessel 1 just before pressure relief as a function of the initial water charge to Vessel 1. The amount of newspaper is constant at $189 \mathrm{~kg}$.

\section{Reduced Gas Make}

The exact stoichiometry of the decomposition reaction as a function of temperature and other conditions is not certain at this time. The stoichiometry used was obtained from small lab scale runs at $300 \mathrm{C}$. Since the amount of noncondensable gas produced plays a role in determining the temperature history of the process a case was run in which the amount of gas produced was reduced 
to half of its base case value. The amount of solid product was held constant as was the standard heat of reaction at $25 \mathrm{C}$.

Fig. 19 shows the computed Vessel 1 temperature and steam mole fraction during the period of peak temperatures for both the base case and the reduced gas cases. As expected, the steam mole fraction is higher in the reduced gas case and this in turn results in slightly higher temperatures during the reaction phase. This slightly higher temperature leads to a slightly higher decomposition fraction of newspaper, see Table 12.

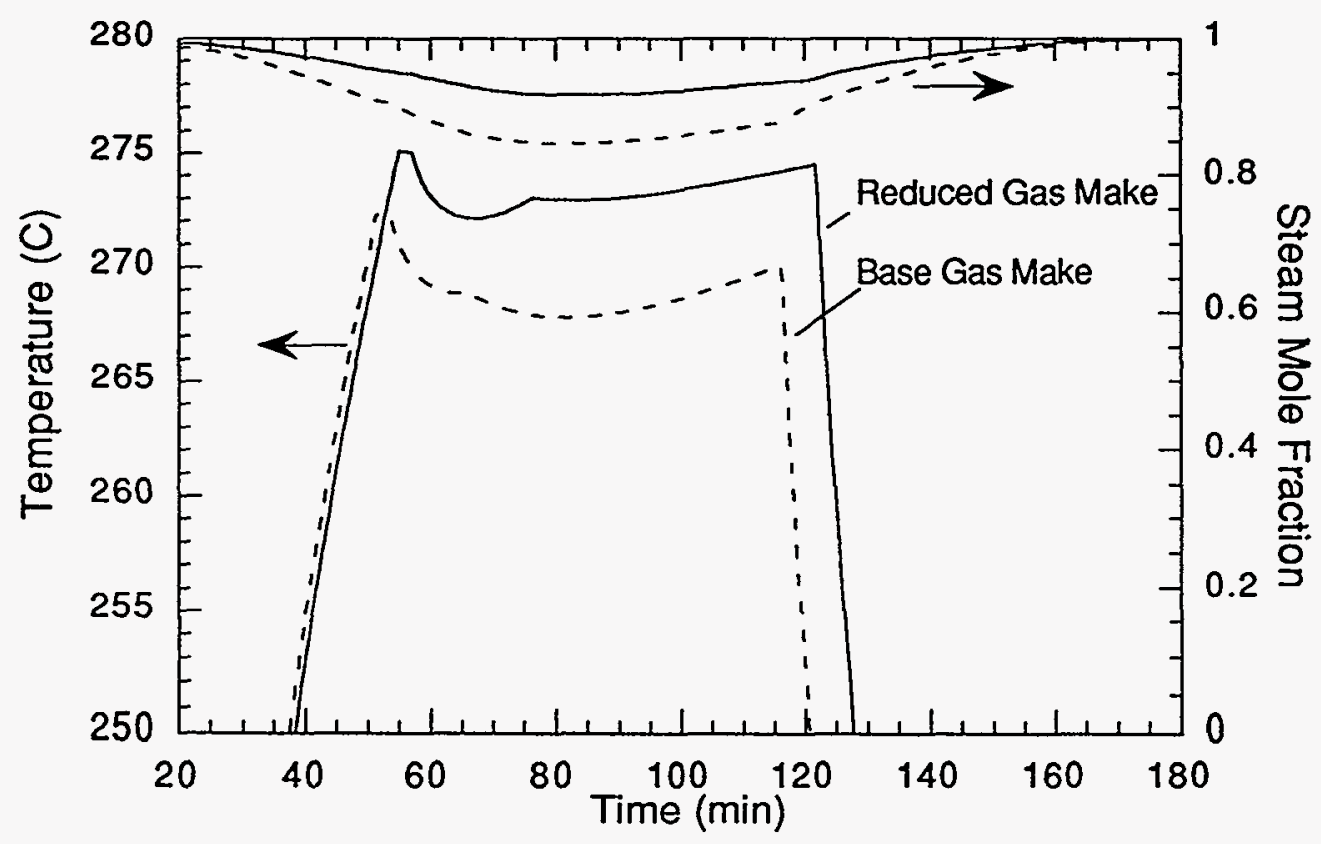

Figure 19. The computed temperature and steam mole fraction in Vessel 1 for the base case and the case in which the amount of gas produced in the decomposition reactions was set at one half the base case value.

The heatup phase for the two cases is very similar, except that the reduced gas case reaches its temperature plateau slightly after the base case. This is a direct result of the reduced gas make retarding slightly the pressure buildup rate and thus causing a slight delay in reaching maximum pressure at which time the system begins to produce exit gas to maintain the selected pressure. The start of the temperature plateau, of course, corresponds to the time of the start of the pressure plateau. 
Table 12. Selected results comparing the base case calculations with a case in which the amount of gas produced in the decomposition reactions was set at one half the base case value.

\begin{tabular}{|ccc|}
\hline$\alpha_{G}$ & 2.38 & 1.19 \\
\hline Initial $N(\mathrm{~kg})$ & 189 & 189 \\
Final $N(\mathrm{~kg})$ & 7.9 & 4.6 \\
Final $S(\mathrm{~kg})$ & 130.4 & 132.8 \\
Maximum $W_{1}(\mathrm{~kg})$ & 93.9 & 95.8 \\
Final $W_{1}(\mathrm{~kg})$ & 56.8 & 57.0 \\
Maximum $W_{2}(\mathrm{~kg})$ & 61.4 & 65.4 \\
Final $W_{2}(\mathrm{~kg})$ & 25.1 & 25.9 \\
Steam in $(\mathrm{kg})$ & 148.3 & 155.6 \\
Steam out $(\mathrm{kg})$ & 100.0 & 107.0 \\
Maximum $T_{1}(\mathrm{C})$ & 272.3 & 275.1 \\
Time to $P_{\mathrm{r}}(\mathrm{min})$ & 53 & 57 \\
Time at $P_{\mathrm{r}}(\mathrm{min})$ & 60 & 60 \\
Total Time $(\mathrm{min})$ & 207 & 210 \\
Maximum $f(\mathrm{~mol} / \mathrm{s})$ & 4.1 & 4.2 \\
Maximum $f_{\mathrm{e}}(\mathrm{mol} / \mathrm{s}$ & 3.8 & 3.8 \\
\hline
\end{tabular}

\section{Change in Heat of Reaction}

No actual measurements are known to be available for the heats of reaction for the newspaper decomposition reaction. The value which has been used, 0.39 $\mathrm{MJ} / \mathrm{kg}$ at $275 \mathrm{C}$, was obtained from heat of combustion data for newspaper and computed heats of combustion of the solid product ${ }^{1}$. The value is relatively small when compared to heats of combustion, but it is of some significance in relation to the heating of the material and the maintenance of the temperature inside Vessel 1.

Since there is considerable uncertainty as to the true value of the heat of reaction, several cases have been run in which the heat of reaction has been changed from its base value. Two cases have been run in which the heat of reaction, at $275 \mathrm{C}$, is set first to $0 \mathrm{MJ} / \mathrm{kg}$ and then to $0.78 \mathrm{MJ} / \mathrm{kg}$, twice its base value. This has been done by altering the heat of formation of solid product. The solid product's base heat of formation is 0 , to get a zero heat of reaction at $275 \mathrm{C}$ the solid product needs to have a heat of formation of $-0.675 \mathrm{MJ} / \mathrm{kg}$, and to get a heat of reaction twice the default value the solid product needs to have a heat of formation of $0.605 \mathrm{MJ} / \mathrm{kg}$.

This change in heat of reaction has a substantial influence on process variables since the change in assumed heat of reaction is on the same order as the energy 
needed to heat the newspaper. In Fig. 20, the Vessel 1 temperature and water content are plotted as a function of time. As the heat of reaction increases, becomes more endothermic, the time to reach maximum temperature increases and the amount of water condensing in Vessel 1 increases substantially.

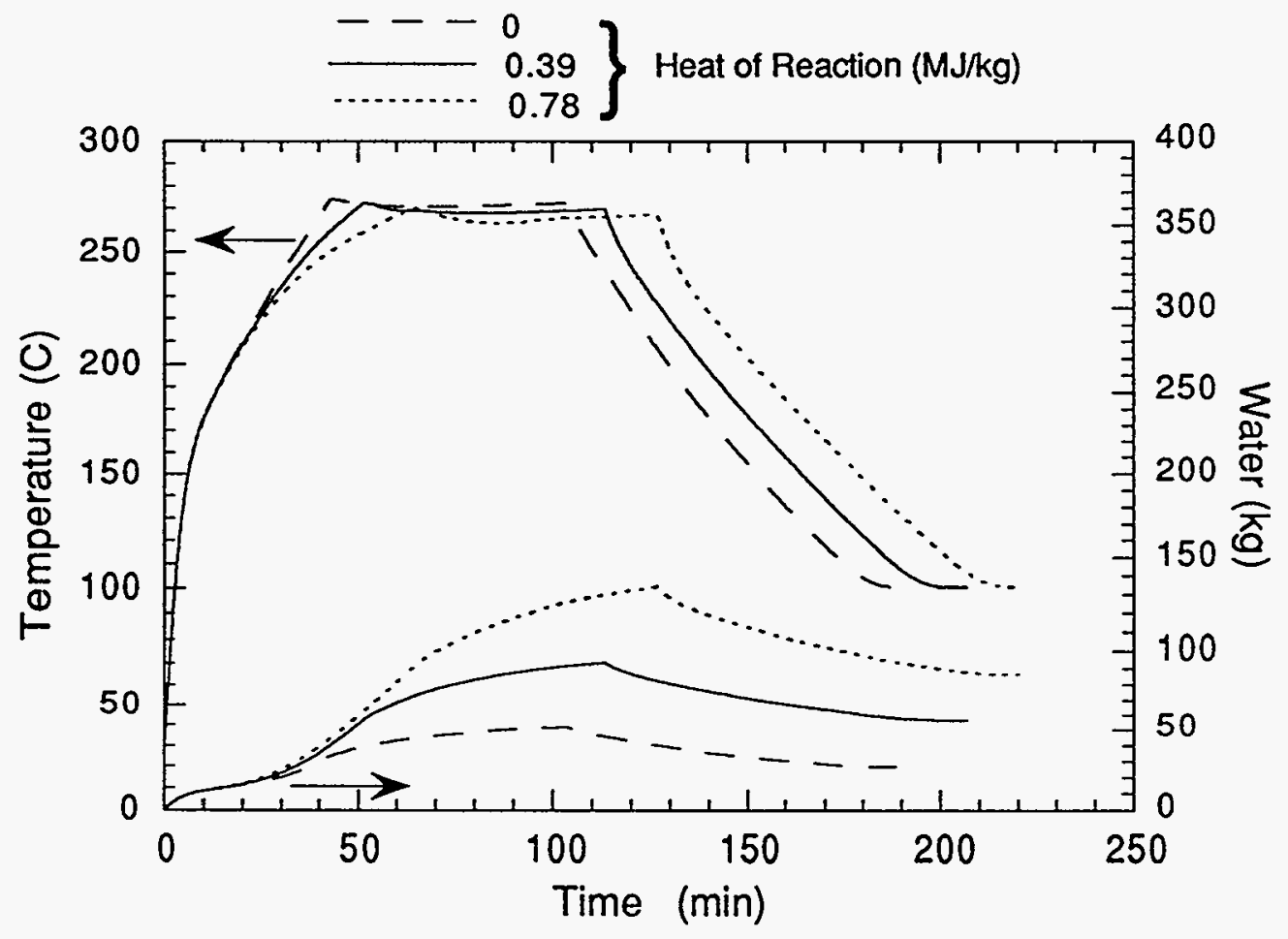

Figure 20. The computed temperature and steam mole fraction in Vessel 1 for the base case and the case in which the amount of gas produced in the decomposition reactions was set at on half the base case value.

The computed water content in Vessel 1 at the end of the process is the most important variable that changes substantially with changes in assumed heat of reaction, see Table 13. From the base case value of $29 \%$ water in Vessel 1 the water content increase to $38 \%$ for the high heat of reaction case and only $19 \%$ for the zero heat of reaction case. There is little computed change in the final water in Vessel 2 and only a small change in water condensed in the downstream condenser, "Steam out" in the table. 
Table 13. Selected results comparing the base case calculations with cases in with different heats of reaction, the base case heat of reaction is $0.39 \mathrm{MJ} / \mathrm{kg}$ (endothermic) at $275 \mathrm{C}$.

\begin{tabular}{|cccc|}
\hline$\Delta H_{N}$ at $275 \mathrm{C}(\mathrm{MJ} / \mathrm{kg})$ & 0 & 0.39 & 0.78 \\
\hline Initial $\mathrm{N}(\mathrm{kg})$ & 189 & 189 & 189 \\
Final $N(\mathrm{~kg})$ & 7.5 & 7.9 & 7.8 \\
Final $S(\mathrm{~kg})$ & 130.7 & 130.4 & 130.4 \\
Maximum $W_{1}(\mathrm{~kg})$ & 52.1 & 93.9 & 134.2 \\
Final $W_{1}(\mathrm{~kg})$ & 26.2 & 56.8 & 86.5 \\
Maximum $W_{2}(\mathrm{~kg})$ & 67.2 & 61.4 & 58.3 \\
Final $W_{2}(\mathrm{~kg})$ & 24.8 & 25.1 & 25.8 \\
Steam in $(\mathrm{kg})$ & 126.8 & 148.3 & 177.1 \\
Steam out $(\mathrm{kg})$ & 109.5 & 100.0 & 98.5 \\
Maximum $T_{1}(\mathrm{C})$ & 274.1 & 272.3 & 270.2 \\
Time to $P_{\mathrm{I}}(\mathrm{min})$ & 43 & 53 & 67 \\
Time at $P_{\mathrm{r}}(\mathrm{min})$ & 60 & 60 & 60 \\
Total Time $(\mathrm{min})$ & 193.3 & 206.7 & 220.0 \\
Maximum $f_{(\mathrm{mol} / \mathrm{s})}$ & 2.8 & 4.1 & 4.9 \\
Maximum $f_{\mathrm{e}}(\mathrm{mol} / \mathrm{s}$ & 3.7 & 3.8 & 4.0 \\
\hline
\end{tabular}

\section{Newspaper Charge}

The size of the initial charge of newspaper used was based on the assumption that dry newspaper can be relatively easily compacted to a density of about 160 $\mathrm{kg} / \mathrm{m}^{3}$, about five times its uncompressed density, and that the Vessel 1 would be filled to the top of its cylindrical portion, a volume of $1.18 \mathrm{~m}^{3}$ (the total volume of Vessel 1 is $1.42 \mathrm{~m}^{3}$ ). It may well be that more newspaper could be loaded then the base case assumption, particularly if it is slightly moist.

Table 14 compares computed results for a newspaper loading 50\% larger than that of the base case. The results indicate the amount of steam required would only increase about $10 \%$, however the amount of water condensing in Vessel 1 would increase almost in proportion to the increase in newspaper loading giving a final product in Vessel 1 containing $29 \%$ water. A very modest decline in the extent of the newspaper decomposition was computed and this could easily be compensated for by a slightly longer reaction time.

Interestingly, the amount of condensate in Vessel 2 and the downstream condenser, "Steam out", changes little. This means that a final slurry product containing all the final process water would have a water content of $50 \mathrm{wt} . \%$ with the higher newspaper loading compared to $57 \mathrm{wt}$.\% for the base case. 
Table 14. Selected results comparing the base case calculations with a case in which the newspaper charge to the reactor is assumed to be $50 \%$ greater.

\begin{tabular}{|ccc|}
\hline Initial $N(\mathrm{~kg})$ & 189 & 284 \\
\hline Final $N(\mathrm{~kg})$ & 7.9 & 19.0 \\
Extent of Reaction $(\%)$ & 95.8 & 93.3 \\
Final $S(\mathrm{~kg})$ & 130.4 & 190.8 \\
Maximum $W_{1}(\mathrm{~kg})$ & 93.9 & 136.1 \\
Final $W_{1}(\mathrm{~kg})$ & 56.8 & 84.8 \\
Maximum $W_{2}(\mathrm{~kg})$ & 61.4 & 57.1 \\
Final $W_{2}(\mathrm{~kg})$ & 25.1 & 25.1 \\
Steam in $(\mathrm{kg})$ & 148.3 & 162.6 \\
Steam out $(\mathrm{kg})$ & 100.0 & 102.4 \\
Maximum $T_{1}(\mathrm{C})$ & 272.3 & 268.0 \\
Time to $P_{\mathrm{r}}(\mathrm{min})$ & 53 & 60 \\
Time at $P_{\mathrm{r}}(\mathrm{min})$ & 60 & 60 \\
Total Time $(\mathrm{min})$ & 206.7 & 216.7 \\
Maximum $f(\mathrm{~mol} / \mathrm{s})$ & 4.1 & 4.1 \\
Maximum $f_{\mathrm{e}}(\mathrm{mol} / \mathrm{s}$ & 3.8 & 3.9 \\
\hline
\end{tabular}

\section{TRANSIENT MODEL REACTOR COOLING}

As described above the model equations allow a heat transfer coefficient to be defined between the vessel walls and their exterior and interior environments. In the above calculations a model provision which allowed for different values during the heatup and cooldown phases has been employed. In each case the transport coefficient was assumed to be constant during each phase of the process. This assumption, for the most part, is probably consistent with the level of simplification made in developing the model. However, it is probably least justifiable during the blowdown/cooldown phase in Vessel 1.

During the post reaction phase, as the pressure is relieved and the temperatures in the vessels decline because of evaporation of water, there is a possibility of developing a dried layer of material near the walls of Vessel 1. This excessive drying near the walls would be a result of the large amount of heat stored in the reactor walls. Part of this heat would be dissipated by transport to the interior. The material would first dry right at the wall and as time progressed the dry layer would expand away from it. At the same time, however, the growing dry layer would act as an insulator reducing the effective heat transfer between wall and interior. A model describing this wall region would be useful in defining one possible scenario for the manner in which the energy stored in the reactor walls is transported to the interior. 
The extent of any dry layer near the wall would depend on the integrity of the material inside the reactor vessel at the time, the amount of water present, the way steam would leave the wall region, effective conductivities and mobility of water within the reactor. A comprehensive model describing the wall region, and thus the manner in which the heat is transferred between walls and interior, is beyond the scope of the present work, however a simplified wall layer model can be constructed consistent with the complexity of the current transient model.

To allow an estimate of the growth of a drying layer near the wall of the reactor vessel a new dependent variable can be added to the transient model describing the dry layer thickness. In Appendix IV, a simple moving front drying model is developed and solved for the case in which the wall and drying front temperatures remain constant. Results presented in the appendix indicate effective average heat transfer coefficient from the walls to interior, in the presence of a drying layer, would be somewhere in the range of 1 to $7 \mathrm{~W} / \mathrm{m}^{2} \mathrm{~K}$. This simple model is recast in the following as an equation for the dry layer thickness, $l$, in terms of previously defined parameters and variables of the transient model

$$
\frac{d l}{d t}=\frac{k\left(T_{\mathrm{w}_{1}}-T_{1}\right)}{l\left(\frac{W_{1}}{0.018 V_{0_{1}}}\right)\left(-\Delta H_{w}\right)} .
$$

This formulation uses the current wall temperature and the current interior temperature as the driving force for the movement of the drying front.

The base case assumes that the Vessel 1 walls are preheated and that no heat transfer occurs between the walls of Vessel 1 and its contents during the blowdown phase. Results from the base case are compared in Table 15 to results calculated using the drying front model for heat transfer in Vessel 1 during the blowdown phase. The conductivity of the dried material was assumed to be low, a value of $0.04 \mathrm{~W} / \mathrm{m}-\mathrm{K}$ was used. This is essentially the conductivity of gas at the process conditions. The computed dried length was $2.8 \mathrm{~cm}$. The computed results for the two cases are very similar. The two primary differences are in the total time and the final water in Vessel 1. At the end of the blowdown phase the internal temperature of Vessel 1 is computed to be $100 \mathrm{C}$ and the wall temperature for the case including the drying layer is $264 \mathrm{C}$ indicating only a small portion of the energy in the wall was transported to the interior. 
Table 15. Selected results comparing the base case calculations with calculations in which a drying front model is used in Vessel 1 during the blowdown phase. The computed dried length was $2.8 \mathrm{~cm}$.

\begin{tabular}{|ccc|}
\hline & Base Case \\
\hline Initial $N(\mathrm{~kg})$ & 189 & 189.0 \\
Final $N(\mathrm{~kg})$ & 7.9 & 7.8 \\
Final $S(\mathrm{~kg})$ & 130.4 & 130.5 \\
Maximum $W_{1}(\mathrm{~kg})$ & 93.9 & 93.9 \\
Final $W_{1}(\mathrm{~kg})$ & 56.8 & 50.2 \\
Maximum $W_{2}(\mathrm{~kg})$ & 61.4 & 61.6 \\
Final $W_{2}(\mathrm{~kg})$ & 25.1 & 26.1 \\
Steam in $(\mathrm{kg})$ & 148.3 & 148.3 \\
Steam out $(\mathrm{kg})$ & 100.0 & 105.6 \\
Maximum $T_{1}(\mathrm{C})$ & 272.3 & 272.3 \\
Time to $P_{\mathrm{r}}(\mathrm{min})$ & 53 & 53 \\
Time at $P_{\mathrm{r}}(\mathrm{min})$ & 60 & 60 \\
Total Time $(\mathrm{min})$ & 206.7 & 233.3 \\
Maximum $f(\mathrm{~mol} / \mathrm{s})$ & 4.1 & 4.1 \\
Maximum $f_{\mathrm{e}}(\mathrm{mol} / \mathrm{s}$ & 3.8 & 3.8 \\
\hline
\end{tabular}

\section{TRANSIENT MODEL - EXTENDED COOLING}

The previous calculations have been done with a termination point determined by the time at which the pressure in the system reaches one atmosphere. At this pressure level the reactor could theoretically be opened and emptied. However, as a practical matter further cooling of the interior would probably be necessary to allow the contents of the reactor to be more easily handled.

In order to determine the possible behavior of the system, when longer cooldown periods are present, a series of runs were performed. All cases run were assumed to extend for a total time of 24 hours, rather than terminating when the internal pressure dropped to 1 atmosphere. In the first run, case $\mathrm{C} 1$, system parameters of the previous base case were used except that the cooldown time was extended for 24 hours. In the second run, case $\mathrm{C} 2$, the drying front model was invoked during the blowdown phase. In case C 3 , it was assumed that Vessel 1 cold be externally cooled by gas flow during the blowdown phase. Estimates of an effective heat transfer coefficient for this external air cooling are discussed in Appendix III and in the calculations used here a value of $6 \mathrm{~W} / \mathrm{m}^{2}-\mathrm{K}$ was used. The final case, case $\mathrm{C} 4$, is equivalent to case $\mathrm{C} 3$ except that a small bleed, $2 \mathrm{mmol} / \mathrm{s}$, of inert gas is introduced during the blowdown phase so that the internal pressure of the system never drops below one atmosphere. 
Results from these four cases are summarized in Table 16. Only in the case in which external cooling of Vessel 1 is assumed does the wall temperature cool significantly. With external cooling the calculations indicate that the internal temperature of Vessel 1 can be brought down to 50 C, and its walls to 57 C, in 24 hours. The results also indicate that the cooling of Vessel 1's interior will be significantly slowed if an inert bleed is used to maintain the system pressure. Since the assumption about the blowdown phase does not influence the heatup phase all cases use the same amount of steam injection and consequently have the same amount of total water accumulated, vessel water and downstream condensate, at the end of the 24 hour period.

Table 16. Selected computed results for four cases representing various assumptions about cooling of Vessel 1 walls for an assumed experiment duration of 24 hours. Case $\mathrm{Cl}$ assumes no wall cooling, $\mathrm{C} 2$ wall cooling based on internal drying layer model, $\mathrm{C} 3$ includes internal drying layer cooling and forced air external cooling, and $\mathrm{C} 4$ is the same as case $\mathrm{C} 4$ except a $2 \mathrm{mmol} / \mathrm{s}$ inert purge is assumed during the blowdown phase.

\begin{tabular}{|ccccc|}
\hline Case & $C 1$ & $C 2$ & $C 3$ & $\mathrm{C} 4$ \\
\hline Initial $N(\mathrm{~kg})$ & 189 & 189 & 189 & 189 \\
Final $N(\mathrm{~kg})$ & 7.9 & 7.7 & 7.8 & 7.7 \\
Final $S(\mathrm{~kg})$ & 130.4 & 130.5 & 130.5 & 130.5 \\
Maximum $W_{1}(\mathrm{~kg})$ & 93.9 & 93.9 & 93.9 & 93.9 \\
Final $W_{1}(\mathrm{~kg})$ & 48.0 & 28.4 & 36.6 & 42.4 \\
Maximum $W_{2}(\mathrm{~kg})$ & 61.4 & 61.6 & 61.6 & 61.6 \\
Final $W_{2}(\mathrm{~kg})$ & 34.6 & 48.5 & 40.9 & 32.7 \\
Steam in $(\mathrm{kg})$ & 148.3 & 148.3 & 148.3 & 148.3 \\
Steam out $(\mathrm{kg})$ & 100.0 & 105.6 & 105.1 & 107.3 \\
Maximum $T_{1}(\mathrm{C})$ & 272.3 & 272.3 & 272.3 & 272.3 \\
Time to $P_{\mathrm{I}}(\mathrm{min})$ & 53 & 53 & 53 & 53 \\
Time at $P_{\mathrm{r}}(\mathrm{min})$ & 60 & 60 & 60 & 60 \\
Total Time $(\mathrm{min})$ & 1440.7 & 1440.7 & 1440.7 & 1440.7 \\
Maximum $f(\mathrm{~mol} / \mathrm{s})$ & 4.1 & 4.1 & 4.1 & 4.1 \\
Maximum $f_{\mathrm{e}}(\mathrm{mol} / \mathrm{s}$ & 3.8 & 3.8 & 3.8 & 3.8 \\
Final Pressure $(\mathrm{kPa})$ & 8 & 21 & 12 & 100 \\
Final $T_{1}(\mathrm{C})$ & 43 & 62 & 50 & 78 \\
Final $T_{1}(\mathrm{C})$ & 275 & 238 & 57 & 59 \\
Final $T_{2}(\mathrm{C})$ & 41 & 60 & 47 & 38 \\
Final $T_{2}(\mathrm{C})$ & 41 & 60 & 47 & 38 \\
\hline
\end{tabular}

For the extended base case results, case $\mathrm{C} 1$, the system pressure, the temperature of the contents of Vessel 1, and the amounts of water in Vessels 1 and 2 are shown as a function of time in Figs. $21 \& 22$. After the pressure drops below one 
atmosphere and gas ceases to exit the system, the temperature decline slowed considerably. In this extended cooldown period the water slowly evaporates from Vessel 1 and accumulates in Vessel 2. This flow of water is driven by the external cooling assumed present for Vessel 2. At the end of the 24 hour period the computed temperature in Vessel 1 is $43 \mathrm{C}$ and the system pressure is only $8 \mathrm{kPa}$, or 0.08 atmospheres.

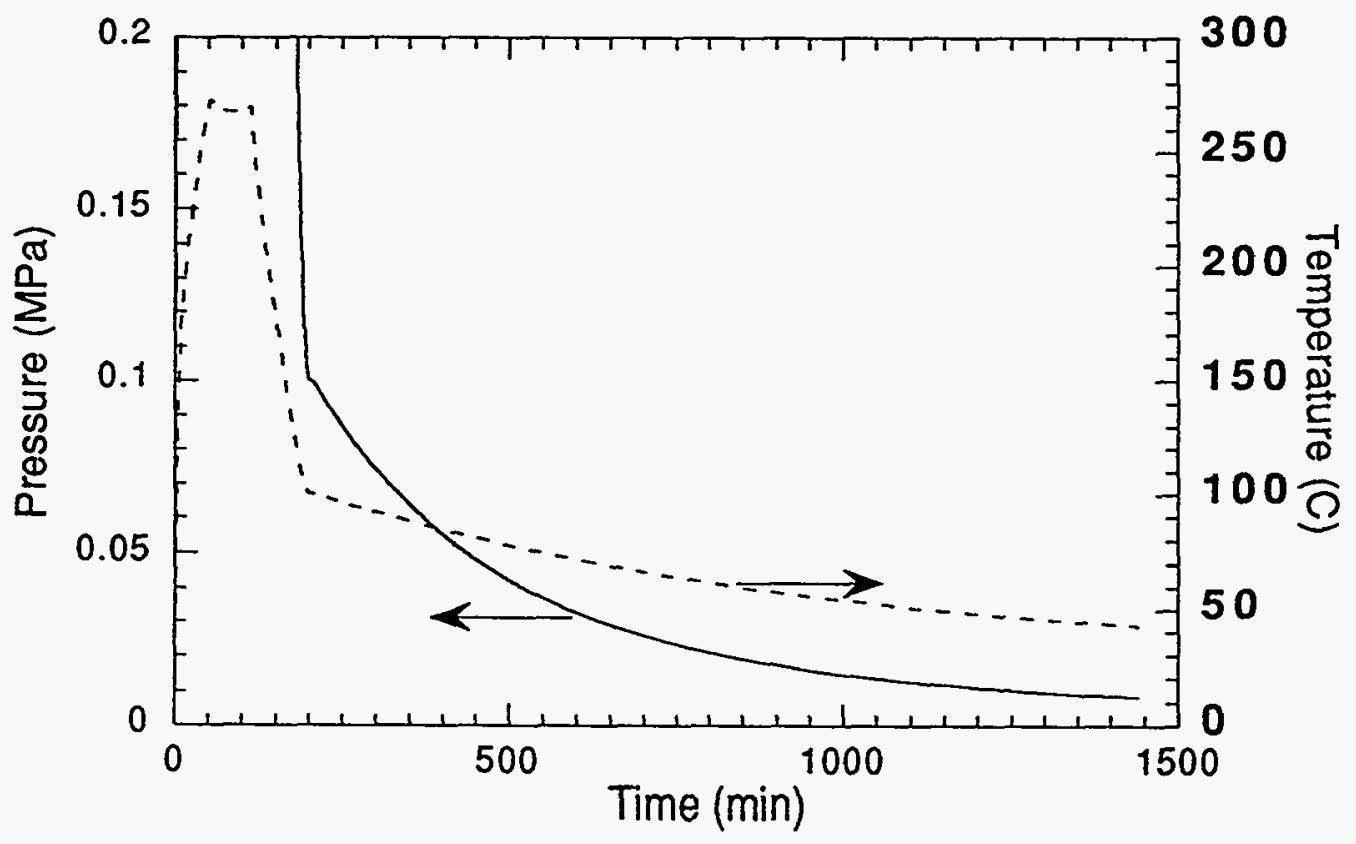

Figure 21. The computed pressure and temperature in Vessel 1 for the base case parameters during an extended cool-down period.

Figs. 23 \& 24 show Vessel 1 temperature and pressure histories for cases $C 3$ and C4. The behavior of case $\mathrm{C} 3$ is very similar to that of the base case, but the character of the case $\mathrm{C} 4$ result are different in that there is no pressure decline after reaching $0.1 \mathrm{MPa}$. This is due to the assumed presence of an inert bleed flow. The presence of the inert gas reduces the cooling rate because it reduces the transport of steam from Vessel 1 to 2, see Fig 25. 


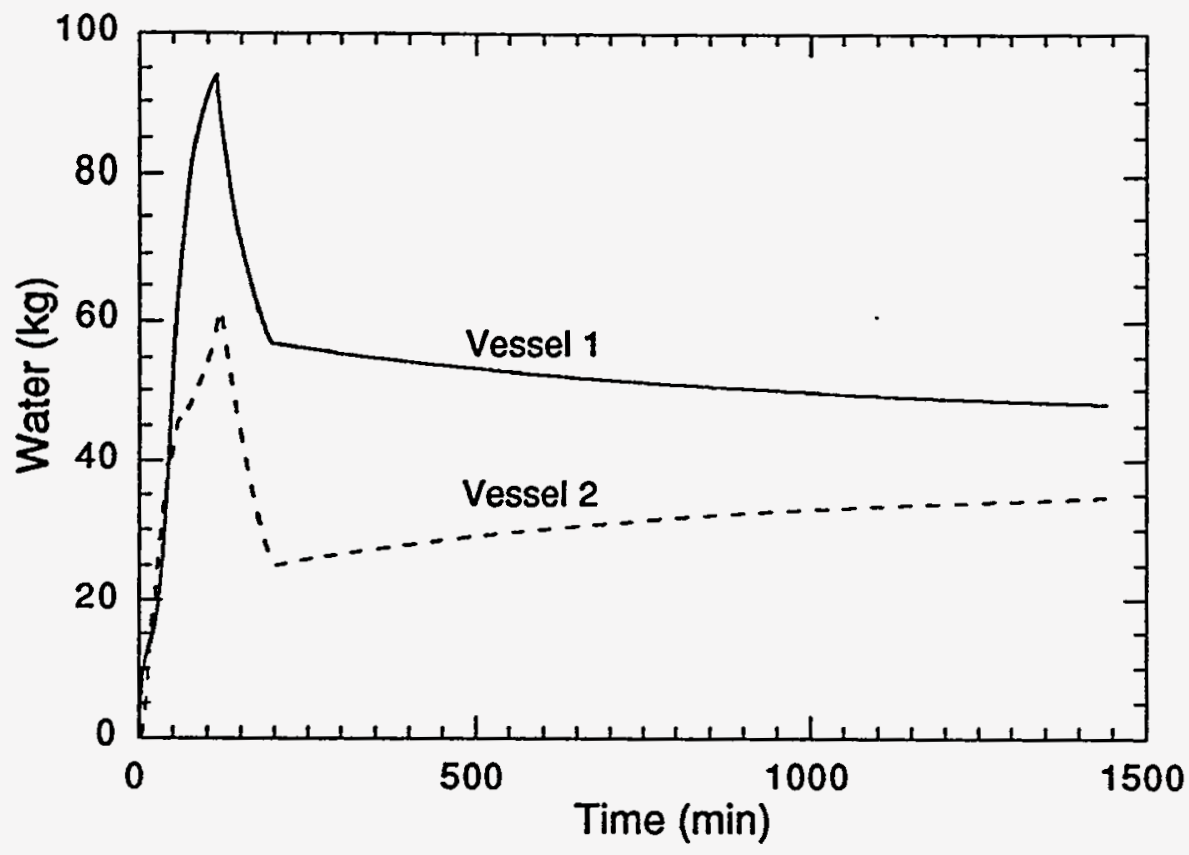

Figure 22. The computed water in Vessels $1 \& 2$ for the base case parameters during an extended cool-down period.

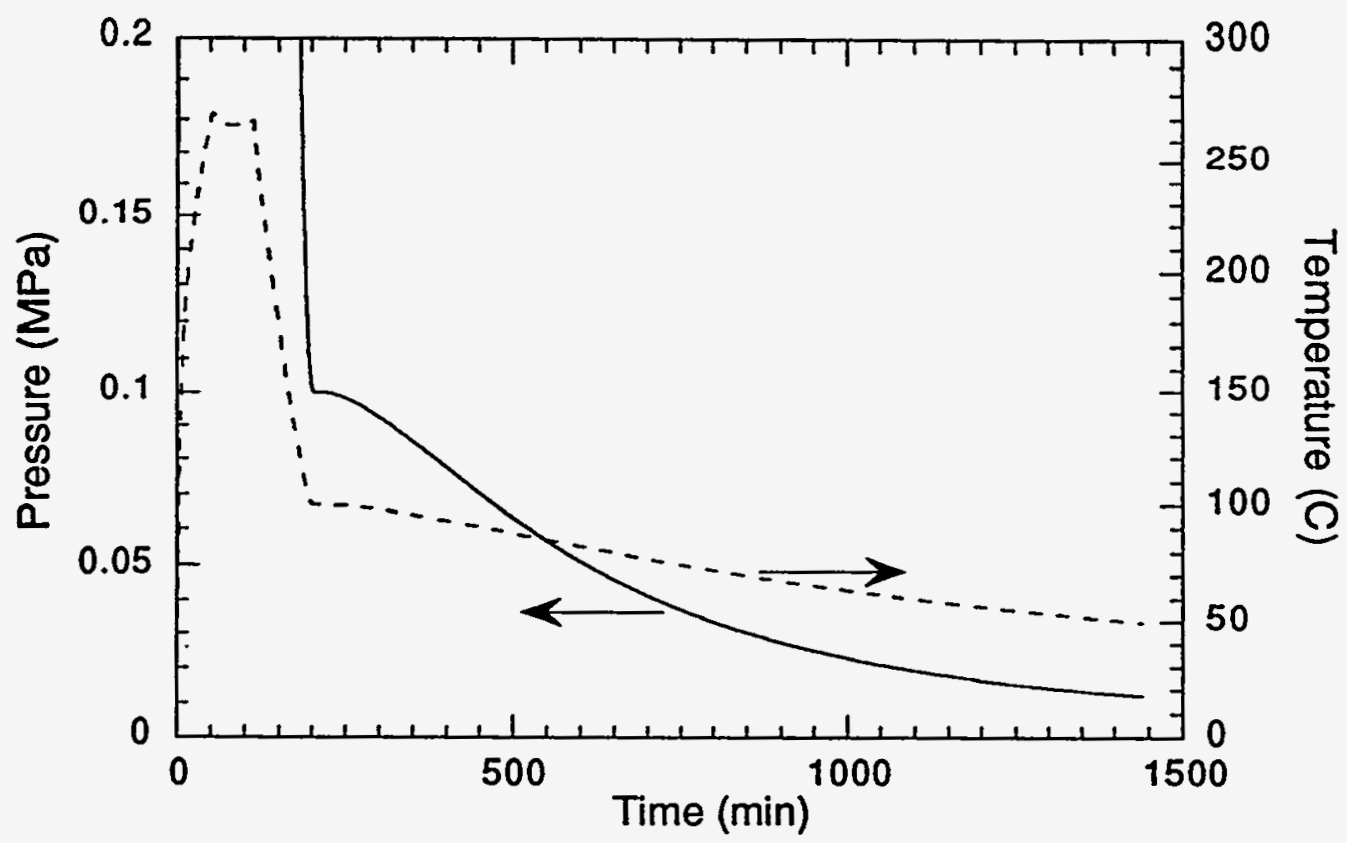

Figure 23. The computed pressure and temperature in Vessel 1 for case C3 parameters during an extended cool-down period. 


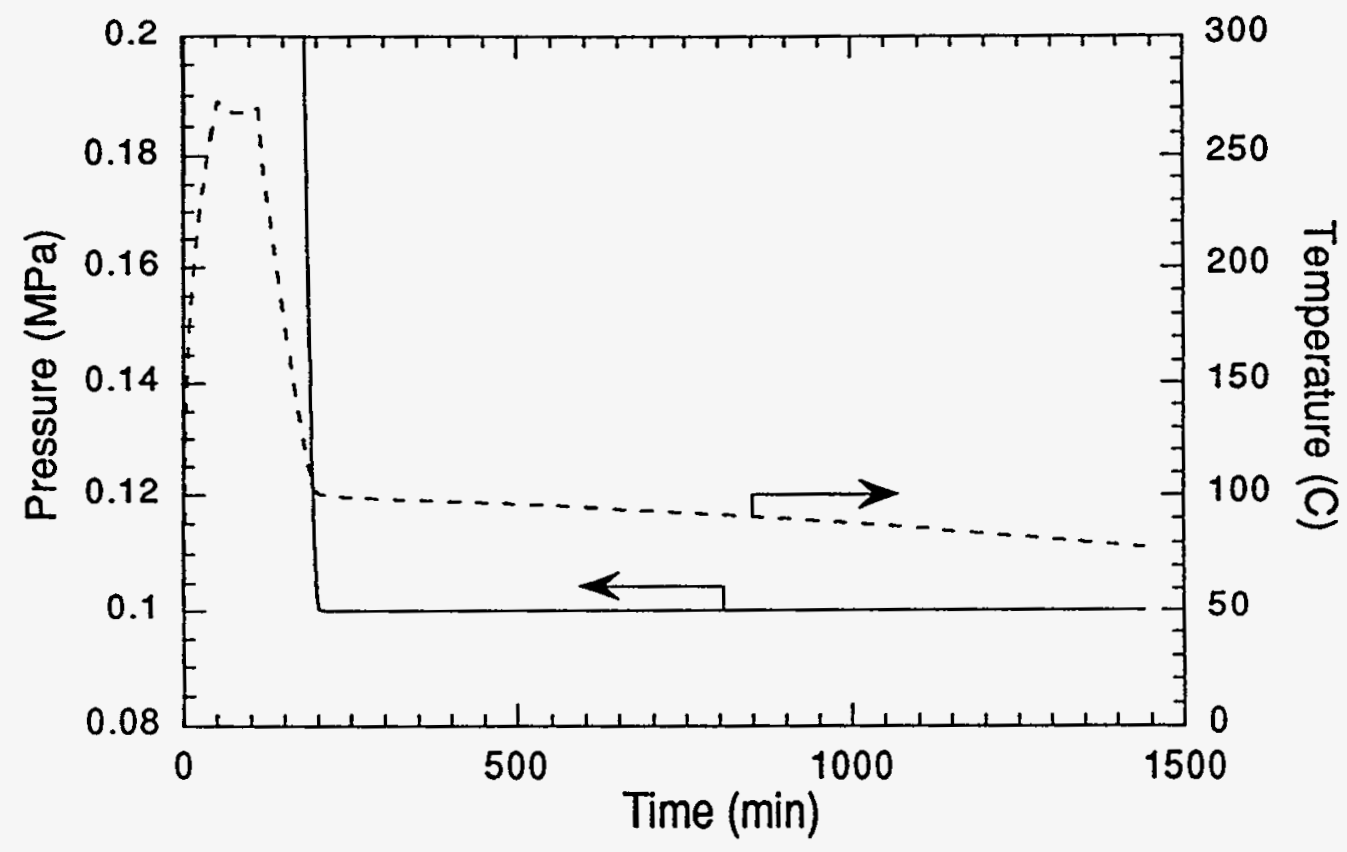

Figure 24. The computed pressure and temperature in Vessel 1 for case $C 4$ parameters during an extended cool-down period.

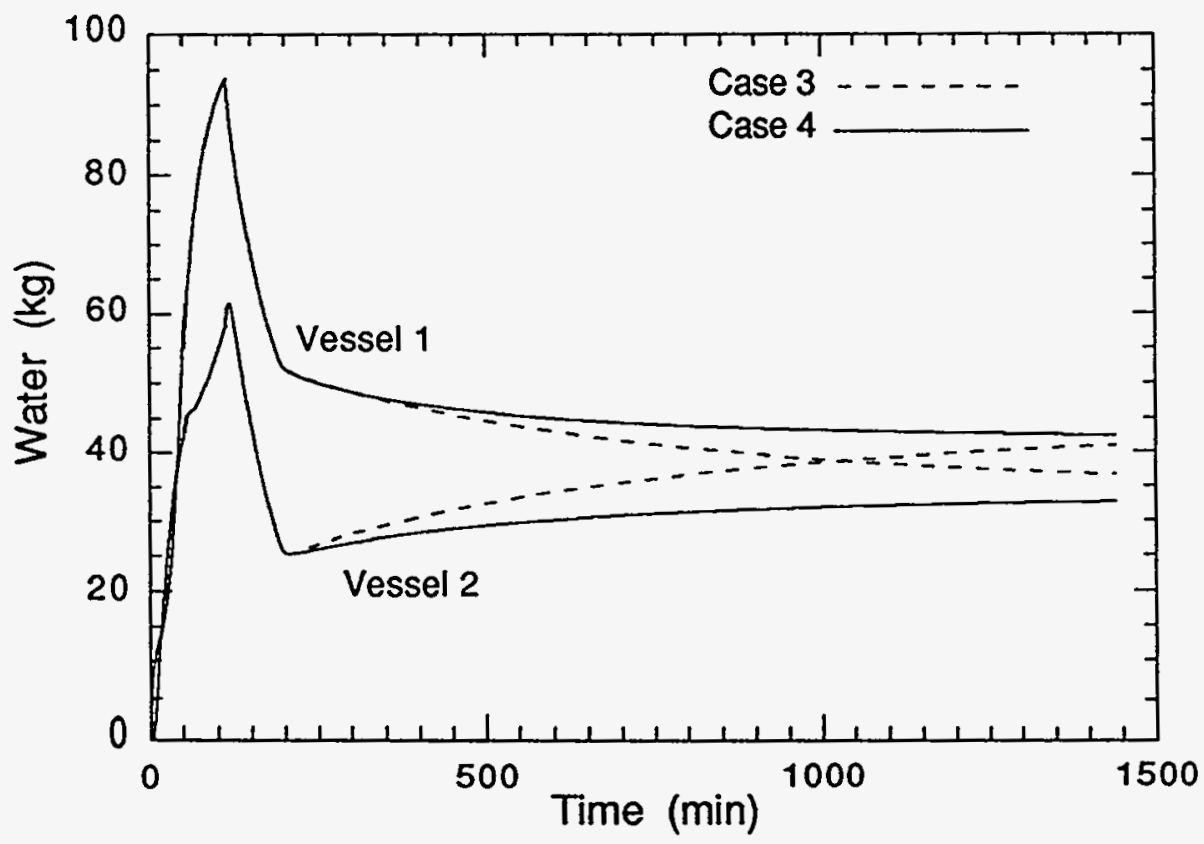

Figure 25. The computed water in Vessels 1 \& 2 for cases C3 \& C4 during an extended cool-down period.

In an actual operation it may be that the system gas production is turned off at some system pressure other than the one atmosphere assumed in the four cases in 
this section. If this is done it would be expected that the final wall and interior temperatures after 24 hours would be affected. In Fig. 26 it is seen that final interior temperature of Vessel 1 increases considerably more than the wall temperature as the assumed shut-in pressure is increased.

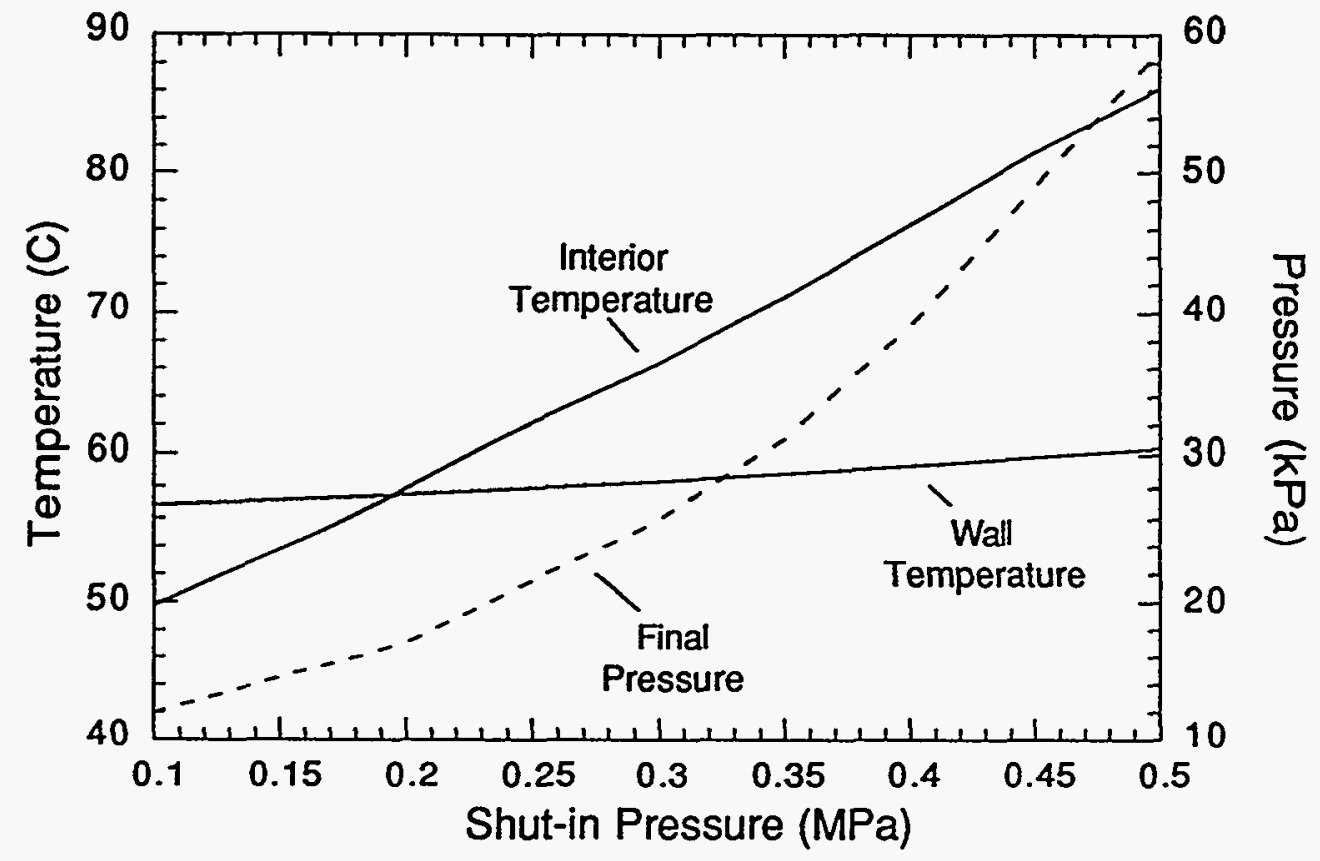

Figure 26. The computed wall and interior temperatures for Vessel 1 as well as final system pressure for case $\mathrm{C} 3$ parameters as a function of pressure at which the exit flow is set to zero.

If lower system temperatures are required, the cooling period can be extended. For C 3 case parameters both the interior and wall temperatures of Vessel 1 are computed to be below $35 \mathrm{C}$ after 48 hours, see Fig. 27. The rate of water transfer and thus the rate of temperature drop in Vessel 1 becomes very slow after about 2000 minutes (33 hours). 


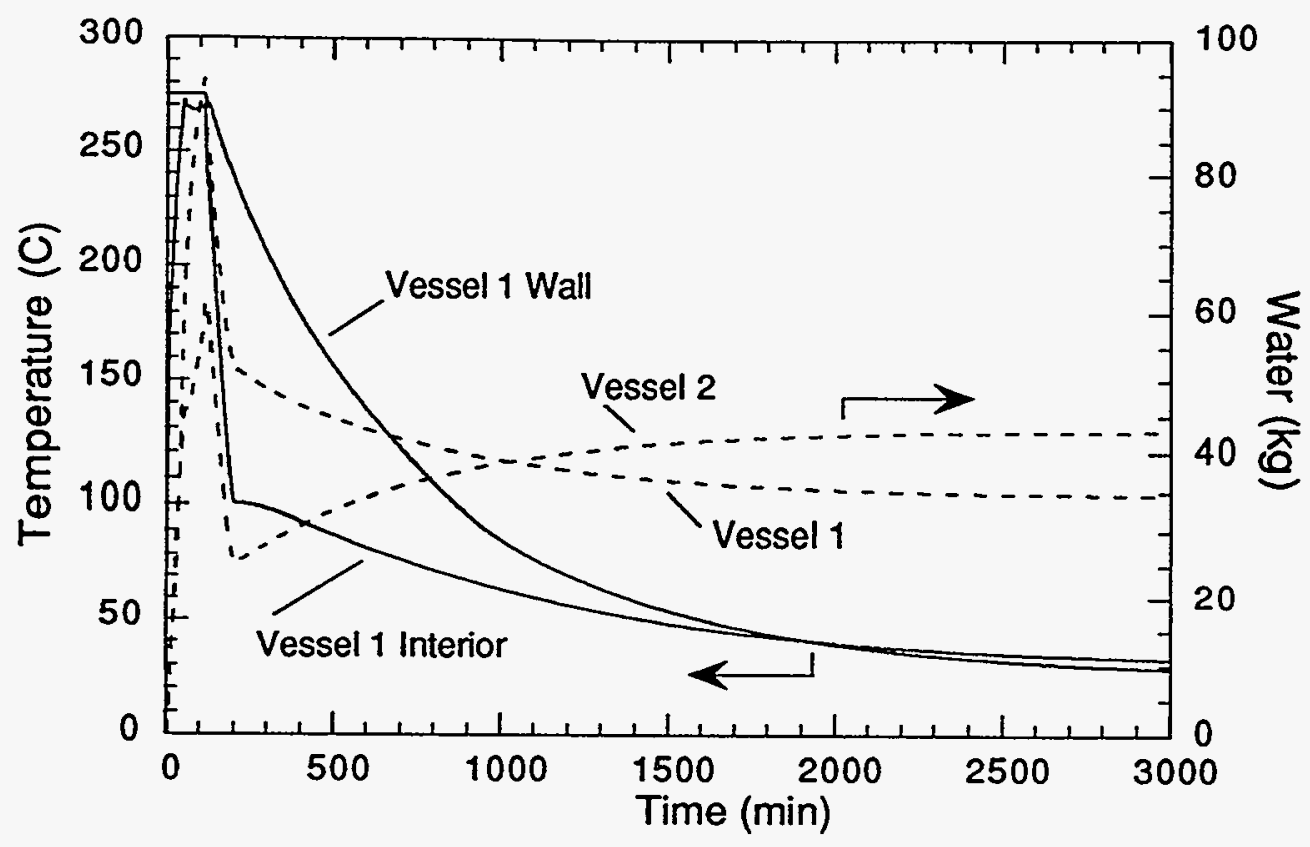

Figure 27. The computed wall and interior temperatures for $\mathrm{C} 3$ parameters for a cooling period extending to 48 plus hours.

\section{TRANSIENT MODEL - PREFERRED OPERATING STRATEGY}

The best operating mode for the pilot process would be one in which no waste water was produced. That is, all condensate would mixed with Vessel 1 contents to produce the final slurry. Currently, it is planned to initially produce a slurry with no more than a 65 wt.\% water content. For a given set of physical assumptions the final total water is most strongly influenced by the assumed water initially loaded with the newspaper. It is also necessary to have sufficient water in the Vessel 1 reactor to allow the decomposition reactions to proceed in optimum fashion. Preliminary laboratory work has shown that dry newspaper decomposes, at a given temperature, far less than wet paper. The tradeoff between extent of decomposition and water content is not known quantitatively at this time, but it is believed that a $1 / 1$ ratio is sufficient to promote reasonably efficient decomposition.

The desire for high water content during the reaction phase and a suitably concentrated final slurry product which includes all condensate water are obviously at odds. To further explore the tradeoff between adding water to the initial charge to increase average water content in Vessel 1 during the reaction phase and minimizing waste water a series of calculations were performed. In these calculations an operating strategy close to that which would be employed in the real experiment and the best available estimates for heat transfer coefficients were used. 
The calculations used all the base case parameters with the following changes. It is assumed that the system is left to cool for 24 hours and the exit gas flow stops when the system pressure reaches one atmosphere, no bleed flow. Vessel 1's exterior is assumed to be actively cooled by air during the blowdown phase and the effective heat transfer coefficient is $6 \mathrm{~W} / \mathrm{m}^{2} \mathrm{~K}$. It is assumed that the drying layer model for heat transfer best represents the real system when it comes to heat transfer in Vessel 1 during the blowdown phase. These assumptions are the same as those made in case $\mathrm{C} 3$ in the previous section. In the following this new composite set of assumptions will be referred to as the BOP (base operating parameters) case.

In Table 17 results of these calculations are listed, focusing primarily on the issue of water amounts. The column labeled "Net Water" is the net water remaining after a run assuming the amount of water used in the charge is taken away from the total water amount left after the reaction. The final column in the table gives the water content of a final slurry product in which all the "Net water" is mixed in with the contents of Vessel 1.

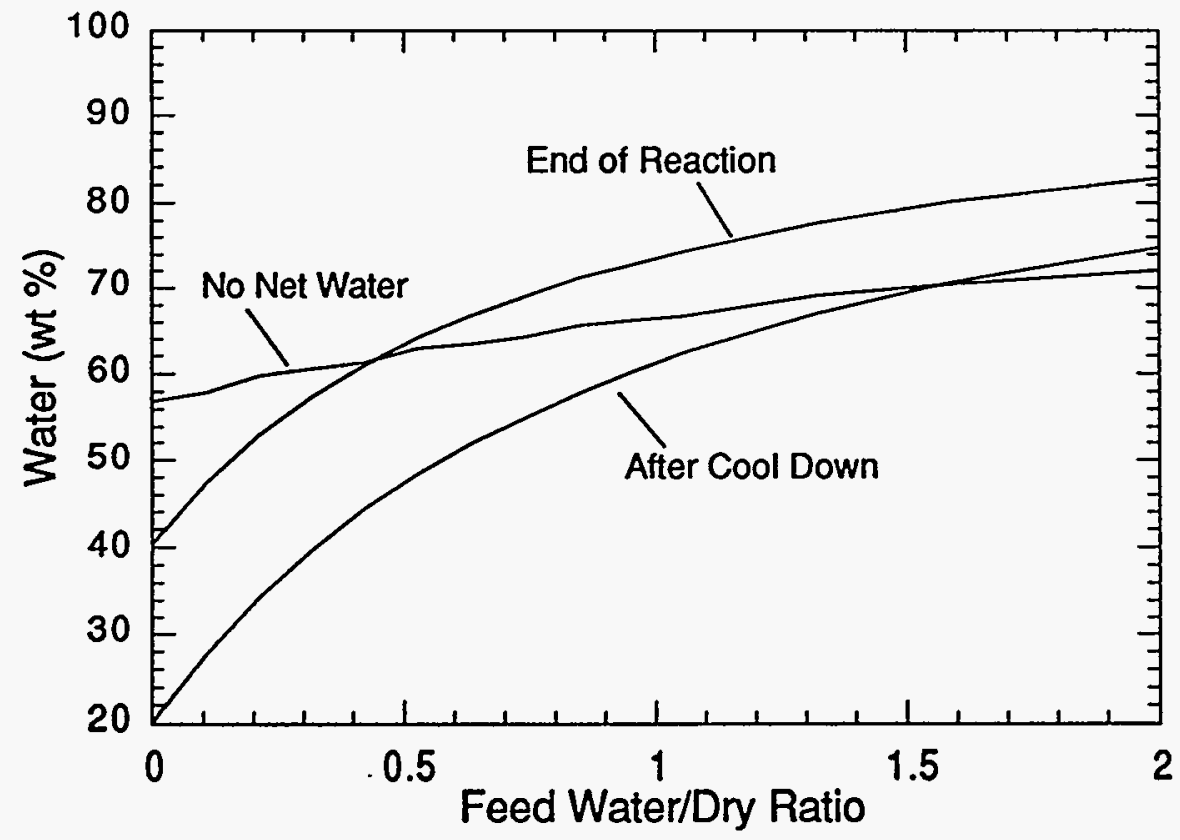

Figure 28. Computed water content of process slurries as a function of the water content of the feed, at the in end of the reaction phase in Vessel 1 labeled "End of Reaction", in Vessel 1 at the end of experiment labeled "After Cool Down", and adding all condensate to the final product slurry labeled "No Net Water". These calculations used the BPO assumptions and assumed the Vessel 1 walls were preheated to $275 \mathrm{C}$. 
Data from Table 17 in conjunction with other computed results were used to construct Fig. 28 which shows the water content for solid/water mixtures of interest to the process as a function of feed water/dry-solid ratio. The "After Cool Down" line represents the water content of the Vessel 1 mixture at the end of the process. The "End of Reaction" line represents the water content of Vessel 1 right at the end of the reaction phase. This value is characteristic of the water content in the vessel during the active decomposition of newspaper. The final line labeled "No Net Water" is the water content of the slurry product in which no net water is produced.

The results of the calculations predict that the lowest water content slurry that can be made contains $20 \mathrm{wt} . \%$ water, but would result in the production of $148 \mathrm{~kg}$ of waste water. The lowest water content of a final product slurry in which no net waste water would be produced is about $57 \mathrm{wt. \%}$. These results are for the case with no water charged to the reactor. If a final slurry containing $65 \mathrm{wt} . \%$ water and no waste water is desired, then the feed should include about $150 \mathrm{~kg}$ of water or a ratio of about 0.8 water to dry newspaper. In this case the water content during the reaction period would be about $70 \mathrm{wt} . \%$ and about $56 \mathrm{wt} . \%$ in Vessel 1 after cool down.

Table 17. Selected computed water contents for varying amounts of water in the feed. The computations were done using the BPO assumptions with the Vessel 1 walls preheated to $275 \mathrm{C}$. In all cases $189 \mathrm{~kg}$ of newspaper feed was assumed.

\begin{tabular}{|cccccccc|}
\hline Water In & $\begin{array}{c}\text { Feed } \\
\text { Water/ Dry }\end{array}$ & Final $W_{1}$ & $\begin{array}{c}\text { Final Water } \\
\text { in Vessel 1 }\end{array}$ & Final $W_{2}$ & $\begin{array}{c}\text { Condenser } \\
\text { Water }\end{array}$ & Net Water & $\begin{array}{c}\text { Mix with } \\
\text { No Net } \\
\text { Water } \\
(\text { wt. \%) }\end{array}$ \\
\hline$(\mathrm{kg})$ & & $(\mathrm{kg})$ & $(\mathrm{wt} \%)$ & $(\mathrm{kg})$ & $(\mathrm{kg})$ & $(\mathrm{kg})$ & $\begin{array}{c}\text { \%) } \\
(0\end{array}$ \\
\hline 0 & 0.000 & 34.7 & 20.1 & 42.9 & 105.1 & 148.0 & 56.9 \\
40 & 0.106 & 53.0 & 27.7 & 45.5 & 111.9 & 137.4 & 57.9 \\
60 & 0.212 & 71.9 & 34.3 & 48.8 & 124.8 & 133.6 & 59.8 \\
80 & 0.317 & 91.1 & 39.7 & 50.5 & 130.7 & 121.2 & 60.6 \\
100 & 0.423 & 110.2 & 44.4 & 52.2 & 136.4 & 108.6 & 61.3 \\
120 & 0.529 & 129.8 & 48.5 & 54.7 & 148.8 & 103.5 & 62.9 \\
140 & 0.635 & 149.4 & 52.0 & 56.2 & 155.0 & 91.2 & 63.5 \\
160 & 0.847 & 169.1 & 55.0 & 57.5 & 161.1 & 78.6 & 64.2 \\
180 & 0.952 & 209.9 & 57.8 & 59.9 & 174.2 & 74.1 & 65.6 \\
200 & 1.058 & 229.1 & 60.2 & 60.9 & 179.6 & 60.5 & 66.2 \\
250 & 1.323 & 279.7 & 67.4 & 62.0 & 185.9 & 47.9 & 66.7 \\
300 & 1.587 & 330.6 & 70.6 & 66.0 & 211.1 & 27.1 & 69.1 \\
378 & 2.000 & 411.1 & 74.9 & 71.5 & 228.0 & -3.5 & 70.4 \\
\hline
\end{tabular}

In the previous results it was assumed that the walls of Vessel 1 would be externally preheated to $275 \mathrm{C}$ to reduce the amount of steam needed in heating the contents. This preheating would tend to dry out the region near the wall and this dried material may not resaturate during the steam heat phase because of its 
elevated temperature. Consequently it would probably be better to preheat the walls to a temperature somewhat below the final desired reaction temperature.

As the amount of preheating of the Vessel 1 walls is reduced the amount of water which will accumulate in the process will increase. Using the BOP case assumptions and assuming good heat transfer coupling of the Vessel 1 contents and wall during the heatup and reaction phases a series of calculations were done to determine the influence of wall heating on the net water and thus on the final product composition with no net waste water. These calculations were done assuming dry feed and the results are listed in Table 18 and plotted in Fig 29.

Table 18. Computed results showing the influence of wall preheating on important water parameters of the process.

\begin{tabular}{|c|c|c|c|c|c|c|}
\hline $\begin{array}{l}\text { Initial } \\
T_{\mathrm{w}_{1}} \\
(\mathrm{C})\end{array}$ & $\begin{array}{c}\text { Final } W_{1} \\
(\mathrm{~kg})\end{array}$ & $\begin{array}{c}\text { Final Water } \\
\text { in Vessel } 1 \\
\text { (wt. \%) }\end{array}$ & Final $W_{2}$ & $\begin{array}{c}\text { Condenser } \\
\text { Water } \\
(\mathrm{kg})\end{array}$ & Net Water & $\begin{array}{l}\text { Mix with } \\
\text { No Net } \\
\text { Water } \\
\text { (wt. \%) }\end{array}$ \\
\hline 275 & 34.7 & 20.1 & 42.9 & 105.1 & 148.0 & 56.9 \\
\hline 200 & 68.8 & 33.3 & 48.5 & 116.5 & 165.0 & 63.0 \\
\hline 150 & 92.9 & 40.3 & 51.4 & 125.5 & 176.9 & 66.2 \\
\hline 100 & 118.0 & 46.2 & 54.7 & 140.2 & 194.9 & 69.5 \\
\hline 27 & 154.8 & 52.9 & 57.1 & 151.7 & 208.8 & 72.5 \\
\hline
\end{tabular}

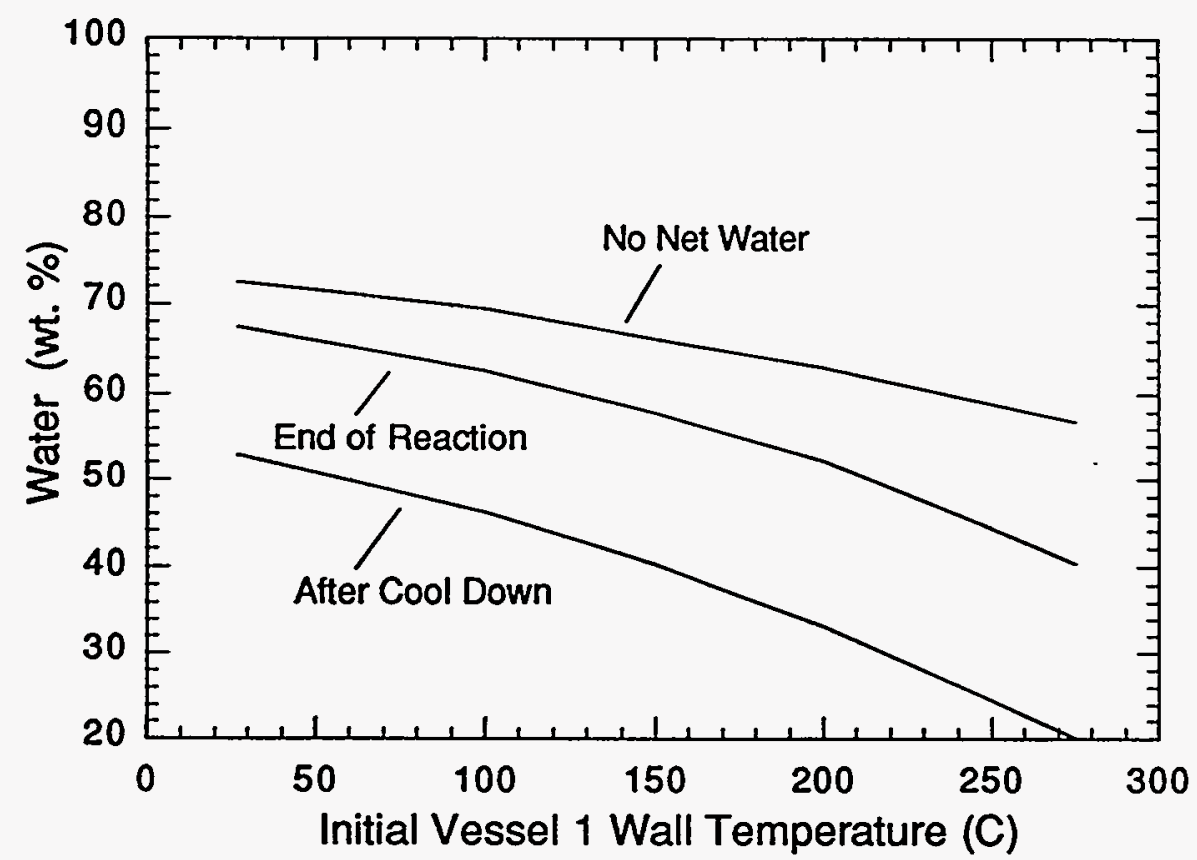

Figure 29. Computed water content of process slurries as a function of the preheat temperature of Vessel 1 walls, at the in end of the reaction phase in Vessel 1 labeled "End of Reaction", in Vessel 1 at the end of experiment labeled "After Cool Down", and adding all condensate to the final product slurry labeled "No Net Water". 
The results indicate that if the walls are heated to only $150 \mathrm{C}$ the final product made with all condensate added back would contain about $66 \mathrm{wt} . \%$ water, which is close to the $65 \mathrm{wt} . \%$ target for initial slurries. The additional water in Vessel 1 computed for this case would tend to be concentrated near the walls and insure moisture would be present at the walls during the reaction phase.

Another set of calculations for the BPO assumptions with varying amounts of initial water in the feed were performed with the walls of Vessel 1 assumed to be preheated to $150 \mathrm{C}$. Results from these calculations are presented in Table 19 and Fig. 30. Contrasting these results with those above for Vessel 1 walls preheated to $275 \mathrm{C}$ it is seen that the water content calculations indicate that the colder walls lead to as much as a $20 \mathrm{wt}$.\% increase in water content and as little as $2 \mathrm{wt}$. \%, depending on the feed and the product considered. For a water/dry feed ratio of 0.5 the final water content in Vessel 1 at the end of the cooldown period would be about $57 \mathrm{wt} . \%$ and the no-net-water product would be about $70 \mathrm{wt} . \%$ water.

Table 19. Selected computed water contents for varying amounts of water in the feed. The computations were done using the BPO assumptions with the Vessel 1 walls preheated to $150 \mathrm{C}$. In all cases $189 \mathrm{~kg}$ of newspaper feed was assumed.

\begin{tabular}{|c|c|c|c|c|c|c|c|}
\hline $\begin{array}{l}\text { Water } \\
\text { In }\end{array}$ & $\begin{array}{c}\text { Feed } \\
\text { Water/ } \\
\text { Dry }\end{array}$ & Final $W_{1}$ & $\begin{array}{l}\text { Final Water } \\
\text { in Vessel } 1\end{array}$ & Final $W_{2}$ & $\begin{array}{c}\text { Condenser } \\
\text { Water }\end{array}$ & $\begin{array}{c}\text { Net } \\
\text { Water } \\
(\mathrm{kg})\end{array}$ & $\begin{array}{l}\text { Mix with } \\
\text { No Net } \\
\text { Water } \\
\text { (wt. \%) }\end{array}$ \\
\hline 0 & 0.000 & 92.9 & 40.3 & 51.4 & 125.5 & 176.9 & 66.2 \\
\hline 20 & 0.106 & 112.5 & 45.0 & 54.2 & 137.8 & 172.0 & 67.4 \\
\hline 40 & 0.212 & 131.8 & 48.9 & 55.7 & 143.8 & 159.5 & 67.9 \\
\hline 60 & 0.317 & 151.3 & 52.4 & 57.3 & 151.0 & 148.3 & 68.5 \\
\hline 80 & 0.423 & 171.3 & 55.5 & 63.9 & 162.5 & 146.4 & 69.8 \\
\hline 100 & 0.529 & 191.1 & 58.2 & 60.8 & 169.1 & 129.9 & 70.0 \\
\hline 120 & 0.635 & 211.0 & 60.5 & 61.7 & 175.0 & 116.7 & 70.4 \\
\hline 140 & 0.741 & 231.0 & 62.7 & 62.9 & 182.1 & 105.0 & 71.0 \\
\hline 160 & 0.847 & 251.9 & 64.7 & 64.5 & 193.6 & 98.1 & 71.8 \\
\hline 180 & 0.952 & 271.4 & 66.4 & 65.8 & 199.6 & 85.4 & 72.2 \\
\hline 200 & 1.058 & 291.6 & 68.0 & 66.5 & 205.2 & 71.7 & 72.5 \\
\hline 250 & 1.323 & 342.4 & 71.3 & 69.3 & 224.4 & 43.7 & 73.7 \\
\hline 300 & 1.587 & 393.3 & 74.0 & 70.4 & 236.9 & 7.3 & 74.4 \\
\hline 378 & 2.000 & 474.2 & 77.4 & 72.0 & 260.6 & -45.4 & 75.6 \\
\hline
\end{tabular}




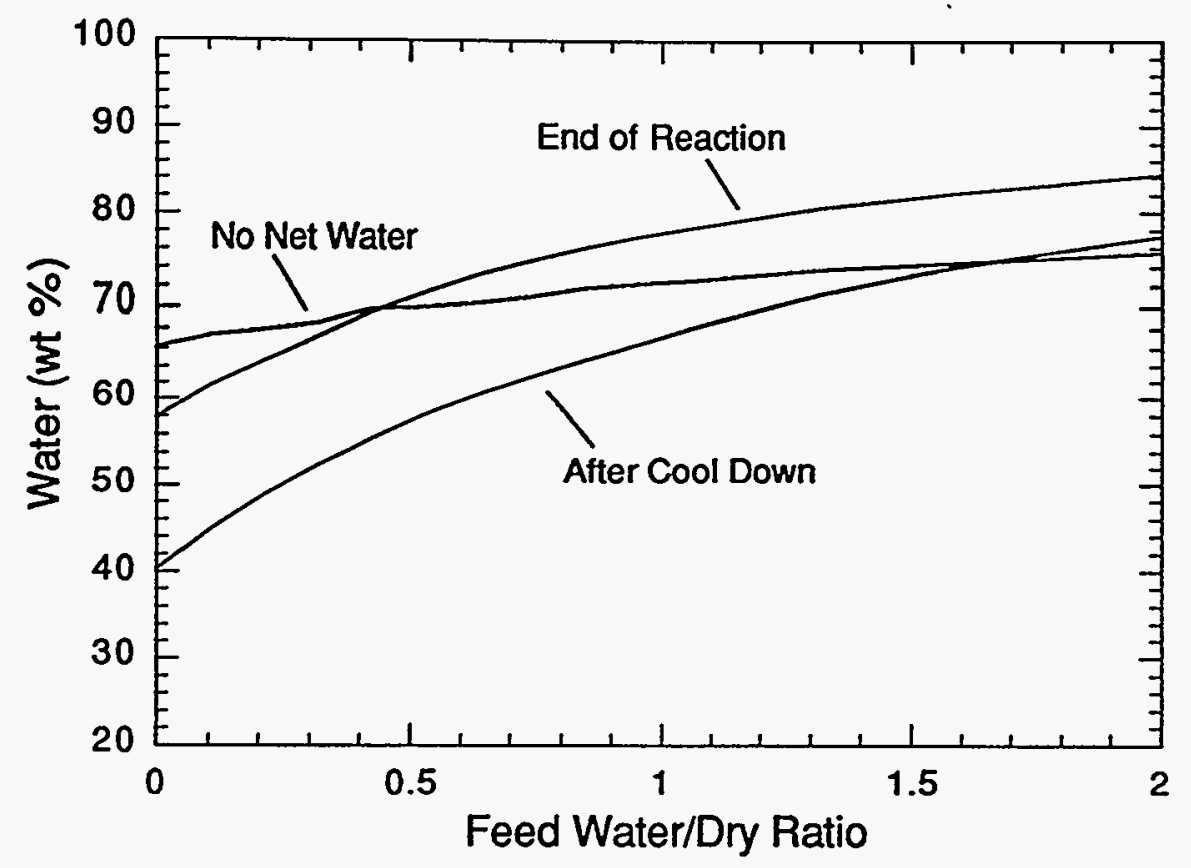

Figure 30. Computed water content of process slurries as a function of the water content of the feed, at the in end of the reaction phase in Vessel 1 labeled "End of Reaction", in Vessel 1 at the end of experiment labeled "After Cool Down", and adding all condensate to the final product slurry labeled "No Net Water". These calculations used the BPO assumptions and assumed the Vessel 1 walls were preheated to $150 \mathrm{C}$.

\section{The First Experiment}

Considering all the above results it appears that the first experiment will probably use conditions which are consistent with the BPO assumptions. To insure adequate water present during the reaction phase in the reactor and at the wall the feed will be moistened to give a 0.5 water/dry material and the walls will be preheated to $150 \mathrm{C}$ prior to introduction of the steam. To insure the product is cooled enough to be easily handled an extended cooldown period lasting two days will be used. In summary the target operating conditions and experimental setup will include the following:

- Vessel 2 will be connected to the gas space of Vessel 1 and remain uninsulated.

- Vessel 1 will be configured so that it is insulated during the heatup and reaction phase but air cooled during the blowdown/cooldown phase.

- Vessel 1 will allow for external heating of the vessel walls

- At least $189 \mathrm{~kg}$ of newspaper feed will be used.

- $2 \mathrm{~mol} / \mathrm{s}$ of steam will be used in the heatup phase and the flow will be reduced to $0.5 \mathrm{~mol} / \mathrm{s}$ after reaching the maximum system pressure of 6.3 $\mathrm{MPa}$ (914 psi). 
- After reaching 6.3 $\mathrm{MPa}$ the pressure will be maintained for 60 minutes.

- The blowdown/cooldown phase will last at least 48 hours.

Computations done for this case are summarized in Table 20 and Figs. 31-35. Only the first 5 hours of results are plotted in the figures. The minimum water content of the product slurry available from the run is calculated to be $57 \mathrm{wt} . \%$. The water content during the reaction phase is computed to be about $70 \%$ which should insure plenty of water to keep the newspaper moist during the high temperature phase of the run.

Table 20. Selected computed results for the proposed first experiment.

\begin{tabular}{|ccc|}
\hline & Value & Units \\
\cline { 2 - 3 } Initial $W_{1}$ & 94.5 & $\mathrm{~kg}$ \\
Initial $N$ & 189 & $\mathrm{~kg}$ \\
Initial $W_{1} / N$ & 0.5 & \\
Final $N$ & 5.7 & $\mathrm{~kg}$ \\
Final $S$ & 132.0 & $\mathrm{~kg}$ \\
Maximum $W_{1}$ & 332.9 & $\mathrm{~kg}$ \\
Final $W_{1}$ & 185.3 & $\mathrm{~kg}$ \\
Maximum $W_{2}$ & 62.1 & $\mathrm{~kg}$ \\
Final $W_{2}$ & 59.5 & $\mathrm{~kg}$ \\
Steam in & 277.9 & $\mathrm{~kg}$ \\
Steam out & 162.4 & $\mathrm{~kg}$ \\
Maximum $T_{1}$ & 269.2 & $\mathrm{C}$ \\
Time to $P_{\mathrm{r}}$ & 113 & $\mathrm{~min}$ \\
Time at $P_{\mathrm{r}}$ & 60 & $\mathrm{~min}$ \\
Total Time & 3003.7 & $\mathrm{~min}$ \\
Maximum $f$ & 5.4 & $\mathrm{~mol} / \mathrm{s}$ \\
Maximum $f_{\mathrm{e}}$ & 4.0 & $\mathrm{~mol} / \mathrm{s}$ \\
Water percent (End of Reaction) & 71 & $\mathrm{wt} \%$ \\
Water percent (After Cool Down) & 57 & $\mathrm{wt} \%$ \\
Water percent (No Net Water) & 69 & $\mathrm{wt} \%$ \\
Final Pressure & 7 & $\mathrm{kPa}$ \\
Final $T_{1}$ & 39 & $\mathrm{C}$ \\
Final $T_{\mathrm{w}}$ & 31 & $\mathrm{C}$ \\
Dried zone & 2.3 & $\mathrm{~cm}$ \\
\hline
\end{tabular}




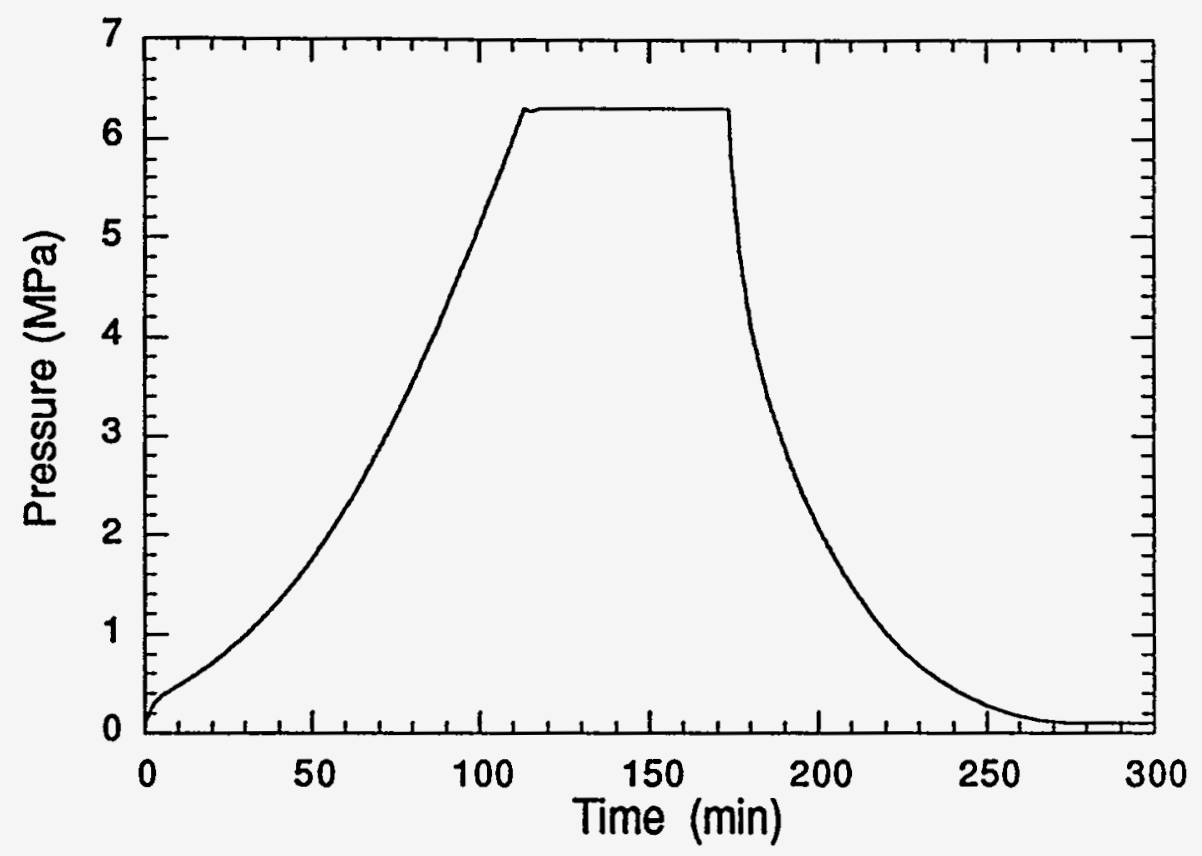

Figure 31. Computed pressure for the first 5 hours of the proposed first experiment.

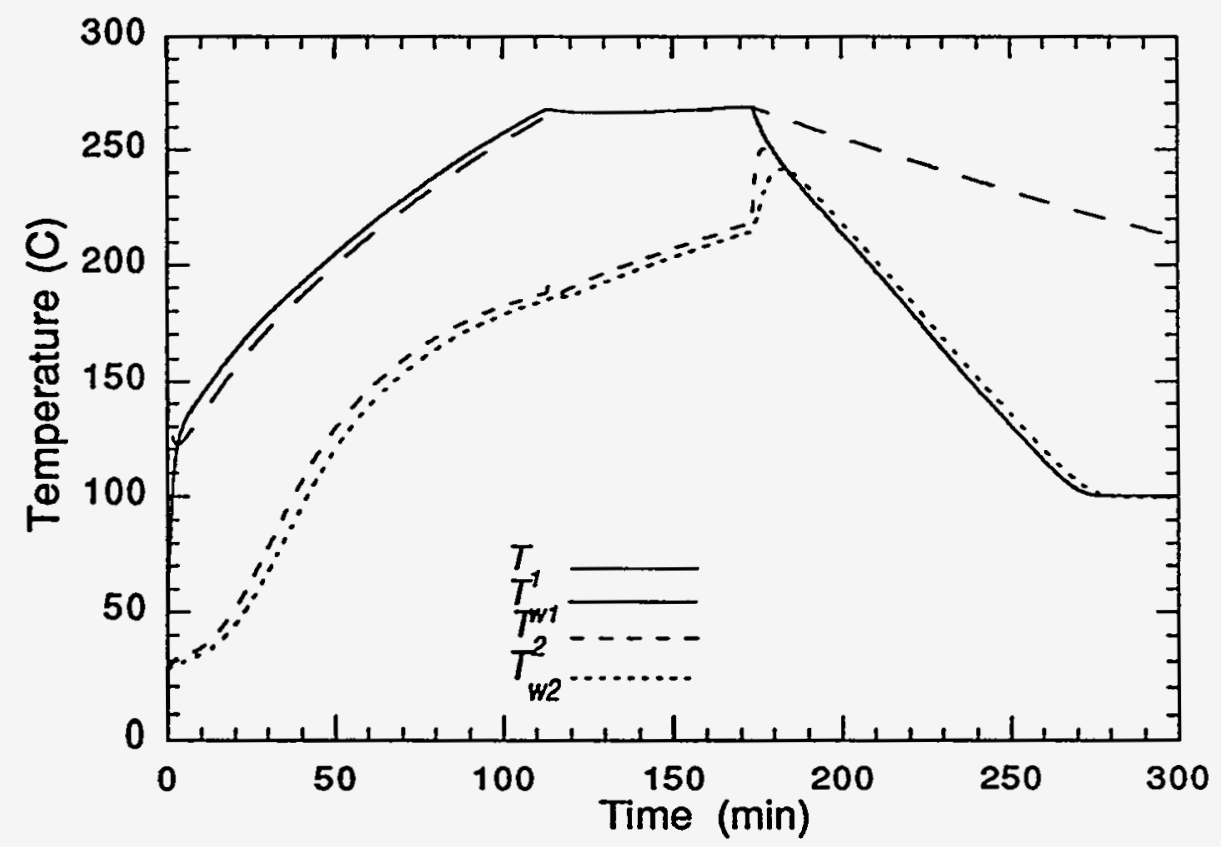

Figure 32. Computed temperatures for the first 5 hours of the proposed first experiment. 


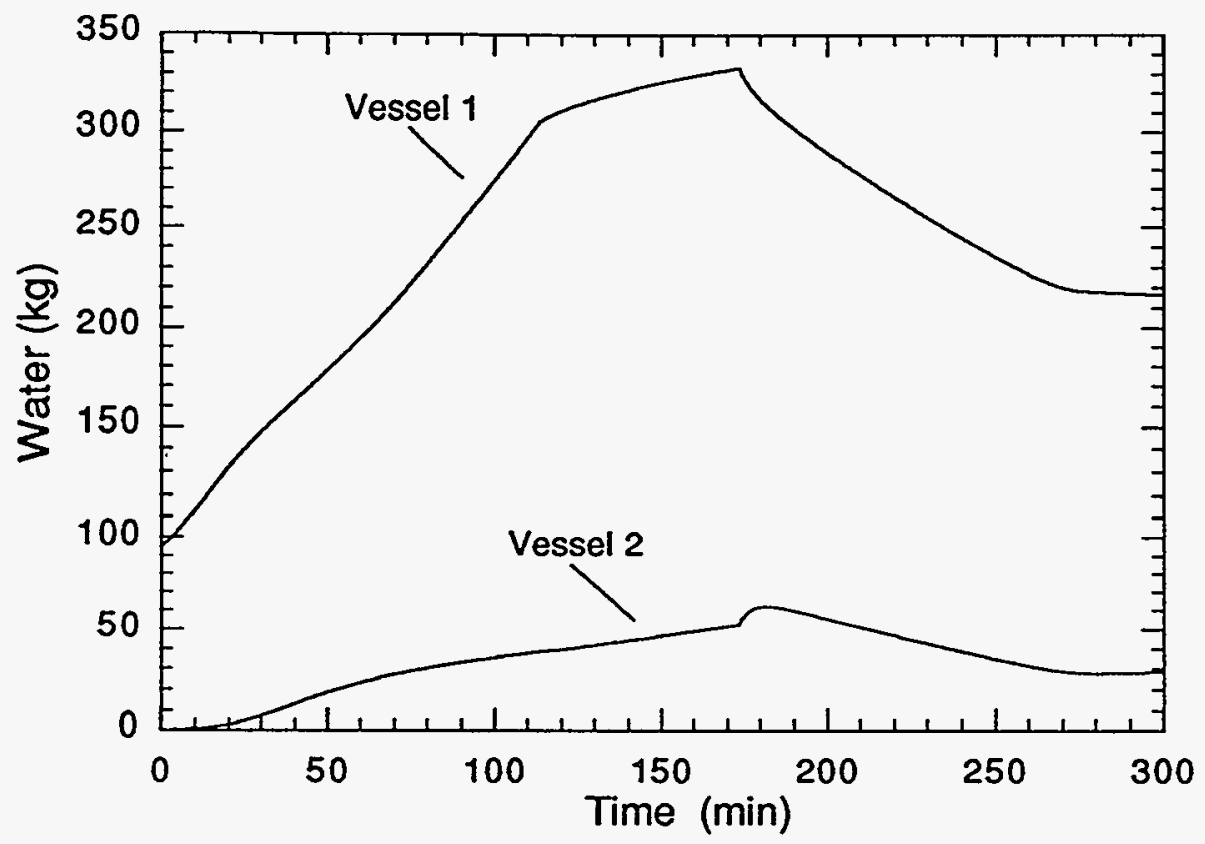

Figure 33. Computed water amounts in Vessels 1 and 2 for the first 5 hours of the proposed first experiment.

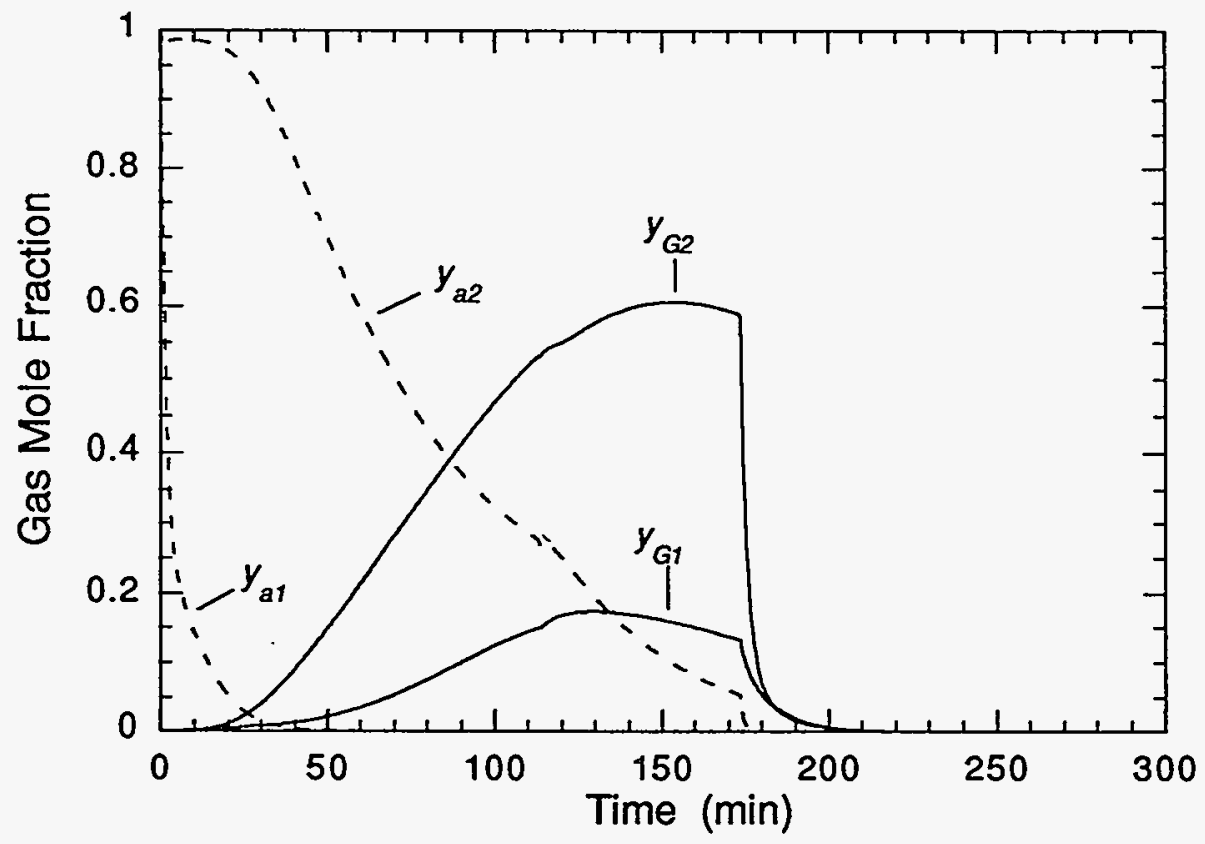

Figure 34. Computed noncondensable gas compositions in Vessels 1 and 2 for the first 5 hours of the proposed first experiment. 


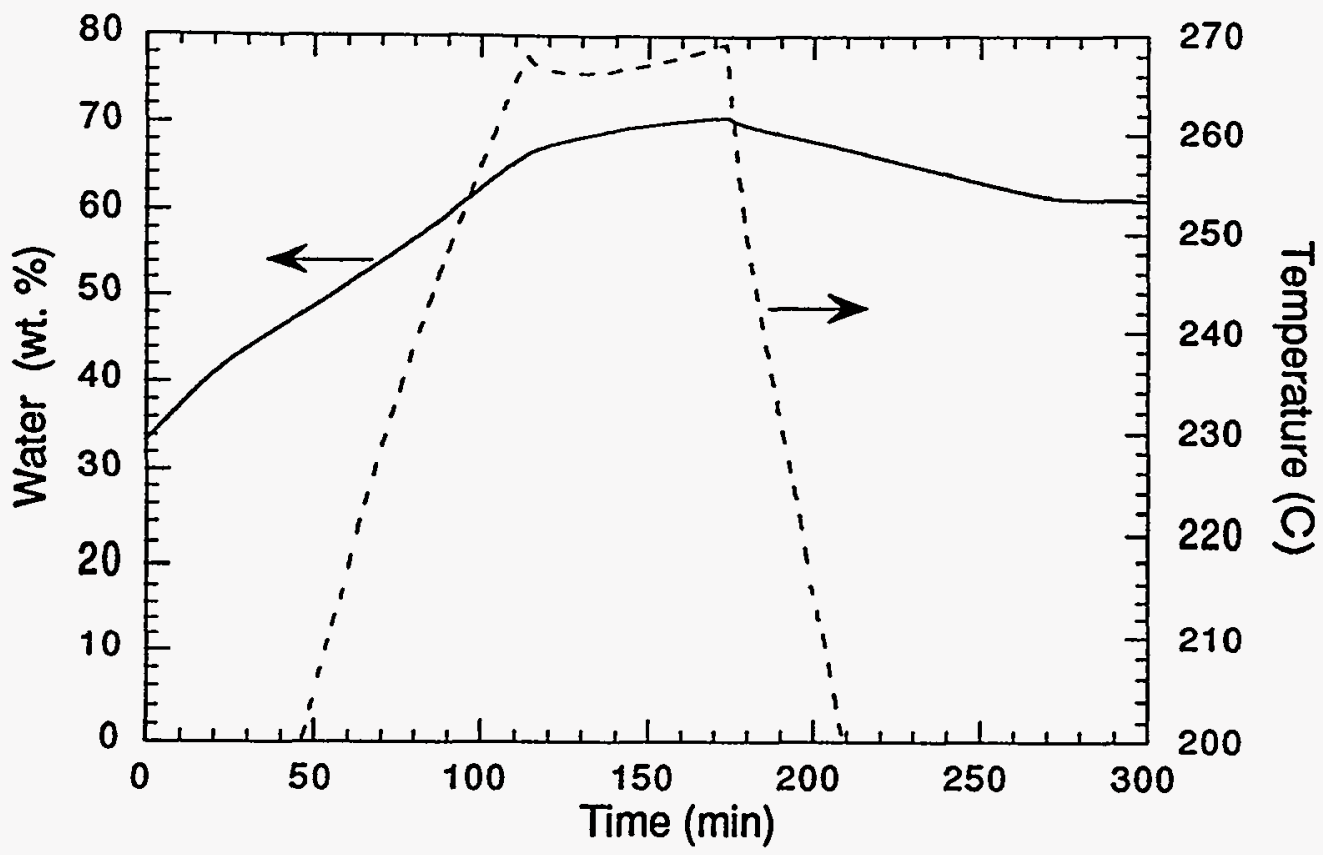

Figure 35. Computed Vessel 1 water content and temperature for the first 5 hours of the proposed first experiment.

\section{SUMMARY}

A transient model of proposed pilot tests of the use of steam to heat surrogate MSW, newspaper, under pressures and temperatures at which hydrothermal decomposition of the newspaper occurs has been outlined. The model allows the time history of important process variables to be explored as a function of changes in assumptions about the nature of physical process occurring in the process and controllable process variables. The model is based on the assumption that two vessels will form the reactor system. One will contain the newspaper to be heated and the other, smaller vessel, will serve as knockout pot to protect the systems pressure control valve. The model is capable of tracking the process through its three stages, the pressurization and heatup phase, the reaction phase where the system pressure is maintained constant and the blowdown/cooldown phase when pressure is relieved and the product slurry is cooled. The model is implemented in the form of a FORTRAN computer code and has been exercised on a HP-9000/730 workstation and generally takes less than one minute to complete a full simulation.

In addition, a much more limited model of the system using the ASPEN steadystate simulator has been developed and run. This model can compute a few important features of the process, such as final water content of the slurry, but is not capable of simulating the actual time variation of the process variables. 
Results from the ASPEN simulation compare very well with those from the transient model.

The transient model was used to explore many operating options and assumptions about the nature of the processes which would actually occur during a pilot run. The results of the calculations indicate that the available pilot system should allow a slurry of suitably high solids content to be produced. Under certain operating conditions the possibility of producing a product slurry with no net waste water production was also indicated by the calculations.

It was found that using a flow of $2 \mathrm{~mol} / \mathrm{s}$ steam and a programmed reduction of pressure in the blowdown phase would yield modest velocities within the reactor system. The model indicates that because of the high heat capacity of the vessel walls it would be advantageous to preheat the walls of the primary reactor vessel externally to reduce the total amount of water which would be present in the vessel at the end of the process. At the same time to adequately cool the material and vessel walls after the decomposition external cooling of the reactor walls will be necessary. Calculations indicate that forced air cooling using $6 \mathrm{~mol} / \mathrm{s}$ $(300 \mathrm{scfm})$ of air should be adequate to cool the system in a reasonable time.

Calculations indicate that there is probably no need to insulate the knockout vessel. Although the computed amount of condensate in the vessel does increase slightly, the total amount of condensate in the full system is not affected. Further, the knockout vessel volume, 0.16 , seems adequate to hold the water that should accumulate. If no knock out vessel is present the model predicts shorter heatup times with little change in the water content of the primary reactor vessel and a reduction of approximately $20 \%$ in the overall condensate production.

Uncertainties in the energetics of the decomposition reaction translate into uncertainties in computed estimates of the amount of water accumulating in the reactor vessel for a given set of conditions. The computed results indicate that for a doubling of the assumed $0.39 \mathrm{MJ} / \mathrm{kg}$ heat of reaction the amount of water in the reactor vessel at the end of the process would increase by about $50 \%$.

The model results indicate that the total amount of condensate resulting from a run per unit newspaper declines as the amount of newspaper processed increases. For typical conditions, an increase in $50 \%$ in the newspaper processed was found to decrease the final slurry product by $7 \mathrm{wt}$.\% water, when the final product is assumed to contain all the condensate from a run.

During the cooldown period the pressure within the reactor will fall below atmospheric as the temperatures drop below $100 \mathrm{C}$. A small purge flow of inert gas, about $2 \mathrm{mmol} / \mathrm{s}$, can maintain the pressure at one atmosphere. However, this purge flow was found by the model to retard the cooling of the product and probably should be avoided if possible. 
The manner in which heat transfer occurs between the reactor vessel walls and the interior can have a substantial influence of the final water content of the reactor vessel. Model calculations indicate that the amount of water remaining in the reactor can change by a factor of two depending on the assumed heat transfer coupling between wall and contents. A drying front model was developed and incorporated into the model to try to address the heat transfer coupling issue. Computed results indicate that actual system will probably exhibit poor heat transfer between wall and reactor interior during the cooldown period in the absence of water movement within the reactor.

Based on the calculations performed an operating strategy and scenario was suggested for the first pilot test. This test would use an uninsulated knockout vessel and a reactor insulated with its walls preheated to $150 \mathrm{C}$, but providing a means to externally air cool the walls during the cooldown period. A maximum reactor pressure of 6.3 MPa was assumed. Model results for this case using a 2 $\mathrm{mol} / \mathrm{s}$ steam flow during the heatup phase indicate that the heatup time would be 113 minutes, the maximum temperature $269 \mathrm{C}$ and the final contents of Vessel 1 would be $57 \mathrm{wt} . \%$ water. After a 48 hour cooldown period the contents of the reactor should have cooled to $39 \mathrm{C}$ while the reactor walls should have cooled to $31 \mathrm{C}$. This initial experiment is tailored to insure a relatively high water content in the reactor during the decomposition of the newspaper. A feed which has a water to dry newspaper ratio of 0.5 was assumed in the calculations. This leads to a computed water content of about $70 \mathrm{wt}$.\% during the reaction phase. 


\section{REFERENCES}

1. C.B. Thorsness, Process Modeling of Hydrogen Production from Municipal Solid Waste, Lawrence Livermore National Laboratory, Livermore CA, UCRL-ID119231 (1994).

2. Stanley M. Walas, Chemical Process Equipment Selection and Design (Butterworth-Heinemann, Boston, 1990), page 129.

3. A.C. Hindmarsh, "LSODE and LSODI, Two New Initial Value Ordinary Differential Equation Solvers", ACS-Signum N ws 410 (1981). 
A Pre-exponential constant in newspaper decomposition (1/s)

$A_{i} \quad$ Wall area of vessel i $\left(\mathrm{m}^{2}\right)$

$\begin{array}{lll}c_{m} \quad \text { Heat capacity of walls } & (\mathrm{J} / \mathrm{kg}-\mathrm{K})\end{array}$

$\begin{array}{lll}c_{N} \quad \text { Heat capacity of newspaper } & (\mathrm{J} / \mathrm{kg}-\mathrm{K})\end{array}$

$c_{S} \quad$ Heat capacity of solid product $\quad(\mathrm{J} / \mathrm{kg}-\mathrm{K})$

$c_{\mathrm{W}}$ Molar heat capacity of water $\quad(\mathrm{J} / \mathrm{mol}-\mathrm{K})$

$c_{p_{a}} \quad$ Molar heat capacity of air $\quad(\mathrm{J} / \mathrm{mol}-\mathrm{K})$

$c_{p G} \quad$ Molar heat capacity of noncondensable product gas $\quad(\mathrm{J} / \mathrm{mol}-\mathrm{K})$

$c_{p_{w}}$ Molar heat capacity of steam (J/mol-K)

$B_{i}$ Inflow energy term for vessel i (W)

$b_{w} \quad$ Flow rate of steam between vessels (mol/s)

$b_{G} \quad$ Flow rate of noncondensable gas product between vessels (mol/s)

$b_{a} \quad$ Flow rate of air between vessels (mol/s)

$C_{v} \quad C_{v}$ of gas outflow valve during pressure letdown phase $\quad(\mathrm{mol} \mathrm{K} 0.5 / \mathrm{Pa}-\mathrm{s})$

$f \quad$ Gas flow between vessels (positive 1->2) ( 1 )

$f_{\text {e }}$ Gas flow rate exiting vessel $2 \quad$ (mol/s)

$g_{i} \quad$ Moles of gas in vessel i (mol)

$H_{f G}$ Relative heat of formation for noncondensable product gas $(\mathrm{J} / \mathrm{mol})$

$H_{f_{N}}$ Relative heat of formation of newspaper $\quad(\mathrm{J} / \mathrm{kg})$

$H_{f S} \quad$ Relative heat of formation of solid product $\quad(\mathrm{J} / \mathrm{kg})$

$H_{f_{W}}$ Relative heat of formation of water (liquid) $\quad(\mathrm{J} / \mathrm{mol}$ )

$H_{f_{w}}$ Relative heat of formation of steam (J/mol)

$h_{i} \quad$ Heat transfer coefficient from vessel $i$ to surroundings $\quad\left(\mathrm{W} / \mathrm{m}^{2}-\mathrm{K}\right)$

$H_{i} \quad$ Heat transfer coefficient from vessel i walls to contents $\quad\left(\mathrm{W} / \mathrm{m}^{2}-\mathrm{K}\right)$

$m_{i} \quad$ Mass of wall of vessel $i$

$N \quad$ Mass of newspaper in vessel i $\quad(\mathrm{kg})$

$P_{i} \quad$ Pressure in vessel i $\quad(\mathrm{Pa})$

$P_{r} \quad$ Relief pressure $\quad(\mathrm{Pa})$

$P_{W_{i}} \quad$ Partial pressure of steam in vessel $i \quad$ (Pa)

$P_{\infty} \quad$ Pressure downstream of letdown valve $\quad(\mathrm{Pa})$

$\mathscr{P}\langle T\rangle$ Partial pressure of water at temperature $T$

$q_{i} \quad$ Heat transfer rate from vessel i walls to surroundings (W)

$Q_{i} \quad$ Heat transfer rate from vessel i walls to contents $(W)$

$r_{N} \quad$ Rate of newspaper decomposition 
$r_{w_{i}} \quad$ Rate of steam condensation in vessel $\mathrm{i}$

$(\mathrm{mol} / \mathrm{s})$

$S \quad$ Mass of solid product in vessel $\mathbf{i}$

$t \quad$ Time

$T_{i} \quad$ Temperature of contents of vessel $i$

(s)

$T_{a} \quad$ Activation temperature for newspaper decomposition

$T_{s} \quad$ Steam injection temperature

$T_{w_{i}} \quad$ Wall temperature of vessel $\mathbf{i}$

$T_{\infty} \quad$ Ambient air temperature

$V_{i} \quad$ Void volume of vessel $\mathrm{i}$

$V_{o_{i}} \quad$ Total volume of vessel $i$

$W_{i} \quad$ Mass of water in vessel $i$

$y_{w_{i}} \quad$ Mole fraction of steam in vessel $i$

$y_{G_{i}} \quad$ Mole fraction of noncondensable product gas in vessel $\mathbf{i}$

$y_{a_{i}} \quad$ Mole fraction of air in vessel $i$

$\alpha_{s} \quad$ Stoichiometric coefficient for solid product from newspaper decomposition (kg/kg-newspaper)

$\alpha_{w} \quad$ Stoichiometric coefficient for water from newspaper decomposition (mol/kg-newspaper)

$\alpha_{G} \quad$ Stoichiometric coefficient for noncondensable gas from newspaper decomposition $\Delta H_{N}\langle T\rangle$ (mol/kg-newspaper)

Heat of reaction for newspaper decomposition at temperature $T \quad(\mathrm{~J} / \mathrm{kg})$ $\Delta H_{w}\langle T\rangle$

Heat of reaction for steam condensation at temperature $T \quad(\mathrm{~J} / \mathrm{mol})$

$\beta \quad$ Constant in condensation rate expression $(\mathrm{mol} / \mathrm{s}-\mathrm{Pa})$

$\gamma \quad$ Specific gravity of gas relative to air at same conditions

$\rho_{N} \quad$ Mass density of newspaper

$\rho_{s} \quad$ Mass density of solid product

$\left(\mathrm{kg} / \mathrm{m}^{3}\right)$

$\rho_{\mathrm{w}} \quad$ Molar density of water

$\left(\mathrm{kg} / \mathrm{m}^{3}\right)$

$\sigma \quad$ Constant in gas outflow expression

$\left(\mathrm{mol} / \mathrm{m}^{3}\right)$

$\Omega$ Constant in inter-vessel gas flow rate expression $(\mathrm{mol} / \mathrm{s}-\mathrm{Pa})$ $(\mathrm{mol} / \mathrm{s}-\mathrm{Pa})$ 


\section{APPENDIX I}

\section{WATER VAPOR PRESSURE AND HEAT OF CONDENSATION CORRELATIONS}

The following correlation has been used in the model for the vapor pressure of water, expressed in $\mathrm{Pa}$, as a function of temperature in kelvins

$$
\begin{aligned}
& \mathcal{P}\langle\mathrm{T}\rangle=8.88888 \times 10^{10} \mathrm{e}^{\frac{-5114.6}{\mathrm{~T}}} \text { for } \mathrm{T}<410.57 \text { and } \\
& \mathcal{P}\langle\mathrm{T}\rangle=2.9929 \times 10^{10} \mathrm{e}^{\frac{-4666.3}{\mathrm{~T}}} \text { for } \mathrm{T} \geq 410.57 .
\end{aligned}
$$

Values obtained from this correlation are compared to literature values over the range of interest in Table I-1. Below $150 \mathrm{C}$ deviations are 5\% or less and above 150 $\mathrm{C}$ the deviations are less than $1 \%$.

Table I-1. Correlation Water vapor pressure estimates used in modeling compared to literature values 1 .

\begin{tabular}{|ccc|}
\hline & \multicolumn{2}{c|}{ Vapor Pressure (MPa) } \\
\cline { 2 - 3 }$T(\mathrm{C})$ & Literature & Correlation \\
\hline 20 & 0.0023 & 0.0023 \\
50 & 0.0123 & 0.0118 \\
80 & 0.0474 & 0.0453 \\
100 & 0.1013 & 0.0986 \\
125 & 0.2321 & 0.2333 \\
150 & 0.4760 & 0.4828 \\
180 & 1.003 & 1.002 \\
200 & 1.555 & 1.549 \\
230 & 2.798 & 2.791 \\
250 & 3.978 & 3.979 \\
270 & 5.505 & 5.527 \\
280 & 6.419 & 6.456 \\
290 & 7.445 & 7.500 \\
300 & 8.592 & 8.668 \\
\hline
\end{tabular}

In the current model structure simple temperature independent heat capacities have been used. This implicitly leads to the following relation for latent heat of condensation for water

$$
\Delta H_{w}=-44+0.041(\mathrm{~T}-25)[\mathrm{kJ} / \mathrm{mol}],
$$


where the temperature, $T$, is expressed in Celsius. The convention of negative heats of reaction representing exothermic reactions is followed.

The heat of condensation computed from this relation is compared to data over the temperature range of interest in Table I-2. At the high temperature end the heat of condensation is over estimated. This largely a result of using a constant heat capacity for steam.

Table I-2. Latent heat of condensation of water computed from simple model equation compared to data from the literature1.

\begin{tabular}{|ccc|}
\hline & \multicolumn{2}{c|}{$-\Delta H_{w}$} \\
\cline { 2 - 3 } $\mathrm{T}(\mathrm{C})$ & Literature & Model \\
\hline 30 & 43.7 & 43.8 \\
50 & 42.9 & 43.0 \\
100 & 40.6 & 40.9 \\
150 & 38.1 & 38.9 \\
200 & 34.9 & 36.8 \\
220 & 33.4 & 36.0 \\
240 & 31.8 & 35.2 \\
260 & 29.9 & 34.4 \\
\hline
\end{tabular}

\section{REFERENCES}

1. N.B. Vargaftik, Tables on the Thermophysical Properties of Liquids and Gases, In Normal and Dissociated States ,2nd Edition (John Wiley \& Sons, Inc., New York, 1975), pp 43-45. 


\section{APPENDIX II}

\section{NATURAL CONVECTIVE COOLING}

The possibility of natural convection cooling of process vessels and piping exists. The size of the heat transfer coefficients can be estimated using standard heat transfer correlations. For vertical surfaces in fluids with Prandtl numbers greater than 0.5, Krieth $^{1}$ suggests the following correlation for systems in which the product of Grashof and Prandtl numbers is greater than $10^{9}$

$$
\overline{\mathrm{Nu}}=0.021(\mathrm{GrPr})^{0.4} \text {, }
$$

where $\overline{\mathrm{Nu}}$ is the average Nusselt number over the surface.

In Table II- 1 the average heat transfer coefficient, $\bar{h}$, is computed for a vertical surface in air having a length of $1.5 \mathrm{~m}$, typical of the reactor vessels. In the calculations an ambient temperature of $25 \mathrm{C}$ is assumed and properties are computed at the average of the wall and ambient temperatures.

Table II-1. Air properties and average estimated average heat transfer coefficients as a function of wall temperature for a vertical surface $1.5 \mathrm{~m}$ in length.

\begin{tabular}{|c|c|c|c|c|c|c|c|c|}
\hline $\begin{array}{l}\text { Wall } \\
\text { (C) }\end{array}$ & $\mathrm{T}$ & $\begin{array}{l}\text { Driving } \\
\text { Force } \\
\text { (C) }\end{array}$ & $\begin{array}{c}\text { Air } \\
\text { Heat } \\
\text { Capacity } \\
(J / \mathrm{kg}-K)\end{array}$ & $\begin{array}{c}\text { Air } \\
\text { Conduc- } \\
\text { tivity } \\
(\mathrm{W} / \mathrm{m}-\mathrm{K})\end{array}$ & $\begin{array}{c}\text { Air } \\
\text { Viscosity } \\
\times 10^{-5} \\
(\mathrm{~Pa}-\mathrm{s})\end{array}$ & $\begin{array}{c}G r \\
\times 10^{-11}\end{array}$ & $\overrightarrow{N u}$ & $\left(\mathrm{~W} / \mathrm{m}^{2}-\mathrm{K}\right)$ \\
\hline$\overline{10 c}$ & & 75 & 1008 & 0.029 & 2.07 & 2.10 & 245 & 4.7 \\
\hline 150 & & 125 & 1009 & 0.032 & 2.15 & 2.82 & 276 & 5.9 \\
\hline 200 & & 175 & 1012 & 0.033 & 2.22 & 3.22 & 291 & \\
\hline 250 & & 225 & 1015 & 0.034 & 2.29 & 3.43 & 298 & 6.8 \\
\hline 270 & & 245 & 1017 & 0.035 & 2.32 & 3.48 & 300 & 7.0 \\
\hline
\end{tabular}

Any uninsulated pipes can also lead to cooling by natural convection. Vertical runs of pipes can be treated as vertical surfaces using the above correlation. Horizontal pipe average heat transfer coefficients can be computed, according to Krieth 1 , using the following

$$
\overline{\mathrm{Nu}}=0.53(\mathrm{Gr} \mathrm{Pr})^{0.25}
$$

This relation is valid for Prandtl numbers greater than 0.5 and Grashof numbers ranging from $10^{3}$ to $10^{9}$. Average heat transfer coefficients computed from this 
correlation are given in Table II-2 for $5 \mathrm{~cm}$ ( 2 in.) horizontal pipes over a range of pipe wall temperatures of interest.

Table II-2. Estimated average heat transfer coefficients as a function of wall temperature for $5 \mathrm{~cm}$ diameter pipes in air having an ambient temperature of $25 \mathrm{C}$.

\begin{tabular}{|c|c|c|c|c|c|}
\hline $\begin{array}{l}\text { Wall } \\
\text { (C) }\end{array}$ & $\mathrm{T}$ & $\begin{array}{l}\text { Driving } \\
\text { Force } \mathrm{Gr} \\
\text { (C) }\end{array}$ & $10^{-6}$ & $x$ & $\left(\mathrm{~W} / \mathrm{m}^{2}-\mathrm{K}\right)$ \\
\hline 100 & & 75 & 0.81 & 14.6 & 8.3 \\
\hline 150 & & 125 & 1.09 & 15.7 & 9.9 \\
\hline 200 & & 175 & 1.25 & 16.2 & 10.5 \\
\hline 250 & & 225 & 1.33 & 16.5 & 11.0 \\
\hline 270 & & 245 & 1.35 & 16.5 & 11.4 \\
\hline
\end{tabular}

\section{REFERENCES}

1. Frank Kreith, Principles of Heat Transfer, Second Edition (International Textbook Company, Scranton, Pennsylvania, 1966), pp 326-358. 


\section{APPENDIX III \\ MOVING DRYING FRONT ESTIMATES}

Interaction of the vessel walls and the material inside the reactor during the cooldown phase will depend on the nature of the material inside the reactor at that time. One possible scenario is that the reacted newspaper maintains enough of its integrity after the decomposition reactions have occurred so that the state of the material inside the vessel would be a moist low density solid. In this case the hot walls would only interact with the material in the vicinity of the walls because the interaction would involve drying of the material and the dried material would act as an insulator.

To estimate the amount of drying which might result from hot reactor walls during the blowdown phase a simple moving front model can be formulated. In this model it is assumed that a drying front is moving away from the walls through the low density material. This drying front is driven by conduction from the wall. Also it is assumed that the amount of energy needed to evaporate moisture at the drying front is far greater than any sensible heat changes occurring in the dried material. In this case the heat flow at any instant from wall to drying front is given by

$$
q=\frac{k}{l}\left(T_{\mathrm{w}}-T_{\mathrm{d}}\right),
$$

where $k$ is the conductivity of the dried region, $l$ is the width of the dried region and $T_{d}$ is the temperature at the drying front. The rate of motion of the drying front is related to this heat flux by

$$
\frac{d l}{d t} x_{w} \rho M_{w}\left(-\Delta H_{w}\right)=q,
$$

where $x_{w}$ is the weight fraction of water in the material filling the vessel, $\rho$ is the solid density and $M_{w}$ is the moles of water per $\mathrm{kg}$ of water. In this simple formulation the steam is assumed to leave the drying front by passing through the undried material.

For a constant wall and drying front temperature Eqns. III-1 \& III-2 lead to a simple solution for the dried length

$$
l=\sqrt{\frac{2 k\left(T_{w}-T_{d}\right) t}{-x_{w} \rho M_{w} \Delta H_{w}}} .
$$

Using this relation an average heat transfer coefficient can be defined for any period of time and is given by 


$$
\bar{h}=\sqrt{\frac{-2 k x_{w} r M_{w} D H_{w}}{\left(T_{w}-T_{d}\right) t}} .
$$

Using Eqn. III-4 some computed $\bar{h}$ 's are given in Table III-1 for typical parameters.

Table III-1. Computed $\bar{h}$ 's for different times and wall temperatures for $k=0.04$ $\mathrm{W} / \mathrm{s}-\mathrm{m}-\mathrm{K}, x_{w}=0.5, \rho=200 \mathrm{~kg} / \mathrm{m}^{3}, \Delta H_{w}=44000 \mathrm{~J} / \mathrm{mol}$, and $T_{d}=100 \mathrm{C}$.

\begin{tabular}{|ccc|}
\hline$T_{\mathrm{w}}(\mathrm{C})$ & $\mathrm{t}(\mathrm{hrs})$ & $\bar{h}\left(\mathrm{~W} / \mathrm{m}^{2}-\mathrm{K}\right)$ \\
\hline 250 & 2 & 4.3 \\
250 & 8 & 2.1 \\
250 & 24 & 1.2 \\
150 & 2 & 7.4 \\
150 & 8 & 3.7 \\
150 & 24 & 2.1 \\
\hline
\end{tabular}




\section{APPENDIX IV}

\section{CONVECTIVE COOLING}

To air cool the main reactor vessel a shroud may be used through which air is blown. The rate at which the vessel walls can be cooled can be estimated using standard heat transfer correlations and estimates of process conditions.

Blowers are available with the potential to deliver about $6 \mathrm{~mol} / \mathrm{s}(300 \mathrm{scfm})$ of air into a shroud around the main reactor. The main reactor has a diameter of $1.3 \mathrm{~m}$. If a separation of $5 \mathrm{~cm}$ between the shroud and the tank is assumed the Reynolds number in the annular space during air flow would be about $6000-8000$ depending on the average temperature. Unfortunately these Reynolds numbers are near the laminar/turbulent transition region and therefore make it more difficult to estimate heat transfer coefficients with accuracy. However, using the standard correlations for turbulent flow in enclosed flows with fully developed velocity and temperature profiles, given by Kays ${ }^{1}$

$$
\mathrm{Nu}=0.021 \mathrm{Pr}^{0.5} \mathrm{Re}^{0.8},
$$

which is valid for $\operatorname{Re}<10^{5}$, a heat transfer coefficient of about $6 \mathrm{~W} / \mathrm{m}^{2}-\mathrm{K}$ is computed. The coefficient is not a strong function of the average temperature over the range of interest.

With the maximum temperature driving force the increase in average air temperature as it passes between the shroud and vessel wall would be about $40 \mathrm{C}$. Since this is considerably smaller then the $250 \mathrm{C}$ driving force, the cooling of the vessel walls can be approximated using the simple relation

$$
c_{m} m \frac{d T}{d t}=A h(T-25),
$$

which along with the initial condition $T=T_{i}$, has the simple solution

$$
\frac{T-25}{T_{i}-25}=e^{\left(\frac{-A h t}{m c_{m}}\right)} .
$$

This solution is for a $25 \mathrm{C}$ ambient air condition. In these relations the $T$ is the wall temperature, $m$ is the mass of the wall and $A$ is the area of the wall..

Using Eqn. IV-3 is easy to compute the time required to cool to any desired wall temperature

$$
t=\frac{-m c_{m}}{A h} \ln \left(\frac{T-25}{T_{i}-25}\right) .
$$


Using Eqn. IV -4 typical cooldown times can be computed for a forced convection air cooled system. Assuming an initial hot temperature of $275 \mathrm{C}$ Table IV-1 shows the times required to cool down reactor walls whose mass is $3553 \mathrm{~kg}$.

Table IV-1. Estimated time to cool a vessel wall to a specific temperature using an air flow of $6 \mathrm{~mol} / \mathrm{s}$ for a reactor vessel with a wall area of $6 \mathrm{~m}^{2}$, a wall mass of $3553 \mathrm{~kg}$ and assuming an average heat transfer coefficient of $6 \mathrm{~W} / \mathrm{m}^{2}-\mathrm{K}$.

\begin{tabular}{|cc|}
\hline $\mathrm{T}(\mathrm{C})$ & $\mathrm{t}$ (hrs) \\
\hline 100 & 13.9 \\
80 & 17.4 \\
60 & 22.6 \\
40 & 32.4 \\
\hline
\end{tabular}

\section{REFERENCES}

1. W.M. Kays and M.E. Crawford, Convective Heat and Mass Transfer, Second Edition (McGraw-Hill Book Company, New York, 1980), page 250. 